\title{
Development of two-moment cloud microphysics for liquid and ice within the NASA Goddard Earth Observing System Model (GEOS-5)
}

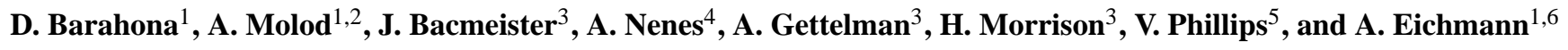 \\ ${ }^{1}$ Global Modeling and Assimilation Office, NASA Goddard Space Flight Center, Greenbelt, MD, USA \\ ${ }^{2}$ University of Maryland, College Park, MD, USA \\ ${ }^{3}$ National Center for Atmospheric Research, Boulder, CO, USA \\ ${ }^{4}$ School of Earth and Atmospheric Sciences and School of Chemical and Biomolecular Engineering, \\ Georgia Institute of Technology, Atlanta, GA, USA \\ ${ }^{5}$ School of Earth and Environment, University of Leeds, Leeds, UK \\ ${ }^{6}$ Science Systems and Applications, Inc., Lanham, MD, USA \\ Correspondence to: D. Barahona (donifan.o.barahona@ nasa.gov)
}

Received: 6 September 2013 - Published in Geosci. Model Dev. Discuss.: 29 October 2013

Revised: 2 June 2014 - Accepted: 1 July 2014 - Published: 20 August 2014

\begin{abstract}
This work presents the development of a twomoment cloud microphysics scheme within version 5 of the NASA Goddard Earth Observing System (GEOS-5). The scheme includes the implementation of a comprehensive stratiform microphysics module, a new cloud coverage scheme that allows ice supersaturation, and a new microphysics module embedded within the moist convection parameterization of GEOS-5. Comprehensive physically based descriptions of ice nucleation, including homogeneous and heterogeneous freezing, and liquid droplet activation are implemented to describe the formation of cloud particles in stratiform clouds and convective cumulus. The effect of preexisting ice crystals on the formation of cirrus clouds is also accounted for. A new parameterization of the subgrid-scale vertical velocity distribution accounting for turbulence and gravity wave motion is also implemented. The new microphysics significantly improves the representation of liquid water and ice in GEOS-5. Evaluation of the model against satellite retrievals and in situ observations shows agreement of the simulated droplet and ice crystal effective radius, the ice mass mixing ratio and number concentration, and the relative humidity with respect to ice. When using the new microphysics, the fraction of condensate that remains as liquid follows a sigmoidal dependency with temperature, which
\end{abstract}

is in agreement with observations and which fundamentally differs from the linear increase assumed in most models. The performance of the new microphysics in reproducing the observed total cloud fraction, longwave and shortwave cloud forcing, and total precipitation is similar to the operational version of GEOS-5 and in agreement with satellite retrievals. The new microphysics tends to underestimate the coverage of persistent low-level stratocumulus. Sensitivity studies showed that the simulated cloud properties are robust to moderate variation in cloud microphysical parameters. Significant sensitivity remains to variation in the dispersion of the ice crystal size distribution and the critical size for ice autoconversion. Despite these issues, the implementation of the new microphysics leads to a considerably improved and more realistic representation of cloud processes in GEOS-5, and allows the linkage of cloud properties to aerosol emissions.

\section{Introduction}

Cloud microphysical schemes in global circulation models (GCMs) have evolved from directly prescribing cloud properties (i.e., particle size and number, cloud amount and 
concentration of condensate) (e.g., Manabe et al., 1965) to explicit representation of the microphysics involving the formation, evolution, and removal of cloud droplets and ice crystals (e.g., Gettelman et al., 2010; Lohmann, 2008; Sud et al., 2013; Quaas et al., 2009). The development of sophisticated cloud schemes allows a more realistic description of the variability and interdependence of cloud properties, and will likely improve model predictions of climate (Lohmann and Feichter, 2005). However, their increased complexity has also brought about new challenges in the description of small-scale dynamics, cloud particle nucleation and growth, and the generation of precipitation. Most models rely on simplified representations of such processes.

Current GCMs typically use either single- (e.g., Del Genio et al., 1996; Bacmeister et al., 1999) or two-moment cloud microphysics schemes (e.g., Gettelman et al., 2010; Sud et al., 2013; Lohmann et al., 2008). More detailed schemes have also been developed; however, their computational costs make them unsuitable for climate studies (Khain et al., 2000). The advantage of two- and higher-moment schemes is that the characteristics of the cloud particle size distribution are explicitly calculated and allowed to interact with radiation and influence the evolution of cloud properties. Some schemes also allow for supersaturation with respect to the ice phase, required to model ice nucleation explicitly (e.g., Gettelman et al., 2010; Wang and Penner, 2010). When coupled to an appropriate aerosol activation parameterization, multi-moment microphysics schemes are capable of modeling the modification of cloud properties by aerosol emissions, a key component of anthropogenic climate change (IPCC, 2007; Lohmann and Feichter, 2005; Kaufman and Koren, 2006).

Mounting evidence suggests that aerosols, both natural and anthropogenic, play a key role in many atmospheric processes. For example, the presence of ice in clouds at temperatures above $235 \mathrm{~K}$ depends on the presence of waterinsoluble ice nuclei (IN) (Pruppacher and Klett, 1997). IN in turn act as precipitation-forming agents in convective systems and mixed-phase clouds (Ramanathan et al., 2001; Rosenfeld and Woodley, 2000). Although IN originate mostly from natural sources (i.e., dust and biogenic material), anthropogenic emissions can modify the natural IN concentration. The effect of aerosols on clouds has also been associated with planetary radiative perturbations from the modification of clouds by anthropogenic aerosol emissions (Twomey, 1977, 1991; Lohmann and Feichter, 2005). Emissions of cloud condensation nuclei $(\mathrm{CCN})$ may also lead to the modification of the precipitation onset in convective cumulus, decreasing the average size of cloud droplets (Rosenfeld et al., 2008). Recent studies suggest that the interplay between CNN and IN plays a significant role in the maintenance of Arctic clouds (Morrison et al., 2012; Lance et al., 2011). Accurate representation of these effects in atmospheric models is critical for reliable climate prediction, yet difficult due to their complexity and gaps in the understanding of $\mathrm{CCN}$ and IN activation and the interactions between clouds and radiation (Stevens and Feingold, 2009).

A recent simulation of the non-hydrostatic implementation of the NASA Goddard Earth Observing System at $14 \mathrm{~km}$ spatial resolution demonstrated that as the spatial resolution increases, the parameterized convective transport of moisture plays a weaker role in the generation of cloud condensate. At high resolution, the simulated cloud properties are controlled by the cloud microphysics (Putman and Suarez, 2011). For typical GCM resolutions $\left(\sim 2^{\circ}\right)$, the parameterization of convective precipitation strongly impacts the simulation of the hydrological cycle and the distribution of cloud tracers in the atmosphere (e.g., Arakawa, 2004). Most GCMs use singlemoment schemes to describe the microphysics of convective systems; two-moment microphysical schemes have also been developed for convective clouds, mostly based on ideas originally developed for stratiform clouds (e.g., Lohmann, 2008; Song and Zhang, 2011; Sud et al., 2013).

The NASA Goddard Earth Observing System, version 5 (GEOS-5) is a system of models integrated using the Earth System Modeling Framework (ESMF) (Rienecker et al., 2008). The operational version of GEOS-5 is regularly used for decadal predictions of climate, field campaign support, satellite data assimilation, weather forecasts and basic research (Rienecker et al., 2008, 2011; Molod, 2012). GEOS5 uses a single-moment cloud microphysics scheme to parameterize condensation, sublimation, evaporation, autoconversion and sedimentation of liquid and ice (Bacmeister et al., 2006). This single-moment approach captures the main climatic features related to the formation of stratocumulus decks and tropical storms (Reale et al., 2009; Putman and Suarez, 2011), but prevents the explicit linkage of aerosol emissions to cloud properties and omits subgrid variability in cloud properties. In this work, we develop a new microphysical package for GEOS-5 that addresses these issues. The new microphysics scheme presented here explicitly predicts the mass and number of cloud ice and liquid, and links the number concentration of ice crystals and cloud droplets to aerosol through the processes of cloud droplet activation and ice crystal nucleation.

\section{Model description}

\subsection{Operational GEOS-5}

The cloud scheme in the operational version of GEOS-5 considers a single phase of condensate; however, the removal and evaporation of cloud water from detrained convection and in situ condensation are treated separately. The fraction of condensate existing as ice is assumed to increase linearly between 273 and 235 K. Processes of autoconversion, evaporation/sublimation and accretion of cloud water and ice are treated explicitly (Bacmeister et al., 2006). Moist convection is parameterized using the relaxed Arakawa-Schubert (RAS) 
scheme (Moorthi and Suarez, 1992). Generation and evaporation of convective, anvil and stratiform precipitation are parameterized according to Bacmeister et al. (2006). Longwave radiative interactions with cloud water, water vapor, carbon dioxide, ozone, $\mathrm{N}_{2} \mathrm{O}$ and methane are treated following Chou and Suarez (1994). The Chou et al. (1992) scheme is used to describe shortwave absorption by water vapor, ozone, carbon dioxide, oxygen, cloud water, and aerosols and scattering by cloud particles and aerosols. Cloud particle effective size is prescribed and tuned to adjust the radiative balance at the top of the atmosphere. The current version of GEOS-5 also accounts for the radiative effect of precipitating rain and snow according to Molod et al. (2012). Aerosol transport is calculated interactively using the Goddard Chemistry, Aerosol, Radiation, and Transport model, GOCART (Colarco et al., 2010), a global aerosol transport model that considers dust, sea salt, black and organic carbon, and sulfate aerosols. Scavenging of aerosol mass is based on a convective mass flux approach; however, it is not explicitly linked to droplet and ice crystal nucleation (Colarco et al., 2010).

The calculation of large-scale condensation and cloud coverage in GEOS-5 follows a total-water probability distribution function (PDF) approach (Smith, 1990; Rienecker et al., 2008; Molod, 2012). The total-water PDF is assumed to follow a uniform distribution characterized by the critical relative humidity, based on the formulation of Slingo (1987). Anvil cloud fraction is parameterized following Tiedtke (1993).

\subsection{New cloud variables}

The cloud microphysical scheme in GEOS-5 was augmented to consider the evolution of the mass and number of ice crystals and cloud droplets. Four new prognostic variables were added to GEOS-5: $q_{1}, q_{\mathrm{i}}, n_{1}$ and $n_{\mathrm{i}}$, representing the gridaverage mass and number mixing ratio of liquid and ice, respectively. The evolution of a given tracer, $\eta$, is described by

$$
\frac{\partial \eta}{\partial t}=\left(\frac{\partial \eta}{\partial t}\right)_{\mathrm{adv}}+\left(\frac{\partial \eta}{\partial t}\right)_{\mathrm{turb}}+\left(\frac{\partial \eta}{\partial t}\right)_{\mathrm{ls}}+\left(\frac{\partial \eta}{\partial t}\right)_{\mathrm{cv}}
$$

where the terms on the right-hand side of Eq. (1) represent the tendency in $\eta$ due to advective and turbulent transport and large-scale and convective cloud processes, respectively. Advective transport and turbulent transport in GEOS-5 are described in Rienecker et al. (2008). $\left(\frac{\partial \eta}{\partial t}\right)_{1 \mathrm{~s}}$ refers to the change in $\eta$ from non-convective cloud processes (i.e., anvil and stratus clouds), whereas $\left(\frac{\partial \eta}{\partial t}\right)_{\mathrm{cv}}$ describes the change in $\eta$ from processes occurring within convective cumulus.

\subsection{Microphysics of stratiform and anvil clouds}

In GEOS-5, clouds are classified as stratiform (cirrus, anvils and stratocumulus) and convective. Stratiform clouds are formed by in situ condensation and anvil detrainment. The stratiform scheme of Morrison and Gettelman (2008, hereafter MG08) was incorporated into GEOS-5 as part of the new cloud scheme. Since MG08 allows for ice supersaturation, and accounts for activation of aerosols based on a subgrid vertical velocity, other aspects of the cloud scheme were updated. The calculation of cloud fraction and large-scale condensation was modified to account for supersaturation with respect to ice and microphysical processing (Sect. 2.3.1). The new scheme uses the $\mathrm{CCN}$ activation and ice nucleation parameterizations of Fountoukis and Nenes (2005) and Barahona and Nenes (2009b), respectively (Sects. 2.3.2 and 2.3.3). A parameterization of subgrid vertical velocity, $w_{\text {sub }}$, was also developed (Sect. 2.3.4), and MG08 was modified to account for the effect of preexisting ice crystals on cirrus formation (Sect. 2.3.5). A new microphysical scheme for convective clouds that explicitly considers CCN and IN activation was implemented (Sect. 2.4). These modifications represent a complete overhaul of the cloud microphysics of GEOS-5.

The MG08 scheme includes prognostic equations for the mass and number mixing ratio of cloud ice and liquid, and diagnostically predicts the vertical profiles of rain and snow. The detailed mass and number balances leading to $\left(\frac{\partial n_{1}}{\partial t}\right)_{1 \mathrm{~s}}$, $\left(\frac{\partial q_{1}}{\partial t}\right)_{1 \mathrm{~s}},\left(\frac{\partial q_{\mathrm{i}}}{\partial t}\right)_{1 \mathrm{~s}}$ and $\left(\frac{\partial n_{\mathrm{i}}}{\partial t}\right)_{1 \mathrm{~s}}$ are presented in Morrison and Gettelman (2008). The MG08 scheme is used to describe the microphysics of convective detrainment and stratiform condensate.

The size distribution of cloud droplets, rain, ice and snow is assumed to follow a gamma distribution; i.e.,

$n_{\mathrm{y}}(D)=N_{0, \mathrm{y}} D_{\mathrm{y}}^{\mu_{\mathrm{y}}} e^{-\lambda_{0, \mathrm{y}} D_{\mathrm{y}}}$,

where the subscript $\mathrm{y}$ is used to represent a hydrometeor species, and $N_{0, \mathrm{y}}$ and $\lambda_{0, \mathrm{y}}$ are the intercept and slope parameters of $n_{\mathrm{y}}(D)$, calculated as in Morrison and Gettelman (2008) (cf. Eq. 3). $D_{\mathrm{y}}$ and $\mu_{\mathrm{y}}$ are the sphere-equivalent diameter and the size dispersion of the y species, respectively. A Marshall-Palmer distribution (Marshall and Palmer, 1948) is assumed for rain and snow; i.e., $\mu_{\mathrm{y}}=0$.

The version of MG08 implemented in GEOS-5 follows closely the description of Gettelman et al. (2010), with some modifications as follows. MG08 also uses an exponential approximation of the size distribution of ice crystals; i.e., $\mu_{\mathrm{i}}=$ 0 . Theoretical considerations however suggest that $n_{\mathrm{i}}\left(D_{\mathrm{i}}\right)$ in recently formed clouds is better represented by log-normal and gamma functions in which the concentration of ice crystals decreases steeply for very small sizes (Barahona and Nenes, 2008). Since this behavior cannot be reproduced using an exponential distribution, setting $\mu_{\mathrm{i}}=0$ may lead to underestimation of $\lambda_{0, i}$ and overestimation of crystal size. This assumption is relaxed in GEOS-5, and $\mu_{\mathrm{i}}$ is calculated as a function of $T$ following the correlation of Heymsfield et al. (2002), obtained from extensive measurements in cirrus clouds. Following Heymsfield et al. (2002), it is assumed 
that $0.5<\mu_{\mathrm{i}}<2.5$. The critical size for ice autoconversion was set to $D_{\mathrm{cs}}=400 \mu \mathrm{m}$. The sensitivity of cloud ice water to $\mu_{\mathrm{i}}$ and $D_{\mathrm{cs}}$ is analyzed in Sect. 4 .

The droplet autoconversion parameterization in MG08 (Khairoutdinov and Kogan, 2000) was replaced by the formulation of Liu et al. (2006). The latter was preferred because of its greater flexibility in representing the effect of cloud droplet dispersion on the autoconversion rate. The liquid water content exponent in Liu's parameterization was set to 2.0 (Liu et al., 2006). Following Liu et al. (2008), the cloud droplet size dispersion, $\mu_{l}$, was parameterized in terms of the grid-scale mean droplet mass.

Other modifications to MG08 include the calculation of the nucleated droplet number and ice crystal concentration and the parameterization of the subgrid-scale vertical velocity (Sects. 2.3.2 to 2.3.4). Partitioning of total condensate accounts for the Bergeron-Findeisen process following Morrison and Gettelman (2008) and Gettelman et al. (2010). Ice and liquid cloud fraction are however not discriminated, and the total cloud fraction is calculated using the probability distribution function (PDF) of total water (Sect. 2.3.1).

\subsubsection{Stratiform condensation and cloud fraction}

Cloud fraction, $f_{\mathrm{c}}$, plays a crucial role in cloud and radiative processes, and is intimately tied to the in-cloud number and mass mixing ratios. In GEOS-5 it is calculated using a totalwater PDF scheme; i.e.,

$$
f_{\mathrm{c}}=\left(1-f_{\mathrm{cn}}\right) \int_{S_{\mathrm{crit}} q^{*}}^{\infty} P_{q}(q) \mathrm{d} q+f_{\mathrm{cn}},
$$

where $P_{q}(q)$ is the normalized total-water PDF in the nonconvective part of the grid cell, and $f_{\mathrm{cn}}$ is the convective detrainment mass fraction. $P_{q}(q)$ is assumed uniform with width equal to $\Delta q$ (Appendix A); $q^{*}$ is the weighted saturation mixing ratio between liquid and ice, given by

$q^{*}=\left(1-f_{\text {ice }}\right) q_{1}^{*}+f_{\text {ice }} q_{\mathrm{i}}^{*}$,

where $f_{\text {ice }}$ is the mass fraction of ice in the total condensate, and $q_{1}^{*}$ and $q_{\mathrm{i}}^{*}$ are the saturation specific humidities for liquid and ice, respectively. The total condensate is given by

$q_{\mathrm{c}}=\left(1-f_{\mathrm{cn}}\right) \int_{S_{\mathrm{crit}} q^{*}}^{\infty}\left(q-S_{\text {crit }} q^{*}\right) P_{q}(q) \mathrm{d} q+q_{\mathrm{c}, \mathrm{det}}$,

where $q_{\mathrm{c}, \text { det }}$ is the contribution of convective detrainment to the total condensate. The term $S_{\text {crit }}$ in Eqs. (3) and (5) is termed the critical saturation ratio. $S_{\text {crit }}$ controls the minimum level of supersaturation required for cloud formation within a model grid cell. Equation (3) implies that regions within the grid cell for which $q_{\mathrm{t}}>q^{*} S_{\text {crit }}$ are covered with cloud (Appendix A). The total water in the non-convective part of the grid, $q_{\mathrm{t}}$, is calculated assuming water saturation for the convective detrainment. Note that Eqs. (3) to (5) are coupled through the energy balance (not shown), and must be solved simultaneously.

In the operational version of GEOS-5, it is assumed that $S_{\text {crit }}=1$ for all conditions. In this work, the same assumption is used for mixed-phase and liquid clouds. However, for ice clouds, linking $S_{\text {crit }}$ to ice nucleation processes increases the minimum relative humidity required for cloud formation, allowing for supersaturation with respect to ice. $S_{\text {crit }}$ is thus controlled by the subgrid-scale dynamics and the aerosol properties. In cirrus clouds, $S_{\text {crit }}$ is calculated by the ice nucleation parameterization (Sect. 2.3.3, Eq. 13).

To make an initial estimate of $f_{\mathrm{c}}$, the width of $P_{q}(q)$ is prescribed and parameterized in terms of a critical relative humidity (Molod et al., 2012). This is fully diagnostic, since the width does not depend on state variables. However, the convective contribution to $f_{\mathrm{c}}$ is fully prognostic and depends on the detrained mass flux parameterized using a Tiedke-style approach (Tiedke, 1993). Using this assumption, an initial estimate of $f_{\mathrm{c}}$ is calculated in the form (Eq. A2)

$f_{\mathrm{c}}=\left(1-f_{\mathrm{cn}}\right) \frac{q_{\mathrm{mx}}-S_{\mathrm{crit}} q^{*}}{\Delta q}+f_{\mathrm{cn}}$,

where $q_{\mathrm{mx}}=q_{\mathrm{t}}+0.5 \Delta q$ and $\Delta q$ are the upper limit and the width of $P_{q}(q)$, respectively. Similarly, for total condensate (Eq. A3),

$q_{\mathrm{c}}=\left(1-f_{\mathrm{cn}}\right) \frac{1}{2} \alpha_{L} \frac{\left(q_{\mathrm{mx}}-S_{\mathrm{crit}} q^{*}\right)^{2}}{\Delta q}+q_{\mathrm{c}, \mathrm{det}}$,

where $\alpha_{L}=\left(1+\frac{L}{c_{\mathrm{p}}} \frac{\partial q^{*}}{\partial T}\right)^{-1}$ accounts for changes in $q^{*}$ due to latent heating during condensation. Equation (6) may lead to a reduction in $f_{\mathrm{c}}$ if $q_{\mathrm{t}}<S_{\text {crit }} q^{*}$, even if $q_{\mathrm{t}}>q^{*}$ (i.e., the grid cell is on average supersaturated), which may lead to inconsistency between ice crystal growth and total condensate. This is resolved by assuming a proportional increase in $f_{\mathrm{c}}$ with water vapor deposition onto preexisting ice crystals. Cirrus clouds thus persist in supersaturated grid cells (however, is not created) even if $q_{\mathrm{t}}<S_{\text {crit }} q^{*}$.

Evaporation, water vapor deposition and condensation, and sedimentation processes can modify $f_{\mathrm{c}}$. Microphysical processes can also alter $q_{\mathrm{t}}$ and $P_{q}(q)$ via the formation of precipitation. Fully prognostic schemes parameterize these effects by assuming some proportionality between changes in $f_{\mathrm{c}}$ and microphysical rates (e.g., Del Genio et al., 1996; Sud and Walker, 1999; Tompkins, 2002; Kärcher and Burkhardt, 2008). Here, an alternative approach, maintaining the form of the PDF, is proposed as follows. Assuming that the totalwater PDF (i.e., anvil and stratiform) after microphysical processing follows a uniform distribution, an equation similar to Eq. (7), but without an explicit contribution from detrainment, can be written for the total condensate (Eq. A5). Since total water, $q_{\mathrm{t}}^{\prime}$, and total condensate, $q_{\mathrm{c}}^{\prime}$, are known after the microphysics, then a new width, $\Delta q^{\prime}$, consistent with 
the new state of the system, can be calculated, as detailed in Appendix A. Using $\Delta q^{\prime}$ in Eq. (3), a new cloud fraction corrected for microphysical processing can be written in the form (Eq. A8)

$f_{\mathrm{c}}^{\prime}=\left(1+\sqrt{1-\frac{q_{\mathrm{t}}^{\prime}-S_{\mathrm{crit}} q^{*}}{q_{\mathrm{c}}^{\prime}}}\right)^{-1}$.

In practice, an initial estimate of $f_{\mathrm{c}}$ (Eq. 6) is used to calculate $q_{\mathrm{c}}$ and $q_{\mathrm{t}}$ at the beginning of the time step. Then assuming that microphysical processes proceed at a constant cloud fraction, $q_{\mathrm{c}}^{\prime}$ and $q_{\mathrm{t}}^{\prime}$ are calculated and introduced into Eq. (8) to calculate $f_{\mathrm{c}}^{\prime}$. This procedure has the limitation that microphysical processes are calculated using an initial estimate of $f_{\mathrm{c}}$ instead of its final value; however ensures consistency between $f_{\mathrm{c}}^{\prime}$ and $q_{\mathrm{c}}^{\prime}$ at the end of the time step.

\subsubsection{Cloud droplet activation}

CCN activation into cloud droplets is parameterized following the approach of Fountoukis and Nenes (2005) (hereafter FN05). FN05 give an analytical solution of the equations of an ascending cloudy parcel using the method of population splitting (Nenes and Seinfeld, 2003). Sulfates, hydrophilic organics and sea salt are considered $\mathrm{CCN}$ active species. Aerosol number concentrations were derived from the predicted mass mixing ratio for each species using size distributions obtained from the literature (Table 1). Sulfate and organics are considered internally mixed, and five separate bins are used to describe dust. Aerosol composition is parameterized in terms of the hygroscopicity parameter (Petters and Kreidenweis, 2007): $\kappa$ was set to $0.65,0.2$ and 1.28 for sulfate, hydrophilic organics, and sea salt, respectively. The water uptake coefficient was set to 1.0 (Raatikainen et al., 2013). In this work, the adiabatic version of the FN05 parameterization is employed. However, FN05 can readily be extended to include dust activation (Kumar et al., 2009b), entrainment (Barahona and Nenes, 2007), and giant CCN (Barahona et al., 2010b). The contribution of CCN activation in stratiform clouds to the droplet number concentration is given by

$$
\left(\frac{\mathrm{d} N_{1}}{\mathrm{~d} t}\right)_{1 \mathrm{~s}, \mathrm{act}}=\frac{\max \left(N_{\mathrm{l}, \mathrm{act}}-N_{1}, 0\right)}{\Delta t},
$$

where $N_{1}$ and $N_{1, \text { act }}$ are the in-cloud preexisting and activated droplet number concentrations, respectively. $N_{1 \text {, act }}$ is calculated at $\bar{w}_{\text {sub }}^{+}=\bar{w}+0.8 \sigma_{w}$ (Peng et al., 2005; Fountoukis and Nenes, 2005), $\bar{w}$ and $\sigma_{w}$ being the mean and standard deviation of the subgrid distribution of vertical velocity (Sect. 2.3.4), and $\bar{w}_{\text {sub }}^{+}$the vertical velocity averaged over the positive side of the distribution. This approximation is valid for $\bar{w} \ll \sigma_{w}$, and may introduce up to $20 \%$ non-systematic discrepancy in $N_{1}$,act when compared to the direct solution of the integral in Eq. (14) (Morales and Nenes, 2010); however, it is justified for its computational efficiency.

\subsubsection{Ice nucleation}

The ice nucleation parameterization implemented in GEOS5 was developed by Barahona and Nenes (2008, 2009a, b) (hereafter BN09), and is summarized in Barahona et al. (2010a). The parameterization of BN09 is derived from the analytical solution of the governing equations of an ascending cloud parcel, and considers the dependency of the ice crystal concentration on cloud formation conditions, subgridscale dynamics, and aerosol properties. At cirrus levels $(T<$ $235 \mathrm{~K}$ ), both homogeneous and heterogeneous ice nucleation and their competition are considered; i.e.,

$N_{\mathrm{i}, \text { nuc }}^{\mathrm{s}}=\left[N_{\text {hom }}+N_{\text {het }}\right]_{S_{\text {i, max }}}$,

where $N_{\mathrm{i} \text {,nuc }}^{\mathrm{s}}$ is the ice crystal concentration nucleated in a single parcel ascent, $N_{\text {hom }}$ and $N_{\text {het }}$ the ice crystal concentrations produced by homogeneous and heterogeneous ice nucleation, respectively, and $S_{\mathrm{i}, \max }$ the maximum saturation ratio reached within the cloudy parcel. In BN09, $S_{\mathrm{i}, \max }$ is explicitly calculated, accounting for the competition between water vapor deposition onto ice crystals and supersaturation generation by expansion cooling. $S_{\mathrm{i}, \max }$ (hence $N_{\mathrm{i}, \mathrm{suc}}^{\mathrm{s}}$ ) thus depends on dynamics, temperature and the concentration of ice nuclei; i.e., $S_{\mathrm{i}, \max }=S_{\mathrm{i}, \max }\left(w_{\mathrm{sub}}, T, N_{\text {het }}\right)$ (Barahona and Nenes, 2009b). Since homogeneous freezing quickly depletes supersaturation, $S_{\mathrm{i}, \max }$ is limited, so that $S_{\mathrm{i}, \max } \leq$ $S_{\text {hom }}, S_{\text {hom }}$ being the saturation threshold for homogeneous freezing (Ren and Mackenzie, 2005; Koop et al., 2000). For $T>235 \mathrm{~K}$ and $S_{\mathrm{i}, \max }<S_{\text {hom }}$, only heterogeneous ice nucleation takes place.

$N_{\text {hom }}$ is determined by the homogeneous ice nucleation rate of sulfate solution droplets, parameterized in terms of the water activity following Koop et al. (2000). Heterogeneous ice nucleation is described through a generalized ice nucleation spectrum, $\mathcal{N}_{\text {het }}=\mathcal{N}_{\text {het }}\left(S_{\mathrm{i}}, T, m_{1 \ldots n}\right)$, so that $N_{\text {het }}=\mathcal{N}_{\text {het }}\left(S_{\mathrm{i}, \max }\right)$, with $S_{\mathrm{i}}$ being the saturation ratio with respect to ice, and $m_{1 \ldots n}$ the moments of the aerosol number distribution. $\mathcal{N}_{\text {het }}$ depends on the aerosol composition, and in principle can have any functional form (Barahona and Nenes, 2009b). The usage of $\mathcal{N}_{\text {het }}\left(S_{\mathrm{i}}, T, m_{1 \ldots n}\right)$ also obviates the need for prescribing fixed nucleation thresholds, which may carry uncertainty (Barahona, 2012). In this work, $\mathcal{N}_{\text {het }}$ is described using the formulation of Phillips et al. (2013) (hereafter Ph13), considering immersion and deposition ice nucleation on dust, black carbon, and soluble organics. In simplified form, the Ph13 spectrum can be written as

$$
\begin{aligned}
& \mathcal{N}_{\text {het }}= \\
& \frac{1}{2} \sum_{\mathrm{x}} N_{\mathrm{x}} \operatorname{erfc}\left[\frac{\ln \left(\frac{D_{\mathrm{g}, \mathrm{x}}}{0.1 \mu \mathrm{m}}\right)}{\sqrt{2} \sigma_{\mathrm{g}, \mathrm{x}}}\right]\left\{1-\exp \left[-\varphi_{\mathrm{x}}\left(S_{\mathrm{i}}, T, \bar{s}_{\mathrm{p}, \mathrm{x}}\right)\right]\right\},
\end{aligned}
$$

where $N_{\mathrm{x}}, D_{\mathrm{g}, \mathrm{x}}, \sigma_{\mathrm{g}, \mathrm{x}}$, and $\bar{s}_{\mathrm{p}, \mathrm{x}}$ are the total number concentration, the geometric mean diameter, the geometric size dispersion, and the mean particle surface area of the $\mathrm{x}$ aerosol 
Table 1. Log-normal size distribution parameters used in this study (Lance et al., 2004). $D_{\mathrm{g}}(\mu \mathrm{m})$ and $\sigma_{\mathrm{g}}$ are the geometric mean diameter and dispersion, respectively. $\Phi_{i}$ is the particle number fraction in mode $i$. The "polluted" size distribution parameters for sulfate and organics are used when the total aerosol mass exceeds $5.0 \mu \mathrm{g} \mathrm{m}^{-3}$.

\begin{tabular}{lccc}
\hline Aerosol species & $D_{\mathrm{g}}$ & $\sigma_{\mathrm{g}}$ & $\Phi_{i}$ \\
\hline Dust1 & 1.46 & 2.0 & 1.0 \\
Dust2 & 2.8 & 2.0 & 1.0 \\
Dust3 & 4.8 & 2.0 & 1.0 \\
Dust4 & 9.0 & 2.0 & 1.0 \\
Dust5 & 16.0 & 2.0 & 1.0 \\
Black carbon & 0.024 & 2.20 & 1.0 \\
Seal salt & {$[0.02,0.092,0.58]$} & {$[1.47,2.0,2.0]$} & {$\left[0.56,0.43,7.6 \times 10^{-3}\right]$} \\
Sulfate and organics & & & \\
$\quad$ Clean & {$[0.016,0.067,0.93]$} & {$[1.6,2.1,2.2]$} & {$\left[0.55,0.44,4.1 \times 10^{-2}\right]$} \\
$\quad$ Polluted & {$[0.014,0.054,0.86]$} & {$[1.8,2.16,2.21]$} & {$\left[0.77,0.23,3.6 \times 10^{-3}\right]$} \\
\hline
\end{tabular}

species, respectively, and $\varphi_{\mathrm{x}}\left(S_{\mathrm{i}}, T, \bar{s}_{\mathrm{p}, \mathrm{x}}\right)$ is the number of active nucleation sites per particle (Phillips et al., 2013, 2008). The summation in Eq. (11) is carried out over five lognormal modes for dust, and single log-normal modes for black carbon and organics (Table 1). Primary biological particles are not predicted by GEOS-5 and are not considered in this work. However, on a global scale, their effect on ice cloud formation may be small (Hoose et al., 2010). Since dust and soot aerosol are typically irregular aggregates rather than spherical particles, $\bar{s}_{\mathrm{p}, \mathrm{x}}$ was obtained from the mean sphere-equivalent particle volume, assuming a bulk surface area density of $10 \mathrm{~m}^{2} \mathrm{~g}^{-1}$ for dust (Murray et al., 2011) and $50 \mathrm{~m}^{2} \mathrm{~g}^{-1}$ for soot (Popovitcheva et al., 2008).

The BN09 parameterization also allows the calculation of $S_{\text {crit }}$ for cirrus (Eq. 6, Sect. 2.3.1). According to BN09, the ice saturation ratio at which most IN freeze in a polydisperse aerosol population, $S_{\text {het }}$, is given by (Barahona and Nenes, 2009b)

$S_{\text {het }}=\max \left[1+S_{\mathrm{i}, \max }-\mathcal{N}_{\text {het }}\left(\frac{\partial \mathcal{N}_{\text {het }}}{\partial S_{\mathrm{i}}}\right)^{-1}, 1\right]$.

If no IN are present, then $S_{\text {het }}$ approaches the saturation threshold for homogeneous freezing, $S_{\text {hom }}$ (Barahona and Nenes, 2009b). $S_{\text {het }}$ and $S_{\text {hom }}$ represent the minimum saturation ratio required for cloud formation by heterogeneous and homogeneous freezing, respectively. They thus have the same meaning as the critical saturation ratio of Eq. (6). $S_{\text {crit }}$ is then calculated as

$S_{\text {crit }}=f_{\text {het }} S_{\text {het }}+\left(1-f_{\text {het }}\right) S_{\text {hom }}$,

where $f_{\text {het }}=N_{\text {het }} /\left(N_{\text {hom }}+N_{\text {het }}\right)$ is the fraction of ice crystals produced by heterogeneous ice nucleation.

The grid cell averaged nucleated ice crystal concentration, $N_{\mathrm{i}, \text { nuc }}$, is calculated by weighting $N_{\mathrm{i}, \text { nuc }}^{\mathrm{s}}$ over the distribution of updrafts within each grid cell (Sect. 2.3.4):

$N_{\mathrm{i}, \text { nuc }}=\frac{\int_{0}^{w_{\max }} N_{\mathrm{i}, \text { nuc }}^{\mathrm{s}}\left(w_{\mathrm{sub}}\right) \phi\left(\bar{w}, \sigma_{w}^{2}\right) \mathrm{d} w_{\mathrm{sub}}}{\int_{0}^{w_{\max }} \phi\left(\bar{w}, \sigma_{w}^{2}\right) \mathrm{d} w_{\mathrm{sub}}}$,

where $\phi\left(\bar{w}, \sigma_{w}^{2}\right)$ is the normal distribution and $w_{\max }=\bar{w}+$ $4 \sigma_{w}$ (Sect. 2.3.4). The latter is used as an upper limit to the integral to avoid numerical instability. Note that, for ice nucleation, using the approximation $\left.N_{\mathrm{i}, \mathrm{nuc}} \approx N_{\mathrm{i}, \mathrm{nuc}}\right|_{\bar{w}_{\mathrm{sub}}^{+}}$may introduce a much larger bias than for cloud droplet activation (Sect. 2.3.2). This is because the competition between homogeneous and heterogeneous nucleation introduces strong nonlinearity in $N_{\mathrm{i} \text {,nuc }}$ (Barahona and Nenes, 2009a). The characteristic value of $w_{\text {sub }}$ for $N_{\mathrm{i} \text {,nuc }}$ therefore generally differs from the average vertical velocity. PDF averaging is also applied for $S_{\text {crit }}$ and $S_{\mathrm{i}, \max }$.

The contribution of ice nucleation in cirrus to the ice crystal number concentration is given by

$$
\begin{aligned}
& \left(\frac{\mathrm{d} N_{\mathrm{i}}}{\mathrm{d} t}\right)_{\text {cirrus,nuc }}= \\
& \frac{\max \left[N_{\mathrm{i}, \mathrm{nuc}} P_{q}\left(q_{\mathrm{t}}>S_{\text {crit }} q_{\mathrm{i}}^{*}\right)-N_{\mathrm{i}}, 0\right]}{\Delta t} .
\end{aligned}
$$

The factor $P_{\mathrm{q}}\left(q_{\mathrm{t}}>S_{\text {crit }} q_{\mathrm{i}}^{*}\right)$ accounts for the probability of finding an air mass leading to cloud formation within the grid cell. This term was proposed by Barahona and Nenes (2011) to account for the effect of prior nucleation events on current cloud formation.

For the mixed-phase regime ( $T>235 \mathrm{~K})$, Eq. (11) is applied directly by assuming saturation with respect to liquid water, to find the contribution of deposition and condensation heterogeneous nucleation to $N_{\mathrm{i}}$. In this regime, cloud droplet freezing by immersion and contact ice nucleation contribute to the ice crystal population. These are explicitly 
treated as follows. The tendency in $N_{\mathrm{i}}$ from immersion freezing of cloud droplets is parameterized in the form

$$
\left(\frac{\mathrm{d} N_{\mathrm{i}}}{\mathrm{d} t}\right)_{\mathrm{imm}}=\sum_{\mathrm{x}} N_{\mathrm{x}} \bar{s}_{\mathrm{p}, \mathrm{x}} \gamma_{\mathrm{c}} \frac{\mathrm{d} n_{\mathrm{s}, \mathrm{x}}}{\mathrm{d} T} \exp \left(-\bar{s}_{\mathrm{p}, \mathrm{x}} n_{\mathrm{s}, \mathrm{x}}\right)
$$

where $\gamma_{\mathrm{c}}=-\bar{w}_{\text {sub }} \frac{\mathrm{d} T}{\mathrm{~d} z}$ is the average cooling rate (Sect. 2.3.4). $N_{\mathrm{x}}$ and $n_{\mathrm{S}, \mathrm{x}}$ are the number concentration and the active site surface density for species $\mathrm{x}$, respectively. The latter is calculated according to Niemand et al. (2012) for dust and Murray et al. (2012) for black carbon.

Contact ice nucleation is parameterized as the product of the collection flux of aerosol particles by the cloud droplets and the ice nucleation efficiency in contact mode. Young (1974) suggested that phoretic effects and Brownian motion are responsible for collection scavenging of ice nuclei. Baker (1991) however showed that Brownian motion is the dominant factor, although phoretic effects may be significant in deep convective clouds (Phillips et al., 2007). Considering only Brownian collection, the contribution of contact ice nucleation to the ice crystal formation tendency is written in the form

$$
\begin{aligned}
& \left(\frac{\mathrm{d} N_{\mathrm{i}}}{\mathrm{d} t}\right)_{\mathrm{cont}}= \\
& \sum_{\mathrm{X}}\left(\frac{\mathrm{d} N_{\mathrm{x}}}{\mathrm{d} t}\right)_{\mathrm{Brw}}\left\{1-\exp \left[-\bar{s}_{\mathrm{p}, \mathrm{x}} n_{\mathrm{s}, \mathrm{x}}\left(T_{\text {cont }}\right)\right]\right\},
\end{aligned}
$$

where $\left(\frac{\mathrm{d} N_{\mathrm{x}}}{\mathrm{d} t}\right)_{\text {Brw }}$ is the Brownian collection flux of the $\mathrm{x}$ aerosol species (Young, 1974). Consistent with laboratory studies (e.g., Fornea et al., 2009; Ladino et al., 2011), the active site density in the contact mode is assumed to be the same as for immersion freezing shifted towards a higher temperature; i.e., $T_{\text {cont }} \approx T-3 \mathrm{~K}$.

The in-cloud contribution of ice nucleation in mixed-phase clouds to the ice crystal number concentration tendency is given by

$$
\begin{aligned}
& \left(\frac{\mathrm{d} N_{\mathrm{i}}}{\mathrm{d} t}\right)_{\text {mixed,nuc }}= \\
& \min \left[\left(\frac{\mathrm{d} N_{\mathrm{i}}}{\mathrm{d} t}\right)_{\text {cont }}+\left(\frac{\mathrm{d} N_{\mathrm{i}}}{\mathrm{d} t}\right)_{\mathrm{imm}}+\left(\frac{\mathrm{d} N_{\mathrm{i}}}{\mathrm{d} t}\right)_{\mathrm{dep}}, \frac{N_{d}}{\Delta t}\right]
\end{aligned}
$$

where the subscripts cont, imm, and dep refer to contact, immersion, and deposition/condensation ice nucleation, respectively. The term $\frac{N_{\mathrm{d}}}{\Delta t}$ is used to limit the nucleated ice crystal concentration to the existing concentration of cloud droplets.

\subsubsection{Subgrid-scale dynamics}

Besides information on the aerosol composition and size, parameterization of cloud droplet and ice crystal formation requires knowledge of the vertical velocity, $w_{\text {sub }}$, on the spatial scale of individual parcels (typically under $100 \mathrm{~m}$ ), which is not resolved by GEOS-5. $w_{\text {sub }}$ depends on radiative cooling (Morrison et al., 2005), turbulence (Golaz et al., 2010), gravity wave dynamics (e.g., Barahona and Nenes, 2011; Kärcher and Ström, 2003; Jensen et al., 2010; Joos et al., 2008) and local convection. To account for these dependencies, we employ a semi-empirical formulation as follows.

In situ measurements (e.g., Peng et al., 2005; Bacmeister et al., 1999; Conant et al., 2004) suggest that $w_{\text {sub }}$ is approximately normally distributed. The mean vertical velocity of the distribution is written as (Morrison et al., 2005)

$\bar{w}=w_{\mathrm{ls}}-\frac{c_{\mathrm{p}}}{g}\left(\frac{\partial T}{\partial t}\right)_{\mathrm{rad}}$,

where $w_{1 \mathrm{~s}}$ is the grid-scale vertical velocity, $c_{\mathrm{p}}$ is the heat capacity of air, $g$ is the acceleration of gravity, and $\left(\frac{\partial T}{\partial t}\right)_{\mathrm{rad}}$ is the diabatic heating due to radiative transfer. Variance in $w_{\text {sub }}$ for stratiform clouds results from subgrid-scale eddy motion, $\sigma_{w, \text { turb }}^{2}$, and gravity wave dynamics, $\sigma_{w, \text { gw }}^{2}$; i.e.,

$\sigma_{w}^{2}=\sigma_{w, \text { turb }}^{2}+\sigma_{w, \mathrm{gw}}^{2}$.

A first-order closure is used to diagnose $\sigma_{w \text {,turb }}^{2}$ (Morrison and Gettelman, 2008):

$\sigma_{w, \text { turb }}^{2}=\frac{K_{T}}{l_{\mathrm{m}}}$

where $K_{T}$ is the mixing coefficient for heat (Louis et al., 1983) and $l_{\mathrm{m}}$ is the mixing length. MG08 prescribed a fixed $l_{\mathrm{m}}=300 \mathrm{~m}$. To account for the spatial variation of $l_{\mathrm{m}}$, the formulation of Blackadar (1962) is used instead; i.e.,

$l_{\mathrm{m}}=\frac{k z}{1+\frac{k z}{\lambda_{\mathrm{m}}}}$,

where $k$ is the von Kármán constant, $z$ is the altitude and $\lambda_{\mathrm{m}}$ is the value of $l_{\mathrm{m}}$ in the free troposphere (Blackadar, 1962). The latter is estimated as $10 \%$ of the boundary layer height from the previous time step (Molod, 2012). This approach also takes into account the vertical variation of $l_{\mathrm{m}}$ within the planetary boundary layer (PBL). The minimum value of $\sigma_{w, \text { turb }}^{2}$ is set to $0.01 \mathrm{~m}^{2} \mathrm{~s}^{-2}$ within the PBL.

Small-scale gravity waves strongly affect the formation of cirrus and mixed-phase clouds (e.g., Haag and Kärcher, 2004; Jensen et al., 2010; Joos et al., 2008; Barahona and Nenes, 2011; Dean et al., 2007). In situ measurements suggest that the dynamics of the upper troposphere are characterized by the random superposition of gravity waves from different sources (e.g., Jensen and Pfister, 2004; Bacmeister et al., 1999; Sato, 1990; Herzog and Vial, 2001). Random wave superposition results in a Gaussian distribution of vertical velocities (e.g., Bacmeister et al., 1999; Barahona and Nenes, 2011). Using this, a semi-empirical parameterization for $\sigma_{w, \mathrm{gw}}^{2}$ is derived in the form (Eq. B5)

$\sigma_{w, \mathrm{gw}}^{2}=0.0169 \min \left[\frac{4 \pi U\left|\tau_{0}\right|}{\rho_{\mathrm{a}} L_{\mathrm{c}} N},\left(\frac{2 \pi U^{2}}{N L_{\mathrm{c}}}\right)^{2}\right]$, 
where $\tau_{0}$ is the surface stress (Lindzen, 1981), $U$ the horizontal wind, $\rho_{\mathrm{a}}$ the air density, $N$ the Brunt-Väisälä frequency, and $L_{\mathrm{c}}$ the wavelength of the highest-frequency waves in the spectrum, also referred to as the characteristic cirrus scale (here assumed to be $100 \mathrm{~m}$ ). Equation (23) is obtained by relating $\left|\tau_{0}\right|$ to the equivalent perturbation height at the surface. This is scaled to obtain the maximum wave amplitude at each vertical level (Joos et al., 2008; McFarlane, 1987) and then used to compute $\sigma_{w, \mathrm{gw}}^{2}$ (Barahona and Nenes, 2011). This approach parameterizes orographically generated gravity waves. In practice, both the background and the orographic surface stress are used in Eq. (23) to avoid underestimation of $\sigma_{w, \mathrm{gw}}^{2}$ in marine regions. The second term in brackets on the right-hand side of Eq. (23) limits $\sigma_{w, \mathrm{gw}}$ to account for wave saturation and breaking (Eq. B3). The derivation of Eq. (23) is detailed in Appendix B. Only activation processes are modified by subgrid vertical velocity variability; i.e., $\phi\left(\bar{w}, \sigma_{w}^{2}\right)$ is assumed to be uncorrelated with the subgrid distribution of condensate.

\subsubsection{Preexisting ice crystals}

Ice nucleation can be inhibited by water vapor deposition onto preexisting ice crystals (i.e., ice crystals present in the grid cell from previous nucleation events). Their impact on cirrus properties may be significant at low temperatures, where ice crystals are small and have low sedimentation rates (Barahona and Nenes, 2011). The effect of preexisting crystals on ice nucleation can be parameterized by reducing the vertical velocity for ice nucleation in cirrus by a factor dependent on the preexisting ice crystal concentration and size (Eq. C5); i.e.,

$$
\begin{aligned}
& w_{\text {sub,pre }}= \\
& w_{\text {sub }} \max \left(1-\frac{N_{\mathrm{i}, \text { pre }} \pi \beta c \rho_{\mathrm{i}} A_{\mathrm{i}}\left(S_{\text {hom }}-1\right)}{2 \lambda_{0, \mathrm{i}, \mathrm{pre}} \alpha w_{\text {sub }} S_{\text {hom }}}, 0\right),
\end{aligned}
$$

where $N_{\mathrm{i}, \text { pre }}$ is the preexisting ice crystal concentration, $\lambda_{0, \mathrm{i}, \mathrm{pre}}$ is the slope of the size distribution of preexisting ice crystals, $c$ is a shape factor (here assumed to be equal to 1 ), $\rho_{\mathrm{i}}$ is the bulk density of ice, and $A_{\mathrm{i}}, \alpha$ and $\beta$ are temperaturedependent parameters (Appendix D). $w_{\text {sub,pre represents a }}$ corrected vertical velocity accounting for the effect of preexisting ice crystals limiting expansion cooling. Water vapor deposition onto preexisting crystals acts against the increase in ice supersaturation from expansion cooling. Thus, by enhancing water vapor deposition within cloudy parcels, preexisting ice crystals tend to decrease $S_{\mathrm{i} \text {, max }}$ (Eq. 10), leading to a reduction in $N_{\mathrm{i}, \text { nuc }}$. To account for this, $S_{\mathrm{i}, \max }$ is calculated using $w_{\text {sub,pre }}$ instead of $w_{\text {sub }}$; i.e., $S_{\mathrm{i}, \max }=S_{\mathrm{i}, \max }\left(w_{\text {sub,pre }}\right.$, $\left.T, N_{\text {het }}\right)$. A similar approach was proposed by Kärcher et al. (2006), who used a numerical integration technique instead of the analytical approach presented here. The derivation of Eq. (24) is detailed in Appendix C. The effect of preexisting ice crystals on cirrus properties is analyzed in Sect. 4.

\subsection{Microphysics of convective cumulus}

While all the main features of RAS are preserved in the new scheme, the removal of condensate is reformulated to account for the effect of IN and CCN emissions on the generation of convective precipitation. RAS calculates the convective cloud condensate and mass flux at each model level by averaging over an ensemble of ascending parcels, each one lifted from the top of the PBL (Molod et al., 2012; Rienecker et al., 2008). Each ascending parcel is characterized by its detrainment level and entrainment rate (Moorthi and Suarez, 1992), and saturation adjustment is used to find the amount of condensate present in each parcel. In the current RAS implementation in GEOS-5, a single parcel detrains at each model level, so that the tendency of the tracer $\eta$ due to cloud convective processes is given by

$$
\left(\frac{\partial \eta}{\partial t}\right)_{\mathrm{cv}}=D \eta-g W \frac{\partial \eta}{\partial p}
$$

where $D$ is the detrainment rate and $W$ the convective mass flux. In the operational GEOS-5, a prescribed fraction of condensate is assumed to precipitate from each parcel before reaching the cloud top. The remaining condensate is then linearly partitioned between ice and liquid as a function of $T$ and detrained at the neutral buoyancy level.

Each convective parcel is assumed to develop independently, and the detrained condensate from different parcels is weighted by the convective mass flux. The subscript "cp" in the following equations refers to processes occurring within each parcel. A detailed description of the GEOS-5 convective scheme is presented elsewhere (Moorthi and Suarez, 1992; Rienecker et al., 2008). The balance of a tracer, $\eta$, within a convective parcel is written as

$\frac{1}{W} \frac{\mathrm{d}(\eta W)}{\mathrm{d} t}=\left(\frac{\mathrm{d} \eta}{\mathrm{d} t}\right)_{\mathrm{cp}}+\lambda w_{\mathrm{cp}}\left(\eta^{\prime}-\eta\right)$,

where $\left(\frac{\mathrm{d} \eta}{\mathrm{d} t}\right)_{\mathrm{cp}}$ is the rate of change in $\eta$ from microphysical processes occurring within convective parcels, $w_{\mathrm{cp}}$ is the parcel vertical velocity, $\lambda$ is the per-length entrainment rate, and $\eta^{\prime}$ is the value of $\eta$ in the cloud-free environment. Detrainment of condensate is assumed to occur only at the cloud top.

The rate of change in $\eta$ from microphysical processes occurring within a convective cloud parcel is given by

$$
\left(\frac{\mathrm{d} \eta}{\mathrm{d} t}\right)_{\mathrm{cp}}=\left(\frac{\mathrm{d} \eta}{\mathrm{d} t}\right)_{\text {source }}+\left(\frac{\mathrm{d} \eta}{\mathrm{d} t}\right)_{\text {precip }}+\left(\frac{\mathrm{d} \eta}{\mathrm{d} t}\right)_{\text {freezing }},
$$

where the subscript "source" refers to nucleation, condensation and deposition processes, "precip" to precipitation, and "freezing" to phase transformation. Equation (26) is integrated for each parcel from cloud base to cloud top, at which all remaining condensate detrains into the 
anvil; i.e., $\left[\frac{1}{W} \frac{\mathrm{d}(\eta W)}{\mathrm{d} t}\right]_{\text {cloud top }}=D \eta$. The initial condition for Eq. (26) depends on the tracer. At cloud base, the concentration of ice crystals and the ice mass mixing ratio are assumed to be zero, whereas the activation of cloud droplets at cloud base is explicitly considered (Sect. 2.4.2).

Solution of Eq. (26) requires knowledge of the vertical velocity within each parcel, $w_{\mathrm{cp}}$, which is also necessary for driving the droplet activation and ice nucleation parameterizations. This is calculated by solving (Frank and Cohen, 1987)

$\frac{1}{2} \frac{\mathrm{d} w_{\mathrm{cp}}^{2}}{\mathrm{~d} z}=\frac{g}{1+\gamma} \frac{T_{v}-T_{v}^{\prime}}{T_{v}^{\prime}}-\lambda w_{\mathrm{cp}}^{2}-g q_{\mathrm{cn}}$,

where $\gamma=0.5$ (Sud and Walker, 1999), $T_{v}$ and $T_{v}^{\prime}$ are the virtual temperature of the cloud and the environment, respectively, and $q_{\mathrm{cn}}$ is the mixing ratio of total condensate in the convective parcel. The first term on the right-hand side of Eq. (28) represents the increase in the convective parcel's kinetic energy by buoyancy, whereas the second and third terms account for the entrainment of stagnant air into the parcel and the drag from the weight of the condensate, respectively. Equation (28) is forward-integrated from the level below cloud base to cloud top using $w_{\mathrm{cp}, \text { in }}=0.8 \mathrm{~m} \mathrm{~s}^{-1}$ as an initial condition (Guo et al., 2008; Gregory, 2001); the vertical profile $w_{\mathrm{cp}}$ is not very sensitive to this assumption (Sud and Walker, 1999). Note that $w_{\mathrm{cp} \text {, in }}$ differs from the vertical velocity used for cloud droplet activation. The latter depends on the local buoyancy; i.e., $w_{\text {cp,cloudbase }}=$ $w_{\mathrm{cp}, \text { in }}+\frac{\mathrm{d} w_{\mathrm{cp}}}{\mathrm{d} z} \Delta z_{\text {base }}$, where $\Delta z_{\text {base }}$ is the model layer thickness at the cloud base.

\subsubsection{Partitioning of convective condensate}

Total condensate is partitioned between liquid and ice as follows. Nucleated ice crystals are assumed to grow by accretion of water vapor in an environment saturated with respect to liquid water. That is, the coexistence of liquid water favors a high concentration of water vapor available for deposition onto the ice crystals, and the ice and liquid phases remain in quasi-equilibrium within the convective parcel. Hydrometeor species are assumed to follow a gamma distribution (Eq. 2). The growth rate of ice crystals within convective cumulus is given by (Pruppacher and Klett, 1997; Korolev and Mazin, 2003)

$$
\left(\frac{\mathrm{d} q_{\mathrm{i}}}{\mathrm{d} t}\right)_{\mathrm{dep}}=\min \left[\frac{n_{\mathrm{i}, \mathrm{cp}} \pi c \rho_{\mathrm{i}} A_{\mathrm{i}}\left(S_{\mathrm{i}, \mathrm{wsat}}-1\right)}{2 \lambda_{0, \mathrm{i}, \mathrm{cp}}}, \frac{\mathrm{d} q_{\mathrm{cn}}}{\mathrm{d} t}\right],
$$

where $\left(\frac{\mathrm{d} q_{\mathrm{cn}}}{\mathrm{d} t}\right)$ is the rate of generation of total condensate calculated by the convective parameterization, $c$ is a shape factor (assumed equal to 1 ), $\rho_{\mathrm{i}}$ the bulk density of ice, $A_{\mathrm{i}}$ is a temperature-dependent growth factor (Appendix D), $n_{\mathrm{i}, \mathrm{cp}}$ is the ice crystal concentration within the convective parcel, $\lambda_{0, i}$ is the slope parameter of the ice size distribution within the convective parcel, and $S_{\mathrm{i}, \text { wsat }}$ is the value of $S_{\mathrm{i}}$ at saturation with respect to liquid water. Using Eq. (29), and since $q_{\mathrm{cn}}=$ $q_{1}+q_{\mathrm{i}}$, the source term for liquid water within convective cumulus is given by

$$
\left(\frac{\mathrm{d} q_{1}}{\mathrm{~d} t}\right)_{\mathrm{cond}}=\left(\frac{\mathrm{d} q_{\mathrm{cn}}}{\mathrm{d} t}\right)-\left(\frac{\mathrm{d} q_{\mathrm{i}}}{\mathrm{d} t}\right)_{\mathrm{dep}},
$$

where $\left(\frac{\mathrm{d} q_{1}}{\mathrm{~d} t}\right)_{\text {cond }}$ is the rate of generation of liquid water within convective parcels.

\subsubsection{Droplet activation and ice crystal nucleation in convective cumulus}

Explicit activation of $\mathrm{CCN}$ into cloud droplets is only considered at cloud base and used as an initial condition to Eq. (26) (Sect. 2.4). Entrained aerosols (sulfate, sea salt, and organics) above cloud base are assumed to activate instantaneously as they enter the cloud parcel. Dust and soot IN lead to the heterogeneous freezing of cloud droplets in the immersion and contact modes, described using Eqs. (16) and (17). Since soot and dust particles would likely adsorb water within convective parcels (Wiacek et al., 2010; Kumar et al., 2009a), ice nucleation in the deposition mode within convective cumulus is not considered. Cloud droplets freeze homogeneously at $235 \mathrm{~K}$. Frozen droplets rapidly quench supersaturation within convective cumulus. The homogeneous nucleation of deliquesced sulfate, which requires high supersaturation $\left(S_{\mathrm{i}} \sim 145-170 \%\right.$, Koop et al., 2000), is thus not likely to occur within convective parcels. Homogeneous freezing of interstitial aerosol is therefore not considered within convective cumulus.

\subsubsection{Generation of convective precipitation}

Precipitation is generated within each convective parcel and assumed to reach the surface during each time step. The remaining condensate is then detrained into anvil clouds following Eq. (25). Ice water in convective cumulus is likely to exist as graupel, snow and ice crystals with different size distributions and falling velocities, affecting the formation of precipitation. Following Del Genio et al. (2005), a simplified treatment is proposed, where total ice is partitioned between ice and snow (assumed as a single species) and graupel. The two species are differentiated by their terminal velocity. This partitioning is prescribed as a function of temperature and used to calculate the formation of ice precipitation within convective clouds. For ice crystal growth and detrainment a single ice species is assumed.

Droplet-to-rain autoconversion is calculated according to Liu et al. (2006), and all autoconverted water is assumed to be lost as surface precipitation within one time step. The size dispersion of the droplet population, $\mu_{l}$, follows the formulation of Liu et al. (2008). Evaporation of convective precipitation is parameterized according to Bacmeister et al. (1999). 
Total ice water within convective parcels is assumed to partition between ice/snow (taken as a a single species) and graupel, and differentiated by their terminal velocity (Table 2). The fraction of total ice existing as graupel is approximated by (Del Genio et al., 2005)

$$
f_{\mathrm{gr}}=0.25\{3.0+\exp [0.1 \min (T-273,0)]\} .
$$

The particle sizes of ice/snow and graupel are assumed to follow an exponential distribution $\left(\mu_{\mathrm{g}}=\mu_{\mathrm{i} / \mathrm{s}}=0.0\right)$ (McFarquhar and Heymsfield, 1997). The number precipitation rate of ice/snow within convective parcels is given by the number flux across the critical size for the ice/snow species, $D_{\mathrm{c}, \mathrm{i} / \mathrm{s}}$ (Seinfeld and Pandis, 1998),

$$
\begin{aligned}
& \left(\frac{\mathrm{d} n_{\mathrm{i} / \mathrm{s}}}{\mathrm{d} t}\right)_{\text {precip,cp }}= \\
& \frac{n_{\mathrm{i} / \mathrm{s}} A_{\mathrm{i}}\left(S_{\mathrm{i}, \mathrm{wsat}}-1\right)}{D_{\mathrm{c}, \mathrm{i} / \mathrm{s}}^{2}}\left[1-\exp \left(-\lambda_{0, \mathrm{i} / \mathrm{s}} D_{\mathrm{c}, \mathrm{i} / \mathrm{s}}\right)\right],
\end{aligned}
$$

where $n_{\mathrm{i} / \mathrm{s}}=\left(1-f_{\mathrm{gr}}\right) n_{\mathrm{i}, \mathrm{cp}}$ is the number concentration of ice/snow particles, and $\lambda_{0, \mathrm{i} / \mathrm{s}}$ is the slope parameter of the ice/snow size distribution. The mass precipitation rate of ice/snow is calculated as

$$
\left(\frac{\mathrm{d} q_{\mathrm{i} / \mathrm{s}}}{\mathrm{d} t}\right)_{\text {precip,cp }}=\frac{q_{\mathrm{i} / \mathrm{s}} \xi_{\mathrm{i} / \mathrm{s}}}{n_{\mathrm{i} / \mathrm{s}}}\left(\frac{\mathrm{d} n_{\mathrm{i} / \mathrm{s}}}{\mathrm{d} t}\right)_{\text {precip,cp }},
$$

where $q_{\mathrm{i} / \mathrm{s}}=\left(1-f_{\mathrm{gr}}\right) q_{\mathrm{i}, \mathrm{cp}}$ is the mixing ratio of ice/snow within the convective parcel, and $\xi_{\mathrm{i} / \mathrm{s}}=\frac{1}{6}\left[\left(\lambda_{0, \mathrm{i} / \mathrm{s}} D_{\mathrm{c}, \mathrm{i} / \mathrm{s}}\right)^{3}+\right.$ $\left.3\left(\lambda_{0, \mathrm{i} / \mathrm{s}} D_{\mathrm{c}, \mathrm{i} / \mathrm{s}}\right)^{2}+6 \lambda_{0, \mathrm{i} / \mathrm{s}} D_{\mathrm{c}, \mathrm{i} / \mathrm{s}}+6\right]$ is the ratio of the volume to number fraction above $D_{\mathrm{c}, \mathrm{i} / \mathrm{s}}$ in the size distribution of ice/snow. The term $\xi_{\mathrm{i} / \mathrm{s}}$ is introduced to account for the preferential precipitation of the largest particles of the population, which tends to enhance the mass over the number precipitation rate. The critical size for precipitation, $D_{\mathrm{c}, \mathrm{i} / \mathrm{s}}$, is calculated by equating the hydrometeor terminal velocity, $w_{\text {term }}$, to $w_{\text {cp }}$ (Table 2).

Equations (32) and (33) assume that ice and snow grow mainly by diffusion within the convective parcel. The same assumption cannot be applied to graupel since it also grows by collection of cloud droplets. The precipitation rate of graupel is therefore calculated by removing the fraction of the size distribution above the graupel critical size, $D_{\mathrm{c}, \mathrm{g}}$, at each model level (Ferrier, 1994)

$$
\left(\frac{\mathrm{d} n_{\mathrm{gr}}}{\mathrm{d} t}\right)_{\text {precip }, \mathrm{cp}}=\frac{n_{\mathrm{gr}} \exp \left(-\lambda_{0, \mathrm{~g}} D_{\mathrm{c}, \mathrm{g}}\right)}{\Delta t_{L}},
$$

where $n_{\mathrm{gr}}=f_{\mathrm{gr}} n_{\mathrm{i}, \mathrm{cp}}$ is the graupel number mixing ratio, $\lambda_{0, \mathrm{~g}}$ the slope parameter of the graupel size distribution and $\Delta t_{L}=\Delta z \bar{w}_{\mathrm{cv}}^{-1}$ is the time spent by the parcel in a given model layer. Similarly for $q_{\mathrm{gr}}$,

$$
\left(\frac{\mathrm{d} q_{\mathrm{gr}}}{\mathrm{d} t}\right)_{\text {precip,cp }}=
$$

$\frac{q_{\mathrm{gr}} \exp \left(-\lambda_{0, \mathrm{~g}} D_{\mathrm{c}, \mathrm{g}}\right)\left[\left(\lambda_{0, \mathrm{~g}} D_{\mathrm{c}, \mathrm{g}}\right)^{3}+3\left(\lambda_{0, \mathrm{~g}} D_{\mathrm{c}, \mathrm{g}}\right)^{2}+6 \lambda_{0, \mathrm{~g}} D_{\mathrm{c}, \mathrm{g}}+6\right]}{6 \Delta t_{L}}$,

where $q_{\mathrm{gr}}=f_{\mathrm{gr}} q_{\mathrm{i}, \mathrm{cp}}$ is the graupel mass mixing ratio.

The total mass precipitation rate for ice within convective parcels is given by

$$
\left(\frac{\mathrm{d} q_{\mathrm{i}}}{\mathrm{d} t}\right)_{\text {precip,cp }}=\left(\frac{\mathrm{d} q_{\mathrm{i} / \mathrm{s}}}{\mathrm{d} t}\right)_{\text {precip,cp }}+\left(\frac{\mathrm{d} q_{\mathrm{gr}}}{\mathrm{d} t}\right)_{\text {precip,cp }} .
$$

Similarly for the ice crystal number concentration,

$$
\left(\frac{\mathrm{d} n_{\mathrm{i}}}{\mathrm{d} t}\right)_{\text {precip,cp }}=\left(\frac{\mathrm{d} n_{\mathrm{i} / \mathrm{s}}}{\mathrm{d} t}\right)_{\text {precip,cp }}+\left(\frac{\mathrm{d} n_{\mathrm{gr}}}{\mathrm{d} t}\right)_{\text {precip,cp }} .
$$

Equations (36) and (37) are used into Eq. (27), which then is used to solve Eqs. (25) and (26). Since graupel is not explictly detrained, only the total ice (ice/snow plus graupel) is used in Eq. (27).

\section{Model evaluation}

Model evaluation is carried out by comparing cloud properties against satellite retrievals and in situ observations. Satellite data sets included level 3 products from the NASA MODIS (http://modis.gsfc.nasa.gov/) combined TERRA and AQUA data product (Platnick et al., 2003), and the International Satellite Cloud Climatology Project (ISCCP) (Rossow and Schiffer, 1999) and CloudSat (Li et al., 2012, 2014) projects. Level 3 MODIS monthly output for the years 20032009 was used. CloudSat data spanned over the years 2007 2008 and a climatology for the years 1983-2008 was used for ISCCP data (Rossow and Schiffer, 1999). When possible, the Cloud Feedback Model Intercomparison Project Observation Simulator Package, COSP (Bodas-Salcedo et al., 2011), was used to compare model output against satellite retrievals. COSP uses the model output to simulate the retrieval of satellite platforms, minimizing in this way errors from the sampling of the model output when comparing against satellite observations.

Global cloud radiative properties were obtained from the Clouds and Earth's Radiant Energy System (CERES) Energy Balanced and Filled (EBAF) level 4 data product (Loeb et al., 2009) and the NASA Earth Radiation Budget Experiment (ERBE; Barkstrom, 1984). Total precipitation was obtained from the Global Precipitation Climatology Project (GPCP) data set (Huffman et al., 1997) and the CPC merged analysis of precipitation (CMAP) (Xie and Arkin, 1997). CERES, GPCP and CMAP data were available over the entire period of simulation. A climatology spanning the years 19852003 was used for the ERBE data. Runs were performed for a period of 10 years starting on 1 January 2001, with a spin-up time of one year using a c48 cubed sphere grid (about $\sim 2^{\circ}$ spatial resolution) and 72 vertical levels. Sensitivity studies (Sect. 4) were performed by running the model for two years at the same resolution. Test runs showed that 
Table 2. Parameters of the terminal velocity relation $w_{\text {term }}=a D_{\mathrm{y}}^{b}(1000 / p)^{0.4}$ (SI units) for convective ice species.

\begin{tabular}{lccl}
\hline Species & $a$ & $b$ & Reference \\
\hline Ice & $2 \exp \left[4 \times 10^{-4}(T-273.0)\right]$ & $0.244-4.9 \times 10^{-3}(T-273.0)$ & Heymsfield et al. (2007) \\
Graupel & 19.3 & 0.37 & Locatelli and Hobbs (1974) \\
\hline
\end{tabular}

two years were enough to elucidate the first-order effect of variation in microphysical parameters on cloud properties. All simulations were forced with observed sea surface temperatures (Reynolds et al., 2002). Initial conditions were obtained from the Modern-Era Retrospective Analysis for Research and Applications (MERRA; Rienecker et al., 2011). The aerosol concentration was calculated interactively using the GOCART model (Colarco et al., 2010), with emissions as described in Diehl et al. (2012). Results obtained with the operational version of GEOS-5 and using the new microphysics are referred to as the CTL and NEW runs, respectively.

\subsection{Cloud fraction}

The parameterization of cloud fraction in GEOS-5 was modified to account for the effect of microphysical processing on $P_{q}(q)$ (Sect. 2.3.1) and allow supersaturation with respect to the ice phase. Figure 1 shows the effect of these modifications on the low (CLDLO), middle (CLDMD), and high (CLDHI) cloud fraction in GEOS-5. In general the CTL and NEW simulations present similar distributions of cloud fraction. However, in NEW, $f_{\mathrm{c}}$ tends to be higher and in better agreement with ISCCP retrievals. The new cloud fraction scheme resulted in higher CLDLO in the remote Atlantic and Pacific oceans and reduced the cloud bias over South America and Asia. CLDLO associated with the low-level stratocumulus decks on the western coasts of North and South America and South Africa is still underpredicted in the NEW simulation. This feature is common in climate models (Kay et al., 2012); in GEOS-5 it is likely caused by the absence of an explicit shallow cumulus parameterization. The overprediction of CLDLO at the high latitudes of the NH in CTL is also significantly reduced in the NEW simulation. Overall, the global mean bias in CLDLO is significantly lower in NEW (-3\%) than in CTL $(-5 \%)$.

The global mean bias in CLDMD is also lower in NEW $(-9 \%)$ than in CTL $(-15 \%)$. The overestimation of CLDMD at the low and middle latitudes of the Southern Hemisphere $(\mathrm{SH})$ and the Northern Hemisphere $(\mathrm{NH})$ in CTL is largely removed in NEW, which results from a more realistic distribution of ice water content in NEW than in CTL (Sect. 3.6). The underestimation in CLDMD at the middle latitudes $\left(\sim 30^{\circ}\right)$ of $\mathrm{NH}$ is also smaller in NEW than in CTL, particularly over land. However, NEW tends to increase the overestimation in CLDMD at the high latitudes of the SH. Similarly, although the CTL and the NEW simulations present similar distributions of high-level clouds

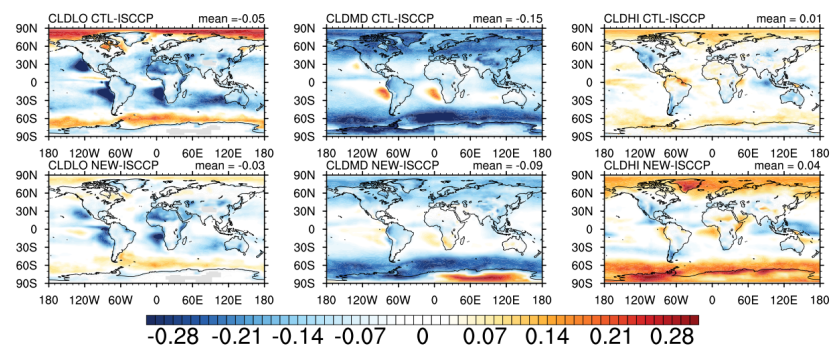

Figure 1. Annual mean differences in low- (CLDLO), middle(CLDMD) and high- (CLDHI) level cloud fraction between GEOS5 and ISCCP (Rossow and Schiffer, 1999) for the CTL and NEW runs using the COSP simulator.

(CLDHI), in general CLDHI tends to be overestimated at the marine high latitudes and underestimated over the continents. The NEW simulation also tends to underpredict CLDHI over the Tropical Warm Pool. The global mean bias in CLDHI is about 1 and $4 \%$ in the CTL and NEW run respectively. Biases in CLDHI and CLDMD at the high latitudes (above $60^{\circ}$ ) of the SH and the NH tend to be more pronounced in NEW than in CTL. Although the source of these biases is not clear, they may be related to a low value of $q^{*}$ (Eq. 4) in mixed phase clouds. Note that ISCCP retrievals tend to be uncertain in those regions as well (Rossow and Schiffer, 1999).

\subsection{Supersaturation over ice}

Restricting cloud formation to $S_{\mathrm{i}}>S_{\text {crit }}$ implies that supersaturation must be built before new ice clouds can form. The term $P_{q}\left(q_{\mathrm{t}}>S_{\text {crit }} q_{\mathrm{i}}^{*}\right)$ in Eq. (15) also restricts ice nucleation to supersaturated regions and reduces the nucleated ice crystal concentration and the water vapor relaxation time scale. Furthermore, MG08 allows for supersaturation within cirrus since it does not apply saturation adjustment for ice clouds. These factors lead to sustained supersaturation at cirrus levels $(T<235 \mathrm{~K})$.

Cloud formation and ice crystal nucleation are controlled in part by $S_{\text {crit }}$, which provides an internal link between ice nucleation, $f_{\mathrm{c}}$ and $q_{\mathrm{i}} . S_{\text {crit }}$ depends on $T$ and on the local vertical velocity at the scale of individual cloudy parcels $(\sim 100 \mathrm{~m}$ to $1 \mathrm{~km}) . S_{\text {crit }}$ is also determined by the availability of IN: in general, high IN concentration leads to low $S_{\text {crit }}$ (Barahona and Nenes, 2009b). The global distribution of $S_{\text {crit }}$ for $T<235 \mathrm{~K}$ (Fig. 2, right panel) presents two characteristic modes, showing predominance of heterogeneous $\left(S_{\text {crit }} \sim\right.$ 

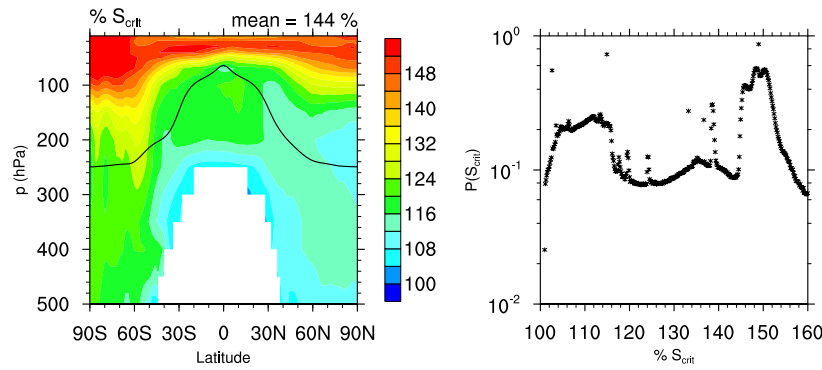

Figure 2. Annual zonal mean (left panel) and global frequency distribution (right panel) of the critical saturation ratio, $S_{\text {crit }}(\%)$, for the cirrus regime $(T<235 \mathrm{~K})$, obtained from $6 \mathrm{~h}$ instantaneous GEOS-5 output over a 3-year subset (2002-2004) of the NEW run. Solid bold lines (left panel) represent the annual mean tropopause pressure.

$120 \%)$ and homogeneous $\left(S_{\text {crit }} \sim 150 \%\right)$ ice nucleation. The peak at $150 \%$ and the highest $S_{\text {crit }}$ values correspond to low $T$ regions with high vertical velocities and low aerosol concentration, common around the tropopause (Fig. 2, left panel). Values of $S_{\text {crit }}$ as low as $105 \%$ are also not uncommon, and are associated with high concentrations of active IN (e.g., dust). These are often located around $T \sim 230-240 \mathrm{~K}$, where deposition/condensation IN are active and abundant enough to impact supersaturation (Sect. 3.5). For lower $T$, the concentration of active IN is too low to decrease supersaturation substantially, and $S_{\text {crit }}$ increases towards $S_{\text {hom }}$ (Fig. 2, left panel).

The global mean value of $S_{\text {crit }}(\sim 144 \%)$ is close to $S_{\text {hom }}$, which would in principle indicate a strong predominance of homogeneous nucleation (Fig. 2, left panel). This however depends on whether a cloud is actually formed under those conditions. Although high values of $S_{\text {crit }}$ are very frequent for $p<50 \mathrm{hPa}$, most cirrus clouds form between 100 and $300 \mathrm{hPa}$ (Sect. 3.6), where $S_{\text {crit }} \sim 110-130 \%$. At these vertical levels, $S_{\text {crit }}$ is relatively high $(\sim 130 \%)$ in the Southern Hemisphere, but lower in the Northern Hemisphere. Homogeneous freezing would thus tend to be more predominant in the Southern Hemisphere. This behavior is further analyzed in Sect. 3.5.

The distribution of clear sky saturation ratio, $S_{\mathrm{i}, \mathrm{c}}=\left(q_{\mathrm{v}}-\right.$ $\left.f_{\mathrm{c}} q^{*}\right) /\left(1.0-f_{\mathrm{c}}\right)$, is shown in Fig. 3. In-cloud $S_{\mathrm{i}}$ is assumed to be $100 \%$. In reality, supersaturation relaxation may be slow in cirrus clouds, particularly at low $T$ (Krämer et al., 2009; Barahona and Nenes, 2011). However, it is expected that for $p>200 \mathrm{hPa}$ most supersaturation is relaxed inside clouds over the time step of the simulation $(\sim 1800 \mathrm{~s})$ (Barahona and Nenes, 2008). Figure 3 also shows data from the AIRS (Atmospheric Infrared Sounder) (Gettelman et al., 2006) and MOZAIC (Measurement of ozone and water vapor by Airbus in-service aircraft) (Gierens et al., 1999) projects. The uncertainty in the retrieval increases with $S_{\mathrm{i}, \mathrm{c}}$. However, both MOZAIC and AIRS data show an exponential decrease in
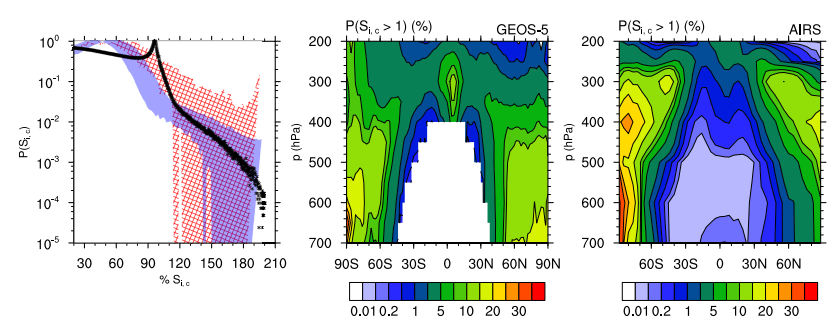

Figure 3. Global frequency distribution of clear sky saturation ratio with respect to ice obtained from $6 \mathrm{~h}$ instantaneous GEOS-5 output over a 3-year subset (2002-2004) of the NEW run (left panel, black dots). Filled areas correspond to the frequency distributions from AIRS (solid area) satellite retrievals (Gettelman et al., 2006) and the MOZAIC (hatched area) data set (Gierens et al., 1999), respectively, for the years 2002-2004. Uncertainty in the observations was calculated as one standard deviation around the mean value within a $2^{\circ} \times 2^{\circ}$ grid cell and introducing a $10 \%$ perturbation in $S_{\mathrm{i}}$ along the $x$ axis. The center and right panels show the zonal mean frequency $(\%)$ of clear sky supersaturation from GEOS-5 and AIRS, respectively.

$P\left(S_{\mathrm{i}, \mathrm{c}}\right)$ with increasing $S_{\mathrm{i}, \mathrm{c}}$ (Fig. 3, left panel). GEOS-5 also shows this exponential decrease and is in agreement with AIRS and MOZAIC data. The peak $P\left(S_{\mathrm{i}, \mathrm{c}}\right)$ in the model is shifted towards $S_{\mathrm{i}, \mathrm{c}} \sim 100 \%$ since retrievals tend to avoid zones with $S_{\mathrm{i}, \mathrm{c}} \sim 100 \%$ near the cloud edges (Gettelman and Kinnison, 2007). The frequency of $S_{\mathrm{i}, \mathrm{c}}>101 \%$ in GEOS-5 distributes almost symmetrically around the tropics (Fig. 3, middle panel), with a slightly higher probability of supersaturation in SH than in NH. This is in part due to lower IN concentrations in SH (Fig. 7), although differences in the dynamics of SH and $\mathrm{NH}$ also play a significant role. In agreement with AIRS data (Fig. 3, right panel), GEOS-5 predicts about $10 \%$ supersaturation frequency in the upper tropical levels. GEOS-5 seems to slightly overpredict $P\left(S_{\mathrm{i}, \mathrm{c}}>100 \%\right)$ above $300 \mathrm{hpa}$ at the high latitudes of the $\mathrm{NH}$ and $\mathrm{SH}$ and near the TTL; however, the uncertainty in the retrieval in these regions is also high (Gettelman and Kinnison, 2007).

\subsection{Subgrid-scale vertical velocity}

The nucleation of ice crystals and cloud droplets is strongly influenced by the subgrid-scale vertical velocity, $w_{\text {sub }}$. $\phi\left(\bar{w}, \sigma_{w}^{2}\right)$ in stratocumulus and anvils is mainly determined by $\sigma_{w}$, whereas $\bar{w}$ is typically small $\left(\sim 10^{-2} \mathrm{~m} \mathrm{~s}^{-1}\right)$. For convective clouds $w_{\mathrm{cp}}$ is explicitly calculated by solving Eq. (28). In general the eddy contribution to $\sigma_{w}^{2}$ is significant near the surface and negligible above $500 \mathrm{hPa}$. At $900 \mathrm{hPa}$, where mostly liquid clouds are formed, $\sigma_{w}$ ranges between 0.1 and $0.7 \mathrm{~m} \mathrm{~s}^{-1}$ and is typically lower over the ocean than over land (Fig. 4). High $\sigma_{w}$ is however found in the storm track regions of the Southern and Northern hemispheres. At this vertical level $\sigma_{w}$ is the lowest in the Arctic region $\left(\sim 0.1 \mathrm{~m} \mathrm{~s}^{-1}\right)$. The range of $\sigma_{w}$ shown in Fig. 4 is in good agreement with in situ measurements of vertical velocity at 

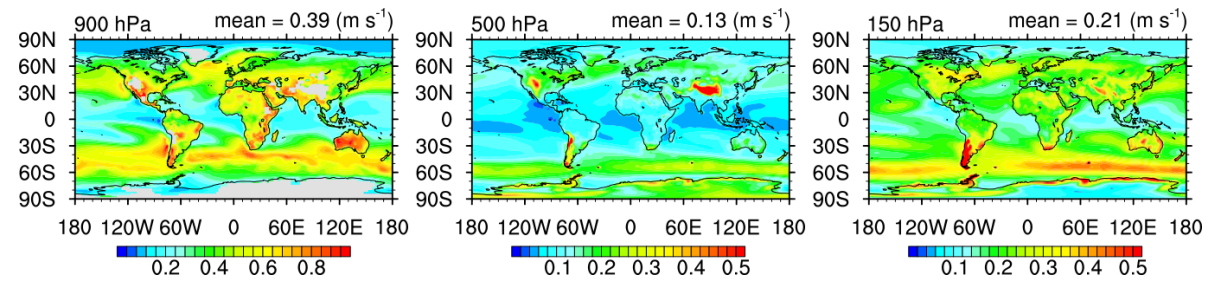

Figure 4. Annual mean subgrid vertical velocity standard deviation, $\sigma_{w}$, for the NEW run.

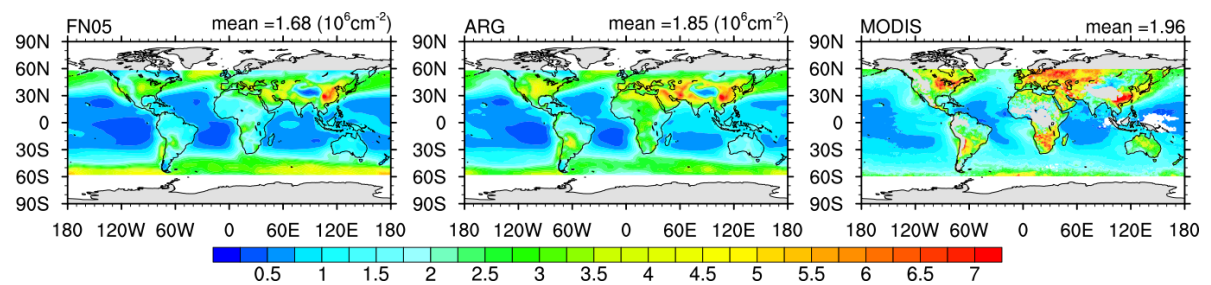

Figure 5. Annual vertically integrated droplet number concentration $\left(10^{6} \mathrm{~cm}^{-2}\right)$ from GEOS-5 using the Fountoukis and Nenes (2005) (FN05) and Abdul-Razzak and Ghan (2000) (ARG) CCN activation parameterization, and from the MODIS retrieval, calculated using Eq. (38). Data for latitudes higher than $60^{\circ}$ have been excluded from the analysis.

cloud base in marine stratocumulus (Peng et al., 2005; Guo et al., 2008), and continental regions (Fountoukis et al., 2007; Tonttila et al., 2011), showing $\sigma_{w}$ mostly between 0.2 and $1 \mathrm{~m} \mathrm{~s}^{-1}$. However, global measurements of $\sigma_{w}$ have not been reported. Compared to similar schemes (e.g., Golaz et al., 2010) Eq. (21) results in higher velocities within the PBL since the characteristic length decreases near the surface, consistent with the vertical momentum balance within the PBL (Blackadar, 1962). $\sigma_{w}^{2}$ thus rarely hits the prescribed minimum $\left(\sim 0.01 \mathrm{~m} \mathrm{~s}^{-1}\right)$ within the PBL.

Gravity wave motion dominates the global distribution of $\sigma_{w}$ at 500 and $150 \mathrm{hPa}$, being typically larger over land than over the ocean (Fig. 4). Air flowing over orographic features produces high-frequency waves that propagate to the free troposphere (Bacmeister et al., 1999; Herzog and Vial, 2001). $\sigma_{w}$ is thus highest over the mountain ranges of Asia, South America, and the Antarctic. At $500 \mathrm{hPa}, \sigma_{w}$ is about $0.1 \mathrm{~m} \mathrm{~s}^{-1}$ over land, and may reach up to $0.5 \mathrm{~m} \mathrm{~s}^{-1}$ over mountain ranges. These values are in good agreement with in situ measurements (Gayet et al., 2004). A similar distribution of $\sigma_{w}$ is found at $150 \mathrm{hPa}$, with values over land slightly higher than at $500 \mathrm{hPa}$. Over the ocean, $\sigma_{w}$ is typically larger at $150 \mathrm{hPa}$ than at $500 \mathrm{hPa}$, particularly over the tropics, since gravity waves in these regions can reach larger amplitudes before breaking. Figure 4 shows that $\sigma_{w}$ in the upper troposphere varies by up to three orders of magnitude around the globe. Such variability has important implications for the effects of IN emissions on cloud formation (Sect. 3.5).

\subsection{Cloud droplet number concentration}

Comparison of cloud droplet number concentration against satellite retrievals is typically challenging. Retrieval algorithms generally introduce assumptions on the droplet size distribution that may bias the cloud droplet number concentration. To compare satellite retrievals and model data over the same basis, we take advantage of the output generated by the COSP MODIS simulator to obtain a "model retrieved" column-integrated droplet concentration, $N_{1, \text { cum }}$, in the form (Han et al., 1998)

$N_{\mathrm{l, \textrm {cum }}}=\frac{\tau}{2 \pi R_{\mathrm{eff}, \mathrm{liq}}^{2}(1-b)(2-b)}$,

where $\tau$ is the liquid cloud optical depth, $b=0.193$ (Han et al., 1998), and $R_{\text {eff, liq }}$ is the effective radius of cloud droplets. To apply Eq. (38), $R_{\text {eff, liq }}$ and $\tau$ are obtained either from the GEOS-5 COSP output or from the MODIS retrieval. This procedure does not aim to produce an accurate retrieval of $N_{\mathrm{l} \text {,cum }}$, but rather to compare GEOS-5 and MODIS data equally. Equation (38) is applied between $60^{\circ} \mathrm{S}$ and $60^{\circ} \mathrm{N}$, where the MODIS retrieval is more reliable (Platnick et al., 2003).

Figure 5 shows the global distribution of $N_{1, \text { cum }}$ from GEOS-5 (NEW run, FN05) and MODIS. GEOS-5 is able to capture the high $N_{\mathrm{l} \text {, cum }}$ found in regions of high sulfate emissions i.e., Europe, Central and Southeast Asia and the eastern coast of North America. There is also agreement between MODIS and GEOS-5 in regions with high biomass burning emissions like Subsaharan Africa and South America. However, the model tends to slightly underpredict $N_{1, \text { cum }}$ in the remote Atlantic and Pacific Oceans. There is also underprediction of $N_{\mathrm{l} \text {, cum }}$ off the western coasts of North and South America and Africa. This is due to underprediction of shallow stratocumulus in GEOS-5 (Fig. 1) and because $w_{\text {sub }}$ tends to be small in these regions (Fig. 4). The global mean 
$N_{\text {l,cum }}$ in GEOS-5 $\left(1.68 \mathrm{~cm}^{-2}\right)$ is slightly lower than with MODIS results $\left(1.96 \mathrm{~cm}^{-2}\right)$.

Droplet concentration is influenced by the $\mathrm{CCN}$ activation parameterization and the aerosol size distribution. The GOCART model uses a single moment aerosol microphysics, and some uncertainty may result from assuming a fixed size distribution to obtain the aerosol number concentration. The impact of this assumption is discussed in Sect. 5. The sensitivity of $N_{1, \text { cum }}$ to the CCN activation parameterization was studied by implementing the Abdul-Razzak and Ghan (2000) activation parameterization (Fig. 5, middle plot) and is analyzed in Sect. 4.

\subsection{Ice crystal number concentration}

At any given $T, N_{\mathrm{i}}$ varies by up to four orders of magnitude, although mostly within a factor of 10 (Fig. 6a). The mean $N_{\mathrm{i}}$ peaks around $200 \mathrm{~L}^{-1}$ at $225 \mathrm{~K}$, decreasing to $\sim 20 \mathrm{~L}^{-1}$ at $190 \mathrm{~K}$, and below $\sim 1 \mathrm{~L}^{-1}$ at $180 \mathrm{~K}$. For $T>245 \mathrm{~K} N_{\mathrm{i}}$ remains mostly below $\sim 10 \mathrm{~L}^{-1}$. Global mean $N_{\mathrm{i}}$ is around $66 \mathrm{~L}^{-1}$ for all clouds and around $166 \mathrm{~L}^{-1}$ for cirrus $(T<$ $235 \mathrm{~K})$. Figure 6 shows agreement of GEOS- 5 values with in situ measurements of $N_{\mathrm{i}}$ over the whole $T$ interval (Krämer et al., 2009; Gultepe and Isaac, 1996). There is good agreement of GEOS-5 with field campaign data at $T<200 \mathrm{~K}$, where most models show a large positive bias (e.g., Barahona et al., 2010a; Salzmann et al., 2010; Gettelman et al., 2012). This results from the proper consideration of the effect of prior nucleation events on ice crystal nucleation (Section 2.3.3). $N_{\mathrm{i}}$ is also influenced by the presence of preexisting ice crystals; their effect is analyzed in Sect. 4.

The relative contribution of different mechanisms to the source of $N_{\mathrm{i}}$ is shown in Fig. 6. To facilitate comparison against in situ measurements, integrated variables, instead of number tendencies, are used. Thus, the ice crystal concentration from ice nucleation in the deposition and condensation modes, $N_{\text {dep }}$, is calculated using Eq. (11) and the BN09 parameterization. $N_{\mathrm{i}}$ from immersion freezing, $N_{\mathrm{imm}}$, is calculated by integration of Eq. (16) over the model time step. The concentration of detrained ice crystals, $N_{\text {cnv }}$, is given by the ice crystal concentration at the cloud top calculated by Eq. (26).

$N_{\text {dep }}$ varies mostly within the range from 0.1 to $50 \mathrm{~L}^{-1}$, and is largest around $240 \mathrm{~K}$, where the aerosol concentration is large enough to result in significant IN concentration (Fig. 6b). There is however large variability in $N_{\text {dep }}$ around the globe. Most deposition IN come from dust, although the concentration of black carbon IN may be significant, reaching $2 \mathrm{~L}^{-1}$ at $T \sim 230 \mathrm{~K}$ (not shown). A few deposition IN $\left(\sim 1 \mathrm{~L}^{-1}\right)$ are found at $T$ as high as $260 \mathrm{~K}$, mostly in regions of large dust concentration.

$N_{\text {imm }}$ reaches up to $40 \mathrm{~L}^{-1}$ around $240 \mathrm{~K}$, but decreases rapidly for lower $T$, where it is prevented by the homogeneous freezing of cloud droplets (Fig. 6c). In agreement with in situ observations of mixed-phase clouds (e.g., DeMott


Figure 6. Global frequency of in-cloud ice crystal number concentration as a function of temperature from $6 \mathrm{~h}$ instantaneous GEOS-5 output over a 3-year subset (2002-2004) of the NEW run. (a) Ice crystal concentration, $N_{\mathrm{i}}$. Solid lines represent the 25 and $75 \%$ quantiles from the field campaign data analysis of Krämer et al. (2009). Solid-dotted lines represent the typical range of mean $N_{\mathrm{i}}$ found in mixed-phase clouds (Gultepe and Isaac, 1996). (b) Ice crystal concentration from deposition/condensation ice nucleation, $N_{\text {dep }}$. (c) Ice crystal concentration from immersion ice nucleation, $N_{\text {imm }}$. (d) Ice crystal concentration from convective cumulus detrainment, $N_{\mathrm{cnv}}$.

et al., 2010), immersion freezing IN are scarce above $250 \mathrm{~K}$, with typical concentrations below $0.1 \mathrm{~L}^{-1}$. Dust is the most important source of immersion IN, whereas black carbon IN typically contribute less than $2 \mathrm{~L}^{-1}$ to $N_{\mathrm{i}}$. Contact freezing IN are not explicitly shown in Fig. 6, but they follow a similar tendency as immersion freezing IN, although with lower concentrations.

$N_{\text {cnv }}$ remains below $50 \mathrm{~L}^{-1}$ for $T>240 \mathrm{~K}$, characteristic of heterogeneous ice nucleation. For $T>250 \mathrm{~K}, N_{\mathrm{cnv}}$ reaches up to $10 \mathrm{~L}^{-1}$ mostly from immersion and contact freezing of supercooled droplets within the convective cumulus (Fig. 6d). Homogeneous freezing of cloud droplets is evident in the strong increase in $N_{\mathrm{cnv}}$ around $T \sim 240 \mathrm{~K}$, which in some instances may reach up to $10 \mathrm{~cm}^{-3}$. Such very high $N_{\text {ncv }}$ is responsible for the highest values of $N_{\mathrm{i}}$ in Fig. 6 . Along with immersion freezing, detrainment from convective cumulus determines $N_{\mathrm{i}}$ for $T>240 \mathrm{~K}$.

Figure 7 (left panel) shows the spatial distribution of ice crystal concentration nucleated in cirrus $(T<235 \mathrm{~K})$ and weighted by cloud fraction. The spatial distribution (also 



Figure 7. Annual mean ice crystal concentration nucleated in cirrus $(T<235 \mathrm{~K})$ weighted by cloud fraction for the NEW run (left panel). Also shown are the weighted average (center panel) and zonal mean (right panel) fractions of ice crystal production by homogeneous freezing in cirrus.

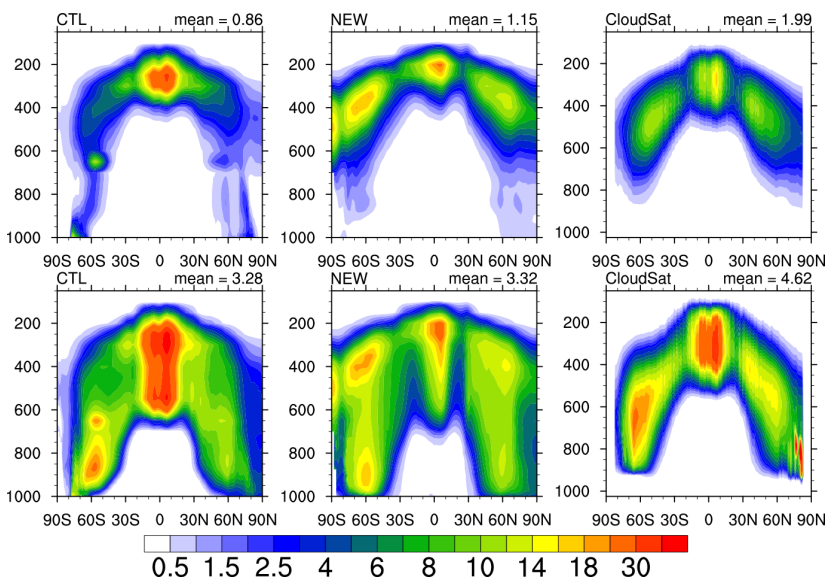

Figure 8. Zonal mean non-convective ice water mass mixing ratio $\left(\mathrm{mg} \mathrm{kg}^{-1}\right)$ (upper panels) and total ice condensate (ice and snow, bottom panels) for non-convective clouds from the CTL and NEW runs and the CloudSat retrieval (Li et al., 2012). Model results span over 10 years of simulation, whereas CloudSat retrievals are plotted for the period 2007 to 2008 .

weighted by cloud fraction) and zonal mean of the contribution of heterogeneous ice nucleation to $N_{\mathrm{i} \text {,nuc }}$ are shown in the middle and right panels of Fig. 7, respectively. Globally, about $70 \%$ of the production of ice crystals in cirrus proceeds by homogeneous freezing, with a clear contrast between the Northern Hemisphere (NH) and the Southern Hemisphere ( $\mathrm{SH})$. Homogeneous freezing is most prevalent in the $\mathrm{SH}$, and only on the western coasts of South America and Africa is the contribution of heterogeneous freezing significant ( $\sim 30 \%$; Fig. 7 , middle panel). By contrast, most of the NH is influenced by IN emissions, which in some cases dominate the ice crystal production.

Part of the higher predominance of heterogeneous ice nucleation in $\mathrm{NH}$ than $\mathrm{SH}$ is explained by the greater abundance of dust in NH. However, comparison of Figs. 4 (right planel) and 7 (left panel) also reveals a marked effect of $\sigma_{w}$ on $N_{\mathrm{i}}$. Low $\sigma_{w}$ tends to enhance the effect of IN on $N_{\mathrm{i}}$ because of the greater residence time of the heterogeneously frozen ice crystals in the parcel before the onset of homogeneous freezing, and the lower rate of increase of supersaturation

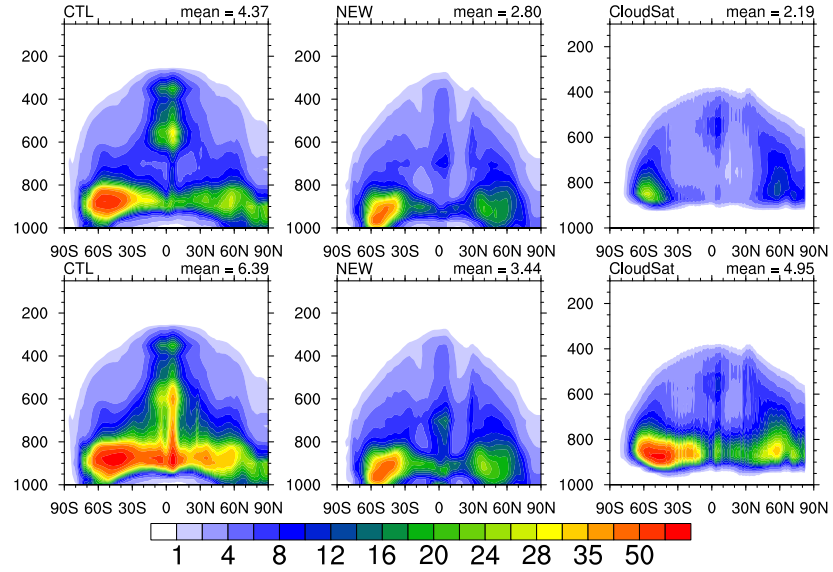

Figure 9. Zonal mean non-convective liquid water mass mixing ratio $\left(\mathrm{mg} \mathrm{kg}^{-1}\right.$ ) (upper panels) and total liquid condensate (water and rain, bottom panels) for non-convective clouds from the CTL and NEW runs and the CloudSat retrieval (Li et al., 2014). Model results span over 10 years of simulation, whereas CloudSat retrievals are plotted for the period 2007 to 2008 .

(Barahona and Nenes, 2009a). Heterogeneous freezing thus tends to dominate ice crystal production in regions of low $\sigma_{w}$ and low $N_{\mathrm{i} \text {,nuc }}$ like Sub-Saharan Africa, the Arctic, and the western coast of North America, even though these regions are not characterized by high emission rates of IN (Fig. 7, left panel). This result is also consistent with the study of Cziczo et al. (2013) who found predominance of heterogeneous ice nucleation in these regions. However, Fig. 7 (middle and right panels) shows that in most other regions, and globally, homogeneous ice nucleation tends to dominate the global production of ice crystals. This suggests that variability in $\sigma_{w}$ plays a significant role in defining the effect of IN emissions on cirrus formation. 


\subsection{Cloud liquid and ice water}

The implementation of the new microphysics resulted in significant improvement of the representation of ice and liquid water content in GEOS-5. Figure 8 shows the zonal mean ice mass mixing ratio, $q_{\mathrm{i}}$, from the NEW and CTL simulation compared to the CloudSat retrieval for non-convective, non-precipitating ice (Li et al., 2012). The global distribution of $q_{\mathrm{i}}$ in the NEW simulation is in better agreement with the satellite retrieval than that obtained in CTL. The excessive freezing around $T=240 \mathrm{~K}$, characterized by the bulls-eye pattern around $600 \mathrm{hPa}$ in the CTL run, is not present in the NEW simulation. In absolute terms, $q_{\mathrm{i}}$ in the NEW and CTL runs is generally lower than CloudSat data, although mostly within the intrinsic error of the retrieval, about a factor of 2 (Li et al., 2012; Eliasson et al., 2011). Including snow in the comparison (Fig. 8, bottom panels) still results in lower ice and snow concentration than in CloudSat, although within the error of the retrieval.

Figure 9 shows the zonal mean liquid mass mixing ratio, $q_{1}$, from GEOS-5 for the CTL and NEW runs compared against the CloudSat retrieval for non-convective, nonprecipitating liquid water ( $\mathrm{Li}$ et al., 2014). There is far lower $q_{1}$ in the NEW than in the CTL run, particularly over the tropics and the subtropics of the NH. Above $900 \mathrm{hPa}$, the spatial distribution of $q_{1}$ in the NEW run is in better agreement than CTL. In absolute terms $q_{1}$ in NEW is closer to CloudSat than in CTL. However, this must be taken with caution as CloudSat may not retrieve liquid water close to the ground (Devasthale and Thomas, 2012). The NEW and CTL simulations however show that most liquid water is held below the $850 \mathrm{hPa}$ level in GEOS-5. The bottom panels of Fig. 9 also suggest that the rain mass mixing ratio is lower in NEW than in the CTL simulation and CloudSat. Still, the spatial distribution of the concentration of liquid and rain from NEW and from the CloudSat retrieval shows similar characteristics.

The spatial distribution of the liquid water path (LWP) (Fig. 10) in the NEW simulation is similar to that observed by CloudSat, although in general LWP is larger in the NEW simulation that in CloudSat, particularly over marine regions. Comparison against other retrievals reveals uncertainty in experimental observations of LWP. Annual average LWP from MODIS is $144 \mathrm{~g} \mathrm{~m}^{-2}$, about twice as much as the GEOS-5 output when using COSP to simulate the MODIS retrieval $\left(60 \mathrm{~g} \mathrm{~m}^{-2}\right)$. MODIS however tends to predict higher LWP in polar regions than in the tropics, pointing to an artifact of the retrieval (Platnick et al., 2003). SSMI data (Spencer et al., 1989) is also typically used for model evaluation, although it is restricted to oceanic regions. Annual mean LWP from SSMI is about $84 \mathrm{~g} \mathrm{~m}^{-2}$, which is higher than predicted by GEOS-5 over the ocean ( $\sim 48 \mathrm{~g} \mathrm{~m}^{-2}$, not shown).

Figure 10 shows the annual mean IWP (non-precipitating, non-convective) from GEOS-5 and CloudSat ( $\mathrm{Li}$ et al., 2012). In general there is reasonable agreement in IWP between CloudSat and GEOS-5, with and slightly higher
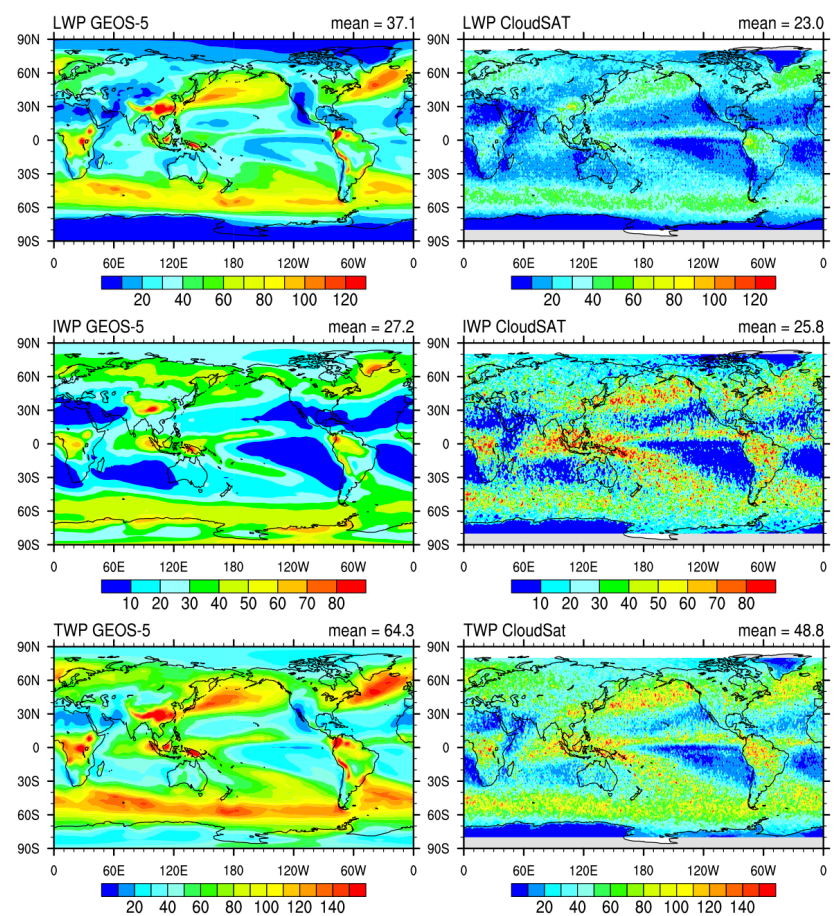

Figure 10. Liquid (LWP), ice (IWP), and total (TWP) water paths $\left(\mathrm{g} \mathrm{m}^{-2}\right)$ for non-convective, non-precipitating clouds from GEOS-5 output using the new microphysics and from the CloudSat retrieval (Li et al., 2012, 2014).

IWP in GEOS-5 (27.1 $\mathrm{g} \mathrm{m}^{-2}$, NEW run) than in CloudSat $\left(25.8 \mathrm{~g} \mathrm{~m}^{-2}\right)$. There is also uncertainty in IWP obtained by different retrievals; however, a recent intercomparison showed agreement between the ISCCP and CloudSat retrieved IWP (Eliasson et al., 2011). GEOS-5 is able to capture the high IWP observed in the Tropical Warm Pool, Central Asia, and over the mountain ranges of Africa, and North and South America. The high IWP of the latter regions results in part from strong ice crystal production over mountain ranges (Sect. 3.5). GEOS-5 however underestimates IWP in the tropical western Pacific Ocean. The spatial distribution of the total-water path (liquid and ice) is similar to that obtained with CloudSat, although the global mean TWP is higher in GEOS-5 $\left(\sim 64 \mathrm{~g} \mathrm{~m}^{-2}\right)$ than in the retrieval $\left(\sim 49 \mathrm{~g} \mathrm{~m}^{-2}\right)$ due to the larger LWP in GEOS-5.

\subsection{Supercooled cloud fraction}

Figure 11 shows the supercooled cloud fraction (e.g., the fraction of cloud condensate present as liquid, $\mathrm{SCF}=1-f_{\text {ice }}$, in mixed-phase clouds for the CTL and NEW simulations. In the CTL simulation the total condensate is linearly partitioned into liquid and ice between 235 and $270 \mathrm{~K}$ (Bacmeister et al., 2006). In the NEW simulation partitioning of the condensate is carried out taking into account the activity and concentration of IN and the Bergeron-Findeisen process. In CTL most values of SCF below $260 \mathrm{~K}$ follow the prescribed 


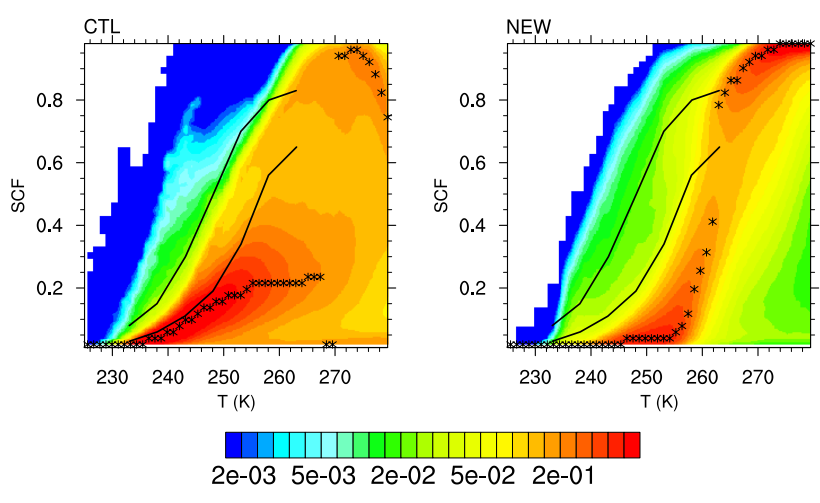

Figure 11. Global frequency of supercooled cloud fraction (SCF) from GEOS-5 for the CTL and NEW runs. The most frequent SCF value for each temperature is marked ${ }^{*}$. The solid lines represent the range of SCF (mean plus and less one standard deviation) derived from the CALIOP satellite retrieval for the years 2006-2007 (Choi et al., 2010).

linear tendency. Variability in SCF increases strongly above $260 \mathrm{~K}$ due to the freezing of condensate at $273 \mathrm{~K}$ and iceenhanced precipitation (Fig. 11). The tendency of SCF with $T$ in NEW shows different features than in CTL following a sigmoidal instead of a linear tendency. This behavior has been observed in satellite retrievals and field campaigns (Choi et al., 2010; Hu et al., 2010) and is characteristic of immersion freezing mediated mainly by dust (e.g., Murray et al., 2011; Marcolli et al., 2007). The region of maximum SCF frequency in Fig. 11 however expands about $10 \mathrm{~K}$, which results from variation in particle size and concentration, the presence of black carbon IN, enhanced precipitation in mixed-phase clouds, and variation in $\sigma_{w}$. There is also a higher frequency of SCF $>0.4$ for $T<255 \mathrm{~K}$ in the NEW than in the CTL simulation, which results from a higher fraction of supercooled liquid in the convective detrainment in NEW than in CTL.

Compared with CALIOP (Cloud-Aerosol Lidar with Orthogonal Polarization) retrievals (Fig. 11, solid lines) (Choi et al., 2010), SCF in NEW is shifted by about $6 \mathrm{~K}$ towards higher $T$, which implies that clouds tend to glaciate at higher $T$ in the model than observed by the satellite. This would indicate higher IN activity (i.e., a higher dust concentration or more active dust) in GEOS-5 than implied by the CALIOP data. However, CALIOP is sensitive mostly to cloud-top properties, and SCF may be biased low in deep convective clouds, where most of the supercooled liquid is found below the cloud top (Hu et al., 2010). The influence of these factors on SCF requires more investigation, and will be undertaken in a future study. The sigmoidal increase of SCF with $T$ in both GEOS-5 and the satellite retrieval still indicates that SCF is significantly influenced by the presence of IN.

\subsection{Cloud droplet and ice crystal effective radii}

The annual mean droplet effective radius $R_{\text {eff,liq }}$ from the NEW simulation $(14.3 \mu \mathrm{m})$ is in agreement with MODIS retrievals $(14.8 \mu \mathrm{m})$ (Fig. 12). This is higher than the prescribed mean for the CTL run and simulated by other models also using the MG08 stratiform microphysics $(\sim 9-11 \mu \mathrm{m})$ (Gettelman et al., 2008; Salzmann et al., 2010) but similar to the one obtained in Sud et al. (2013) in GEOS-5. The results presented in Fig. 12 benefit from using the COSP package that accounts for the preferential cloud-top sampling of MODIS (Bodas-Salcedo et al., 2011). Other studies (Gettelman et al., 2008; Salzmann et al., 2010) however did not use COSP for comparison. In agreement with the MODIS retrieval the spatial distribution of $R_{\text {eff,liq }}$ in the NEW run shows a clear ocean-land contrast (Fig. 12). $R_{\text {eff, liq is overes- }}$ timated in the western coasts of South America, Africa, and to a lesser extent, North America, due to low $N_{1}$ over these regions. Over the land $R_{\text {eff,liq }}$ is underestimated in southern and central Asia, Europe and the western coast of North America, likely due to the high concentration of cloud droplets predicted by GEOS-5 in these regions (Sect. 3.4).

The global distribution of ice effective radius, $R_{\text {eff, ice, }}$, for the NEW run is presented in Fig. 13 along with MODIS retrievals. The global mean value of $R_{\text {eff,ice }}$ in the NEW simulation $(26.2 \mu \mathrm{m})$ is in good agreement with the satellite $(24.2 \mu \mathrm{m})$. GEOS-5 is able to reproduce the low $R_{\text {eff, ice }}$ seen by MODIS over most of the large mountain ranges, e.g., over the Andean and Himalayan regions, although it tends to underestimate $R_{\text {eff,ice }}$ over northeastern Asia. Low $R_{\text {eff,ice }}$ is caused by strong homogeneous freezing events with $N_{\mathrm{i}}>$ $1 \mathrm{~cm}^{-3}$ in high orographic uplift (Fig. 4), although local convection may also have an effect on $R_{\text {eff,ice }}$ as detrainment from deep convection tends to increase $N_{\mathrm{i}}$ (Sect. 3.5). There is some contrast in $R_{\text {eff,ice }}$ between land and ocean in the MODIS retrievals, which is captured by GEOS-5. However, the model tends to overestimate $R_{\text {eff, ice }}$ in the subtropical regions of $\mathrm{NH}$ and $\mathrm{SH}$, which may be caused by low $\sigma_{w}$ leading to low $N_{\mathrm{i}}$.

There may be some uncertainty in the retrieval of $R_{\text {eff,ice, }}$, particularly for optically thick clouds (Chiriaco et al., 2007). To corroborate the GEOS-5 results further, in situ observations of the volumetric ice crystal radius, $R_{\mathrm{vol}, \text { ice }}=$ $\left(\frac{3 q_{\mathrm{i}}}{4 \pi N_{\mathrm{i}} \rho_{\mathrm{i}}}\right)^{1 / 3}$, are used. Figure 14 shows $R_{\mathrm{vol}}$,ice as a function of $T$ along with a composite of in situ data from several field campaigns (Krämer et al., 2009; McFarquhar and Heymsfield, 1997). There is reasonable agreement between the field data and the model, particularly for $T<230 \mathrm{~K}$, where both show a decrease in $R_{\mathrm{vol}, \text { ice }}$ with decreasing $T$. Around $T \sim$ $230 \mathrm{~K}$ the model tends to predict slightly higher $R_{\mathrm{vol}, \text { ice }}$ than the observations, although mostly within the spread of the data. The discrepancy may also be a result of crystal shattering in ice crystal probes, which tends to increase measured $N_{\mathrm{i}}$ decreasing $R_{\mathrm{vol}, \text { ice }}$ (Krämer et al., 2009). The smooth 

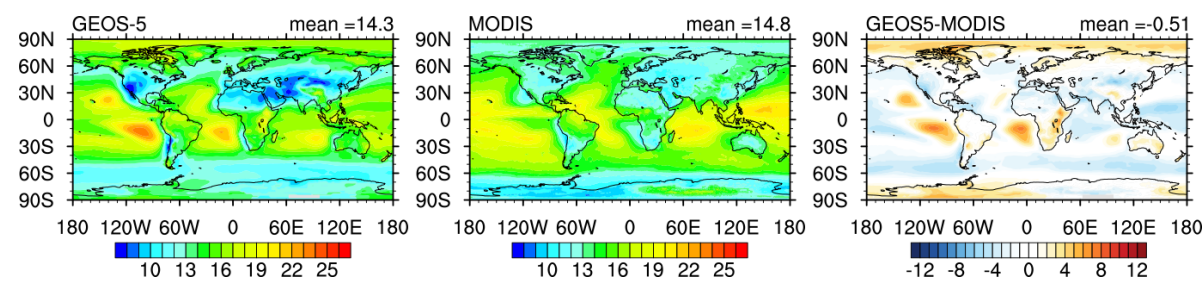

Figure 12. Liquid cloud effective radius $(\mu \mathrm{m})$ from GEOS-5 (NEW run) using COSP and from the MODIS retrieval.


Figure 13. Ice cloud effective radius $(\mu \mathrm{m})$ from GEOS-5 (NEW run) using COSP and from the MODIS retrieval.

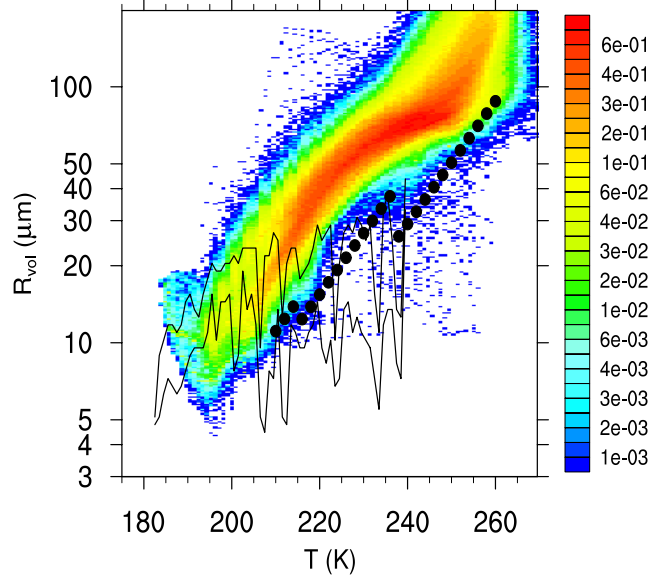

Figure 14. Global frequency of ice volumetric radius as a function of temperature from GEOS-5, NEW run. Solid lines represent the 25 and $75 \%$ quantiles from the field campaign analysis of Krämer et al. (2009). Filled circles were calculated using the correlation obtained by McFarquhar and Heymsfield (1997) from field measurements in mixed-phase and cirrus clouds.

transition in $R_{\text {vol,ice }}$ at $235 \mathrm{~K}$ indicates that both homogeneous and heterogeneous ice nucleation significantly contribute to ice crystal formation at this temperature (Sect. 3.5). In agreement with observations (McFarquhar and Heymsfield, 1997) $R_{\text {vol,ice }}$ increases steadily for $T>235 \mathrm{~K}$, which results from increasing vapor deposition rates and decreasing $N_{\mathrm{i}}$ as $T$ increases (Sect. 3.5).

\subsection{Annual mean diagnostics}

Table 4 and Fig. 15 show the summary of the annual mean cloud properties analyzed in this work. Annual mean LWP for the NEW run is 37.1 , and $60 \mathrm{~g} \mathrm{~m}^{-2}$ if the MODIS COSP simulator is used. LWP in NEW is higher than the CloudSat retrieval $\left(23.0 \mathrm{~g} \mathrm{~m}^{-2}\right)$ (Li et al., 2014) mostly from higher LWP at the middle latitudes of the $\mathrm{SH}$, and lower than MODIS retrievals $\left(\sim 100 \mathrm{~g} \mathrm{~m}^{-2}\right)$. Ocean-only LWP is also lower than SSMI output by about a factor of two (not shown). LWP in GEOS-5 refers only to non-convective (anvil and stratiform) clouds and it is likely that the discrepancy with SSMI and MODIS originates from the consideration of convective clouds in the retrievals. IWP in NEW $\left(27.2 \mathrm{~g} \mathrm{~m}^{-2}\right)$ is in better agreement with CloudSat $\left(25.8 \mathrm{~g} \mathrm{~m}^{-2}\right)(\mathrm{Li}$ et al., 2012), although GEOS-5 tends to overestimate IWP at the middle latitudes of the $\mathrm{SH}$ and the $\mathrm{NH}$. Including snow in the comparison does not affect IWP in the tropics, but results in larger subtropical IWP in NEW than in CloudSat. Global mean LWP in CTL is higher $\left(60.0 \mathrm{~g} \mathrm{~m}^{-2}\right)$ and IWP slightly lower $\left(19.0 \mathrm{~g} \mathrm{~m}^{-2}\right)$ than in NEW.

The prescribed $R_{\text {eff,liq }}$ and $R_{\text {eff,ice }}$ in CTL are generally smaller than those retrieved by MODIS with a global mean bias of about -5 and $-4 \mu \mathrm{m}$ for $R_{\mathrm{eff}, \text { liq }}$ and $R_{\mathrm{eff}, \text { ice, }}$, respectively. $R_{\text {eff, liq }}$ and $R_{\text {eff, ice }}$ in NEW are closer to MODIS with a global bias of about -0.5 and $2 \mu \mathrm{m}$, respectively (Table 4 ), well within the intrinsic error of the retrieval (King et al., 2003). Zonal mean $R_{\text {eff,liq }}$ is however overestimated in the Northern Hemisphere from underestimation of $N_{1}$ in oceanic regions (Sect. 3.4).

Global mean cloud fraction in the NEW simulation is higher than in CTL but still lower than ISSCP retrievals (Rossow and Schiffer, 1999). The higher $f_{\mathrm{c}}$ in NEW results from higher cloud coverage over continental regions (Sect. 3.1). There is good agreement between NEW and ISCCP cloud fraction at the continental middle latitudes and most of the underestimation in NEW originates in marine regions. However, in these regions both the NEW and CTL simulations show agreement with the MODIS retrieval. The reason for the better agreement of GEOS-5 with MODIS than 
Table 3. Description of sensitivity runs performed with GEOS-5 using the new microphysics.

\begin{tabular}{ll}
\hline Run & Description \\
\hline NOCNV & Single moment microphysics within convective clouds \\
NOBC & Black carbon not acting as IN \\
LC400 & $L_{\mathrm{c}}=400 \mathrm{~m}$ \\
PDA08 & Usage of the Phillips (2008) heterogeneous ice nucleation spectrum \\
MUIZERO & Prescribed constant $\mu_{\mathrm{i}}=0.0$ \\
ARGACT & Usage of the Abdul-Razzak and Ghan (2000) activation parameterization \\
NOGLASS & Glassy organics not considered as IN \\
NOPREEX & Preexisting ice crystals not considered \\
DCS200 & $D_{\mathrm{cs}}=200 \mu \mathrm{m}$ \\
\hline
\end{tabular}

with ISCCP in these regions is however not clear but may be related to differences in the cloud masks of ISCCP and MODIS (Pincus et al., 2012).

Global annual mean precipitation, $P_{\text {tot }}$, is lower in the NEW $\left(2.72 \mathrm{~mm} \mathrm{~d}^{-1}\right)$ than in the CTL $\left(2.85 \mathrm{~mm} \mathrm{~d}^{-1}\right)$ simulation and in better agreement with GPCP (Huffman et al., 1997) and CMAP (Xie and Arkin, 1997) observations ( $2.6 \mathrm{~mm} \mathrm{~d}^{-1}$ ), although both simulations tend to overestimate $P_{\text {tot }}$ in the tropics. In SH the NEW simulation tends to predict $P_{\text {tot }}$ higher than CMAP and lower than GPCP, whereas CTL is in better agreement with GPCP data. In NH, $P_{\text {tot }}$ in the NEW and CTL simulations is closer to GPCP than to CMAP data, although in NEW it tends to be lower than the GPCP observations.

The global top of the atmosphere (TOA) net radiative balance is about $+0.95 \mathrm{~W} \mathrm{~m}^{-2}$ in the NEW simulation. The slight radiative imbalance in NEW results in part from the negative bias in stratocumulus cloud coverage in the NEW simulation (Sect. 3.1). The liquid cloud optical depth in NEW however agrees with MODIS data (Fig. 15), particularly over the tropics. In CTL liquid clouds tend to be optically much thicker than MODIS observations (Fig. 15), which results from larger LWP and smaller $R_{\text {eff,liq }}$ than the observations (Sects. 3.6 and 3.8). The higher optical depth in CTL leads to a more negative SWCF $\left(-52.1 \mathrm{~W} \mathrm{~m}^{-2}\right)$ than in CERES and to a higher net radiative imbalance $-2.4 \mathrm{~W} \mathrm{~m}^{-2}$. Longwave cloud effect (LWCF) is similar in the CTL and NEW runs $\left(\sim 25.0 \mathrm{~W} \mathrm{~m}^{-2}\right)$ and in agreement with CERES data $\left(26.2 \mathrm{~W} \mathrm{~m}^{-2}\right)$. Compared to MODIS ice cloud optical depth is however overestimated in CTL and underestimated in NEW. In NEW the low bias in ice optical depth is compensated by a positive bias in the high-level cloud fraction (Sect. 3.1).

\section{Sensitivity studies}

Tables 3 and 4 present a summary of the sensitivity of GEOS5 to different microphysical parameters. To study the sensitivity of cloud properties to the description of $\mathrm{CCN}$ activation, the parameterization of Abdul-Razzak and Ghan (2000) (hereafter, ARG) was implemented (run ARGACT, Table 3 and Fig. 5, middle panel). ARG is based on a fit to the numerical solution of the equations of an ascending parcel written in terms of dimensionless parameters. Compared to the NEW run, the usage of ARG resulted in slightly higher $N_{1}$ than with the FN05 formulation, particularly over marine regions (Fig. 5, middle panel). The ARG parameterization also predicts higher droplet concentration in regions of high aerosol emissions like Southeast Asia and southern Africa. Global mean $R_{\text {eff,liq }}$ was lower for ARG than for FN05 by about $0.7 \mu \mathrm{m}$ leading to about $2 \mathrm{~W} \mathrm{~m}^{-2}$ more negative SWCF (Table 4). LWP and cloud fraction remained almost the same as in NEW suggesting that the change in SWCF was driven by modification of cloud albedo.

The sensitivity of cloud properties to the characteristic cirrus scale, $L_{\mathrm{c}}$, was also investigated. $L_{\mathrm{c}}$ is associated with the wavelength of the highest-frequency waves leading to cirrus formation (Eq. 23), and impacts the subgrid vertical velocity variability in the upper troposphere. Increasing $L_{\mathrm{c}}$ from 100 to $400 \mathrm{~m}$ reduced global $N_{\mathrm{c}}$ by about a factor of two (run LC400) due to a reduction in $\sigma_{w}$ and a decrease in the rate of ice crystal formation. The global mean $R_{\text {eff,ice }}$ increased by about $3 \mu \mathrm{m}$ and LWCF decreased by $2 \mathrm{~W} \mathrm{~m}^{-2}$. Global mean $\sigma_{w}$ for $L_{\mathrm{c}}=400 \mathrm{~m}$ is about $0.07 \mathrm{~m} \mathrm{~s}^{-1}$ and $0.11 \mathrm{~m} \mathrm{~s}^{-1}$ at 500 and $150 \mathrm{hPa}$, respectively, about half the value obtained in the NEW simulation (Fig. 4). These values are still within the observed values in field campaigns (e.g., Gayet et al., 2004), and further observations are needed to better constraint $L_{\mathrm{c}}$. Table 4 however shows that GEOS-5 results are robust to moderate changes in $\sigma_{w}$.

The effect of the dispersion in the ice crystal size distribution, $\mu_{i}$, on ice cloud properties (Table 4 ) was analyzed by setting $\mu_{\mathrm{i}}=0.0$ (run MUIZERO) instead of using a temperature dependent parameterization for $\mu_{\mathrm{i}}$ (Sect. 2.3). This led to about a factor of two lower IWP and $R_{\text {eff,ice }}$ than in NEW, which resulted from an increase in autoconversion and accretion of ice by snow at low $T$ (not shown). Despite the lower IWP, the lower ice crystal size increased the ice cloud optical depth and resulted in slightly higher LWCF and SWCF than in the NEW simulation. Because of this compensating effect the radiative properties of ice clouds are robust to moderate 
Table 4. Annual mean model results and observations. The experimental data sets are described in Sect. 3. CTL and NEW refer to runs with the operational version of GEOS-5 and with the implementation of the new microphysics, respectively. Sensitivity studies are described in Table 3 and Sect. 4.

\begin{tabular}{|c|c|c|c|c|c|c|c|c|c|c|c|c|}
\hline Simulation & CTL & NEW & ARGACT & NOBC & NOGLASS & PDA08 & NOPREEX & LC400 & NOCNV & MUIZERO & DCS200 & OBS \\
\hline$P_{\text {tot }}\left(\mathrm{mm} \mathrm{d}^{-1}\right)$ & 2.85 & 2.72 & 2.72 & 2.71 & 2.72 & 2.73 & 2.66 & 2.77 & 2.90 & 2.70 & 2.83 & $\begin{array}{l}2.68 \text { (GPCP), } \\
2.60 \text { (CMAP) }\end{array}$ \\
\hline $\operatorname{LWP}\left(\mathrm{g} \mathrm{m}^{-2}\right)$ & 60.0 & 37.3 & 38.0 & 37.6 & 37.5 & 37.1 & 37.3 & 37.2 & 36.1 & 36.5 & 35.3 & $\begin{array}{l}23.0 \text { (CloudSat), } \\
109.8 \text { (MODIS), } \\
88.4 \text { (SSMI, ocean) }\end{array}$ \\
\hline IWP $\left(\mathrm{g} \mathrm{m}^{-2}\right)$ & 19.0 & 27.1 & 27.3 & 27.0 & 26.9 & 27.3 & 32.8 & 21.3 & 25.2 & 10.3 & 16.1 & 25.8 (CloudSat) \\
\hline $\operatorname{TWP}\left(\mathrm{g} \mathrm{m}^{-2}\right)$ & 79.0 & 64.4 & 65.3 & 64.6 & 64.4 & 64.4 & 70.1 & 58.6 & 61.3 & 46.8 & 51.4 & 48.8 (CloudSat) \\
\hline$f_{\mathrm{c}}(\%)$ & 46.0 & 56.0 & 56.8 & 56.3 & 55.8 & 55.2 & 58.3 & 54.2 & 51.0 & 56.8 & 50.0 & $\begin{array}{l}52 \text { (MODIS), } \\
62 \text { (ISCCP) }\end{array}$ \\
\hline$N_{1, \text { cum }}\left(\mathrm{cm}^{-2}\right)$ & & 1.68 & 1.85 & 1.67 & 1.68 & 1.70 & 1.66 & 1.55 & 2.29 & 1.65 & 2.33 & 1.96 (MODIS) \\
\hline$N_{\mathrm{i}}\left(\mathrm{L}^{-1}\right)$ & & 66 & 65 & 64 & 67 & 55 & 135 & 38 & 74 & 60 & 62 & \\
\hline$N_{\mathrm{i}}\left(\mathrm{L}^{-1}\right)$ (cirrus) & & 166 & 163 & 160 & 168 & 139 & 359 & 91 & 183 & 154 & 158 & \\
\hline$R_{\text {eff,liq }}(\mu \mathrm{m})$ & 10.2 & 14.2 & 13.5 & 14.3 & 14.3 & 14.3 & 14.6 & 14.6 & 13.2 & 13.7 & 13.0 & 14.8 (MODIS) \\
\hline$R_{\text {eff,ice }}(\mu \mathrm{m})$ & 20.8 & 26.2 & 26.0 & 26.0 & 26.2 & 27.2 & 23.2 & 29.3 & 25.5 & 12.5 & 23.6 & 24.2 (MODIS) \\
\hline $\operatorname{SWCF}\left(\mathrm{W} \mathrm{m}^{-2}\right)$ & 52.1 & 49.5 & 52.0 & 50.3 & 49.7 & 49.5 & 53.2 & 46.7 & 45.0 & 49.7 & 44.6 & $\begin{array}{l}47.2 \text { (CERES), } \\
51.8 \text { (ERBE) }\end{array}$ \\
\hline $\operatorname{LWCF}\left(\mathrm{W} \mathrm{m}^{-2}\right)$ & 25.2 & 26.6 & 27.3 & 27.2 & 26.2 & 25.8 & 31.2 & 23.2 & 22.2 & 26.9 & 20.8 & $\begin{array}{l}26.2 \text { (CERES), } \\
30.67 \text { (ERBE) }\end{array}$ \\
\hline $\operatorname{OLR}\left(\mathrm{W} \mathrm{m}^{-2}\right)$ & 238.9 & 238.3 & 237.3 & 237.5 & 238.2 & 238.9 & 233.3 & 241.4 & 243.0 & 237.0 & 244.5 & $\begin{array}{l}239.8 \text { (CERES), } \\
240.2 \text { (ERBE) }\end{array}$ \\
\hline OSR $\left(\mathrm{W} \mathrm{m}^{-2}\right)$ & 236.5 & 239.3 & 236.7 & 238.4 & 238.9 & 239.2 & 235.6 & 242.0 & 243.8 & 239.2 & 244.2 & $\begin{array}{l}240.6 \text { (CERES), } \\
255.7 \text { (ERBE) }\end{array}$ \\
\hline Net TOA $\left(\mathrm{W} \mathrm{m}^{-2}\right)$ & -2.4 & 0.95 & -0.52 & 0.90 & 0.77 & 0.32 & 2.24 & 0.58 & 0.75 & 2.08 & -0.28 & 0.75 (CERES) \\
\hline
\end{tabular}

changes in the ice crystal size distribution. Decreasing the critical size for ice autoconversion from 400 to $200 \mu \mathrm{m}$ (run DCS200) also increased ice autoconversion leading to lower IWP than in NEW. $R_{\text {eff,ice }}$ was also reduced, although to a lower extent than in MUIZERO. The net radiative effect of reducing $D_{\mathrm{cs}}$ was thus a decrease of about $\sim 6 \mathrm{~W} \mathrm{~m}^{-2}$ in LWCF.

Several studies were performed to investigate the sensitivity of GEOS-5 to the description of heterogeneous ice nucleation. In NOBC and NOGLASS the effect of black carbon and glassy IN, respectively, was switched off. These runs suggested that black carbon and glassy IN only have a subtle effect on global climate (Table 4), although their local effects may be significant. In particular black carbon IN tend to increase LWCF in regions of high aerosol emissions like East Asia and the eastern coast of North America. In the same regions glassy IN tend to reduce $N_{\mathrm{i}}$ at low $T$ (Fig. 16). The global TOA radiative imbalance due to black carbon and glassy IN amounts to -0.05 and $-0.18 \mathrm{~W} \mathrm{~m}^{-2}$, respectively. Although these values are comparable to other published studies (Gettelman et al., 2012), they must be taken with caution, since they are based on limited results. A comprehensive description of the aerosol indirect effect in GEOS-5 will be addressed in future studies.

In the PDA08 run the Phillips et al. (2008) (hereafter Ph08) ice nucleation spectrum was used. Ph08 was employed in previous studies to study the effect to the ice nucleation spectrum on $N_{\mathrm{i}}$ (Barahona et al., 2010a; Morales Betancourt et al., 2012; Liu et al., 2012). Ph08 accounts for the effect of both soluble and insoluble organic material acting as IN, whereas in Ph13, only soluble organics are considered to be
IN. Using the Ph08 parameterization reduced $N_{\mathrm{i}}$ increasing

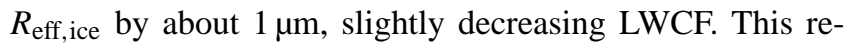
sulted in part from the effect of organic IN inhibiting homogeneous freezing in cirrus clouds. Other cloud properties remained similar as in NEW.

The effect of preexisting ice crystals on ice crystal formation was analyzed in NOPREEX, where it was assumed that $N_{\mathrm{i}, \text { pre }}=0$. For this run, the global mean $N_{\mathrm{i}}$ was $359 \mathrm{~L}^{-1}$, about twice that in NEW, with the greater increase occurring between 200 and $240 \mathrm{~K}$ (Fig. 16), and mostly in the tropics (not shown), indicating that the presence of ice crystals from convective detrainment tends to inhibit new ice nucleation events. Mean $R_{\text {eff,ice }}$ was reduced by about $6 \mu \mathrm{m}$, increasing LWCF by $5 \mathrm{~W} \mathrm{~m}^{-2}$.

In NOCNV the generation of precipitation in cumulus convection was described by a single-moment approach (Bacmeister et al., 2006). Some studies (e.g., Gettelman et al., 2008; Salzmann et al., 2010) did not consider explicitly the freezing and activation of aerosol particles in convective cumulus. It is thus important to study how this assumption would affect GEOS-5 results. In NOCNV the contribution of convective detrainment to ice crystal and droplet number concentration was approximated by assuming a fixed droplet size of $10 \mu \mathrm{m}$ for droplets and using the correlation of McFarquhar and Heymsfield (1997) to obtain the ice crystal size as a function of $T$. Compared to NEW, the single-moment approach resulted in enhanced precipitation rates, particularly over the Tropical Warm Pool. SWCF and LWCF were lower than in NEW by about $3 \mathrm{~W} \mathrm{~m}^{-2}$, which was in part the result of a lower detrainment flux of condensate in the tropical upper troposphere. $R_{\text {eff, liq }}$ decreased by about of $1 \mu \mathrm{m}$ due 

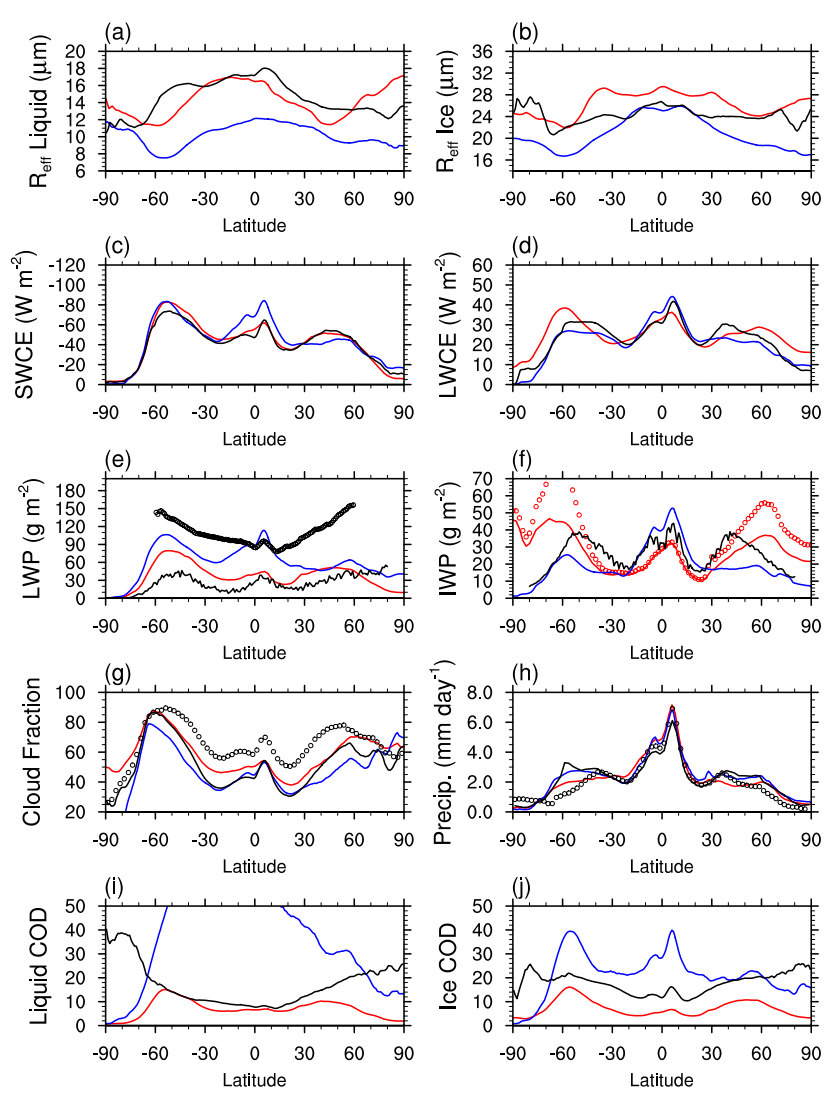

Figure 15. Annual zonal means from the GEOS-5 model for the CTL (blue lines) and NEW (red lines) runs compared against different observations (black lines). (a, b) Liquid $\left(R_{\text {eff, liq }}\right)$ and ice ( $\left.R_{\text {eff,ice}}\right)$ effective radius from COSP output against MODIS. (c, d) Shortwave (SWCF) and longwave (LWCF) cloud forcing against CERES-EBAF retrievals (Loeb et al., 2009). (e) Liquid water path against CloudSat (black lines) and MODIS (black circles) retrievals. (f) Non-convective, non-precipitable ice water path against CloudSat retrievals (Li et al., 2012, 2014). Also shown is the total (ice and snow) non-convective ice water path (red circles) from GEOS-5 using the new microphysics. (g) Total cloud fraction from COSP output against MODIS (black lines) and ISCCP (black circles). (h) Total precipitation against GPCP data (Huffman et al., 1997). Also shown are data from the CMAP data set (Xie and Arkin, 1997) (black circles). (i, j) Liquid and ice optical depth (COD) from COSP output against MODIS retrievals.

to an increase in droplet number concentration. Mean $R_{\text {eff, ice }}$ only changed by about $0.5 \mu \mathrm{m}$; however, $N_{\mathrm{i}}$ was slightly increased, particularly at low $T$ (Fig. 16).

Finally it is important to analyze the effect of microphysical parameters on $N_{\mathrm{i}}$ at low $T$. Figure 16 shows the temperature dependency of $N_{\mathrm{i}}$ for the runs of Table 4 . All curves of Fig. 16 show the same characteristics, increasing $N_{\mathrm{i}}$ with decreasing $T$ to a maximum around $210 \mathrm{~K}$ and then decreasing to values typically below $10 \mathrm{~L}^{-1}$ at $185 \mathrm{~K}$. The only exception to the latter is the NOCNV run in which mean $N_{\mathrm{i}}$ is about $140 \mathrm{~L}^{-1}$ at $185 \mathrm{~K}$, resulting from the lower detrained



Figure 16. Annual mean ice crystal concentration as a function of temperature for the different runs of Table 4.

$N_{\mathrm{i}}$ acting as preexisting ice crystals at low $T$. The maximum $N_{\mathrm{i}}$ is around $300 \mathrm{~L}^{-1}$ for most runs, and only for the NOPREEX run does it increase up to $800 \mathrm{~L}^{-1}$. The fact that in all runs $N_{\mathrm{i}}$ decreases for $T$ below $200 \mathrm{~K}$ indicates that as the $T$ decreases, $N_{\mathrm{i}}$ becomes more dependent on $S_{\text {crit }}$ (Sect. 3.2). This indicates that parcel history plays a primary role in determining $N_{\mathrm{i}}$ at low $T$, whereas preexisting ice crystals and IN only play a secondary role.

\section{Summary and conclusions}

A new cloud microphysics scheme was developed for the NASA GEOS-5 global atmospheric model. The main features of the new microphysics are

- A comprehensive two-moment microphysics description for stratiform clouds (Morrison and Gettelman, 2008).

- Consistent coupling of the cloud fraction and stratiform condensation with the microphysics. The stratiform condensation scheme was modified to allow supersaturation in ice clouds.

- A two-moment microphysics scheme embedded within the RAS convective parameterization. The new scheme explicitly treats the formation of droplets and ice crystals, the partitioning of condensate between ice and liquid, and the generation of precipitation within convective cumulus.

- A comprehensive description of cloud droplet activation and ice nucleation in stratiform and convective clouds, linked to the aerosol physicochemical properties. The description of ice formation considers homogeneous freezing of cloud droplets and interstitial aerosol as well as heterogeneous ice nucleation on ice nuclei. Competition between homogeneous and heterogeneous ice nucleation, and between different ice nuclei is explicitly 
treated. Immersion, contact, condensation and deposition ice nucleation modes are considered.

- Explicit calculation of the critical saturation ratio for ice formation considering aerosol properties, temperature and subgrid-scale dynamics.

- Explicit parameterization of the effect of preexisting ice crystals on ice nucleation.

- Explicit parameterization of the distribution of subgridscale vertical velocity in stratiform clouds, accounting for the effect turbulence and gravity wave motion on the vertical velocity variance. A new parameterization in terms of large-scale variables was developed for the latter.

The new microphysics was evaluated against satellite retrievals and field campaign data. Usage of the COSP satellite simulator greatly facilitated the comparison with satellite observations, reducing the uncertainty in the sampling of the model results. In general, cloud microphysical fields like ice water, liquid water content and droplet and ice crystal size were in much better agreement with observations than when obtained with the operational version of GEOS-5. The model performance in reproducing the observed total cloud fraction and longwave and shortwave cloud forcings is also improved, and is in reasonable agreement with satellite observations.

In the new microphysics ice and cloud droplet nucleation are tightly linked to the evolution of the cloud properties. Cloud droplet number impacts the formation of precipitation. Precipitation decreases total water, which in turn feeds back into the cloud fraction through modification of $P_{q}(q)$ (Sect. 2.3.1). The link between $N_{\mathrm{i}}, f_{\mathrm{c}}$, and $q_{\mathrm{i}}$ is stronger, since the production of condensate is controlled in part by $S_{\text {crit }}$, which depends on the presence of IN (Eq. 13). The linkage between cloud micro- and macro-physical variables in the model emphasizes the internal consistency of the new cloud scheme.

A new cloud coverage scheme was developed to allow supersaturation with respect to the ice phase. The frequency and spatial distribution of supersaturation simulated by the model was in good agreement with satellite and in situ observations. It was shown that supersaturation is controlled in part by ice crystal nucleation and the value of $S_{\text {crit }}$. The latter dictates the minimum water vapor threshold required for cloud formation. $S_{\text {crit }}$ is highly variable over the globe, and dependent on aerosol concentration and temperature. Models that assume a single threshold for ice cloud formation are thus inherently biased.

The variation of supercooled cloud fraction with temperature in the new microphysics followed a sigmoidal tendency. This is in agreement with CALIOP data (Choi et al., 2010) and differs from the typical linear increase of SCF with $T$ assumed in most GCMs. There are no temperature-based constraints to the occurrence of the Bergeron-Findeisen process nor to the partition of total condensate between ice and liquid in the new microphysics. The sigmoidal tendency in SCF resulted from explicit consideration of homogeneous, immersion and contact freezing in the model. This suggests that rather than temperature alone, the presence of IN greatly influences the frequency of supercooled liquid in mixed-phase clouds.

A new approach was proposed to parameterize the distribution of subgrid-scale vertical velocity in cirrus and stratocumulus, which takes into account turbulence and gravity wave motion. Although no observational studies have been reported on the global distribution of $\sigma_{w}$, the parameterization results were within reported values in field campaigns. Since the parameterization proposed here focuses on surface and orographic stresses, which are higher over land, $\sigma_{w}$ may be underestimated in the upper troposphere in oceanic regions. The ability to predict $\sigma_{w}$ as a function of large-scale variables still points in the right direction to reduce one of the main sources of uncertainty in the modeling of the effect of aerosol emissions on climate. It was also shown that the variability in $\sigma_{w}$ is a determining factor defining the effect of IN emissions on cirrus formation.

The simulated ice crystal concentration was in agreement with field campaign data, even at very low $T$, where most models tend to overestimate $N_{\mathrm{i}}$ (e.g., Barahona et al., 2010a; Salzmann et al., 2010; Hendricks et al., 2011). In GEOS5 , the decrease in $N_{\mathrm{i}}$ with decreasing $T$ results from an increase in $S_{\text {crit }}$ (Fig. 2), which limits $P_{q}\left(q_{\mathrm{t}}>S_{\text {crit }} q_{\mathrm{i}}^{*}\right)$ at low $T$, decreasing the probability of homogeneous freezing events. The term $P_{q}\left(q_{\mathrm{t}}>S_{\text {crit }} q_{\mathrm{i}}^{*}\right)$ in Eq. (15) provides a link between current cloud formation and prior ice nucleation events (Barahona and Nenes, 2011). This suggests that a statistical rather than a single-parcel approach (e.g., Jensen et al., 2012; Spichtinger and Cziczo, 2010) is required for the correct modeling of low-temperature cirrus.

A new parameterization of the effect of preexisting ice crystals on ice cloud formation was developed. It was shown that their effect is more pronounced for $T$ around $200 \mathrm{~K}$, typically reducing $N_{\mathrm{i}}$. However, preexisting ice crystals alone can not explain the low ice crystal concentration at low $T$. The effect of organic glassy IN on cloud formation was also analyzed and it was found that it tends to reduce $N_{\mathrm{i}}$ at low temperatures. Although these factors alone cannot explain the tendency of $N_{\mathrm{i}}$ at $T<190 \mathrm{~K}$, they are still necessary for reproducing the observed $N_{\mathrm{i}}$ in the upper troposphere. In fact, it was found that the observed values of ice crystal concentration in the upper troposphere result from a combination of several factors: parcel history, IN concentration, convective detrainment and subgrid dynamics.

Effective cloud droplet size simulated with GEOS-5 was in agreement with the MODIS retrieval. There was however a slight underestimation in $R_{\text {eff,liq }}$ over the land, and overestimation over the tropical marine regions. This points to the need for a more sophisticated description of aerosol microphysics in GEOS-5. Sensible assumptions were made 
regarding the aerosol size distribution; however, there is high variability in the aerosol properties around the globe, which may affect CCN activation. The inclusion of a more comprehensive aerosol microphysics in GEOS-5 will be addressed in a future study. The simulated cloud droplet number concentration also showed some sensitivity to the parameterization of $\mathrm{CCN}$ activation, which in turn influences the cloud albedo.

There was good agreement in the global mean ice effective radius between GEOS-5 and the MODIS retrieval. The decrease in $R_{\mathrm{vol} \text {,ice }}$ as $T$ decreases, a common feature of in situ observations (Krämer et al., 2009) was also captured by GEOS-5. The model was able to capture key features of the spatial distribution of $R_{\text {eff,ice, }}$ as for example the predominance of low $R_{\text {eff,ice near mountain ranges. This was a result }}$ of the explicit consideration of ice nucleation and of the spatial variation of $\sigma_{w, \mathrm{gw}} . R_{\text {eff,ice was however overestimated }}$ in marine regions, particularly in the Southern Hemisphere. The parameterization of $\sigma_{w, \mathrm{gw}}$ developed in this work may underestimate $\sigma_{w}$ over the ocean. Other IN sources like biological particles (Burrows et al., 2013) and sea salt (Wise et al., 2012) were not considered in this study but may enhance ice nucleation in marine environments. Some uncertainty may be introduced by the single-moment approach used for the aerosol microphysics in GEOS-5 ice nucleation, although ice nucleation is less dependent on aerosol size than $\mathrm{CCN}$ activation. There is also uncertainty in the formulation of the heterogeneous ice nucleation spectrum, since factors like mixing of dust/soot with sulfate, which may lead to IN deactivation/activation, are not taken into account in Ph13. The role of the uncertainty in the satellite retrieval must also be accounted for when comparing $R_{\text {eff,ice against model re- }}$ sults. All of these factors require further investigation. Nevertheless, the approach proposed here results in a realistic and reasonable spatial distribution of $R_{\text {eff,ice }}$.

It was shown that the cloud radiative fields modeled in GEOS-5 with new microphysics are in good agreement with observations, although local biases may be significant. GEOS-5 tends to underestimate the optical depth of persistent stratocumulus decks, which leads to a negative radiative bias in the western Pacific. Reducing such bias requires an explicit representation of shallow cumulus condensation in GEOS-5. The long-term and large-scale climatic response of GEOS-5 with the new microphysics will be analyzed in a future study.
A simple approach was assumed to describe the cloud microphysics in convective clouds. The description of precipitation within convective cores is highly complex due to the interplay of several cloud species (e.g., graupel, hail, rain, ice and snow). Some authors have developed more comprehensive microphysical packages for convective clouds, including processes of autoconversion, aggregation, collection and accretion (e.g., Song and Zhang, 2011; Sud and Walker, 1999; Lohmann, 2008). To be effective, a detailed description of microphysics in convective clouds requires prognostic prediction of the vertical profiles of rain and snow, which is not implemented in most GCMs. Also, collection and aggregation rates depend on the vertical profiles of rain and snow, which are not known in advance. The advantages of a complex representation of the microphysics of convective cores must thus be weighted against the uncertainty introduced in accommodating such descriptions within the diagnostic integration schemes of the convective parameterizations in GCMs.

The model results were quite robust to variation in microphysical parameters. The largest differences from the base configuration were found for a decrease in the size dispersion parameter of the ice crystal size distribution and in the critical size for ice autoconversion. Both changes lead to a reduction in $R_{\text {eff,ice }}$ and IWP and modified the long wave cloud forcing. The high sensitivity of $R_{\text {eff,ice }}$ and IWP to the value of $\mu_{\mathrm{i}}$ suggests that more attention must be put on its correct parameterization in GCMs.

The implementation of the comprehensive microphysics developed in this work resulted in a more realistic simulation of cloud properties in GEOS-5. Mounting evidence suggests that the explicit description of processes of droplet and ice crystal nucleation and precipitation is necessary for the correct representation of clouds in Earth system models. The new microphysics would likely result in improved and more realistic climate simulations in GEOS-5. The new parameterizations developed here may also help to improve our understanding of the role of microphysics and aerosol emissions on the evolution of clouds. Within the larger picture, the further development of the microphysics GEOS-5 will help to understand the role of clouds on climate and eventually reduce the uncertainty in their prediction. 


\section{Appendix A: Cloud fraction scheme}

The total-water PDF for stratiform condensation is assumed to follow a uniform distribution in the form (Fig. A1)

$P_{q}(q)=\left\{\begin{array}{ll}\frac{1}{\Delta q}, & \text { if } q_{\mathrm{mn}} \leq q \leq q_{\mathrm{mx}} \\ 0, & \text { otherwise }\end{array}\right.$,

where $P_{q}$ is the total-water PDF, $\Delta q$ the width of the PDF, $q_{\mathrm{mx}}=q_{\mathrm{t}}+0.5 \Delta q$ and $q_{\mathrm{mn}}=q_{\mathrm{t}}-0.5 \Delta q$ the upper and lower limits of the PDF, respectively, and $q_{\mathrm{t}}$ the non-convective total-water mixing ratio. Equation (A1) is applied to nonconvective part of the grid cell, whereas the contribution of convective detrainment to cloud fraction follows a prognostic approach (Tiedtke, 1993). The vertical profile of $\Delta q$ is initially prescribed following Molod (2012). Application of Eq. (3) to the PDF (Fig. A1a) gives

$$
\begin{aligned}
f_{\mathrm{c}} & =\left(1-f_{\mathrm{cn}}\right) \int_{S_{\mathrm{crit}} q^{*}}^{\infty} P_{q}(q) \mathrm{d} q+f_{\mathrm{cn}} \\
& =\left(1-f_{\mathrm{cn}}\right) \frac{q_{\mathrm{mx}}-S_{\mathrm{crit}} q^{*}}{\Delta q}+f_{\mathrm{cn}},
\end{aligned}
$$

where $f_{\text {cn }}$ is the detrained cloud fraction. Application of Eq. (5) gives, for the total condensate,

$$
\begin{aligned}
q_{\mathrm{c}} & =\left(1-f_{\mathrm{cn}}\right) \int_{S_{\mathrm{crit}} q^{*}}^{q_{\mathrm{mx}}} \frac{\left(q-S_{\mathrm{crit}} q^{*}\right)}{\Delta q} \mathrm{~d} q+q_{\mathrm{c}, \operatorname{det}} \\
& =\left(1-f_{\mathrm{cn}}\right) \frac{1}{2} \alpha_{L} \frac{\left(q_{\mathrm{mx}}-S_{\mathrm{crit}} q^{*}\right)^{2}}{\Delta q}+q_{\mathrm{c}, \operatorname{det}} .
\end{aligned}
$$

After microphysical processes have taken place, $P_{q}(q)$ is assumed to follow a uniform PDF (Fig. A1b); however, the contribution of convective detrainment is not explicitly treated, since anvil clouds are considered stratiform (Sect. 2.3). Thus, in analogy with Eq. (A2), but without the explicit contribution from detrained condensate, we can write for the cloud fraction after the microphysics,

$f_{\mathrm{c}}^{\prime}=\frac{q_{\mathrm{mx}}^{\prime}-S_{\mathrm{crit}} q^{*}}{\Delta q^{\prime}}$

where the prime superscripts indicate values after the microphysics. The width of the distribution $\Delta q^{\prime}$ may be different from its original value $\Delta q$ since precipitation and sedimentation processes alter $q_{\mathrm{t}}$. Similarly, for the cloud condensate,

$q_{\mathrm{c}}^{\prime}=\frac{1}{2} \frac{\left(q_{\mathrm{mx}}^{\prime}-S_{\mathrm{crit}} q^{*}\right)^{2}}{\Delta q^{\prime}}$

where $q_{\mathrm{mx}}^{\prime}=q_{\mathrm{t}}^{\prime}+0.5 \Delta q^{\prime}$. The correction factor $\alpha_{L}$ is not applied to Eq. (A5) since there is no additional condensation after the microphysics. Since $q_{\mathrm{c}}^{\prime}$ and $q_{\mathrm{t}}^{\prime}$ are known, Eqs. (A4)
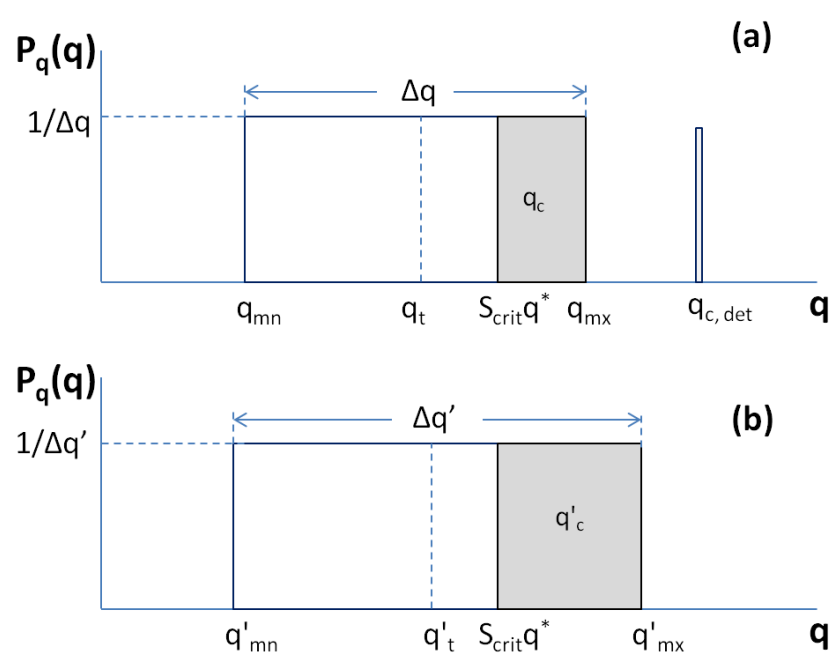

Figure A1. Probability distribution function of total water before (a) and after (b) the microphysics. $\Delta q, q_{\mathrm{mx}}$ and $q_{\mathrm{mn}}$ represent the width and the upper and lower limits of the total water distribution, respectively. Shaded regions represent stratiform condensate, $q_{\mathrm{c}}$, and $q_{\mathrm{c} \text {,det }}$ represents the contribution of convective detrainment to total condensate. Prime superscripts are used to denote values affected by microphysical processes.

and (A5) can be used to estimate $\Delta q^{\prime}$, hence $f_{\mathrm{c}}^{\prime}$. Making $X=q_{\mathrm{mx}}^{\prime}-S_{\text {crit }} q^{*}$ and $Y=q_{\mathrm{t}}^{\prime}-S_{\text {crit }} q^{*}$ then $\Delta q^{\prime}=2(X-Y)$, $f_{\mathrm{c}}^{\prime}=0.5 X /(X-Y)$ and $q_{\mathrm{c}}^{\prime}=0.25 X^{2} /(X-Y)$. Since $f_{\mathrm{c}}^{\prime}=$ $2 q_{\mathrm{c}}^{\prime} / X$, these equations can be combined into

$X^{2}-4 q_{\mathrm{c}}^{\prime} X+4 Y q_{\mathrm{c}}^{\prime}=0$.

The only physical root of Eq. (A6) is given by

$X=2 q_{\mathrm{c}}^{\prime}\left(1+\sqrt{1-\frac{Y}{q_{\mathrm{c}}^{\prime}}}\right)$.

Using the definitions of $X$ and $Y$, we obtain, for $f_{\mathrm{c}}^{\prime}$,

$f_{\mathrm{c}}^{\prime}=\left(1+\sqrt{1-\frac{q_{\mathrm{t}}^{\prime}-S_{\mathrm{crit}} q^{*}}{q_{\mathrm{c}}^{\prime}}}\right)^{-1}$.

Equation (A8) provides the cloud fraction corrected for microphysical processing, consistent with $q_{\mathrm{t}}^{\prime}$ and $q_{\mathrm{c}}^{\prime}$.

\section{Appendix B: Parameterization of the subgrid vertical velocity variance from gravity wave motion}

Parameterizations of the subgrid vertical velocity from gravity wave motion consider either the displacement of a single wave from orographic uplift (Joos et al., 2008; Dean et al., 2007) or the spectrum of velocities resulting from the superposition of waves from different sources (Barahona and Nenes, 2011; Jensen and Pfister, 2004). The characteristic 
scale of gravity wave motion leading to the formation of clouds is typically smaller than the scale of the GCM grid cell. A spectrum of vertical velocities rather than a single wave may thus be a more realistic representation of the subgrid dynamics in the upper troposphere. Still, surface perturbations are likely to determine the maximum $w_{\text {sub }}$ in the spectrum (Joos et al., 2010; Barahona and Nenes, 2011). Using this concept, a semi-empirical parameterization for $\sigma_{w, \mathrm{gw}}$ can be developed as follows.

The mean vertical momentum flux at the surface (McFarlane, 1987) is given by

$\tau=\frac{1}{2} k \rho_{\mathrm{a}} U_{\mathrm{s}} N_{\mathrm{s}} \delta h_{\mathrm{s}}^{2}$,

where $\delta h_{\mathrm{s}}$ is the vertical displacement at the surface caused by the orographic perturbation, $N_{\mathrm{s}}$ the Brunt-Väisälä frequency at the surface and $U_{\mathrm{s}}$ the surface wind (taken as the geometrical mean between the meridional and zonal components), and $k$ is the horizontal wave number. Equating $\tau$ with the mean surface stress, $\tau_{0}$, and scaling $\delta h$ according to McFarlane (1987) i.e, $\delta h=\delta h_{\mathrm{s}}\left[\rho_{\mathrm{a}} U_{\mathrm{s}} N_{\mathrm{s}} / \rho_{\mathrm{a}} U N\right]^{1 / 2}$, the mean wave amplitude, $\delta h$, at any height can be written as

$\delta h^{2}=\min \left(\frac{2\left|\tau_{0}\right|}{k \rho_{\mathrm{a}} U N}, \frac{U}{N}\right)$,

where $\frac{U}{N}$ is the saturation wave amplitude (Dean et al., 2007). The maximum vertical velocity in the gravity wave spectrum is related to $\delta h$ by (Joos et al., 2008)

$w_{\max }=k U \delta h$.

In a spectrum of randomly superimposed gravity waves, $w_{\max }$ can be empirically related to $\sigma_{w, \mathrm{gw}}$ by (Barahona and Nenes, 2011)

$\sigma_{w, \mathrm{gw}} \approx 0.133 w_{\max }$

making $k=\frac{2 \pi}{L_{\mathrm{c}}}$ and combining Eqs. (B2) to (B4), we obtain

$\sigma_{w, \mathrm{gw}}^{2}=0.0169 \min \left[\frac{4 \pi U\left|\tau_{0}\right|}{\rho_{\mathrm{a}} L_{\mathrm{c}} N},\left(\frac{2 \pi U^{2}}{N L_{\mathrm{c}}}\right)^{2}\right]$,

where $L_{\mathrm{c}}$ is a characteristic scale associated with the wavelength of the highest-frequency waves in the spectrum, typically between 50 and $500 \mathrm{~m}$ (Bacmeister et al., 1999), although considered a free parameter.

\section{Appendix C: Parameterization of the effect of preexisting crystals on ice nucleation}

Water vapor deposition onto ice crystals from previous nucleation events decreases supersaturation and may reduce $N_{\mathrm{i}}$, particularly at low temperatures (Barahona and Nenes, 2011). To account for this effect, the local rate of change of
$S_{\mathrm{i}}$ in a cloudy parcel with preexisting crystals is written in the form (Barahona and Nenes, 2011)

$\frac{\mathrm{d} S_{\mathrm{i}}}{\mathrm{d} t}=\alpha w_{\mathrm{sub}} S_{\mathrm{i}}-\beta \frac{\mathrm{d} q_{\mathrm{i}, \text { nuc }}}{\mathrm{d} t}-\beta \frac{\mathrm{d} q_{\mathrm{i}, \text { pre }}}{\mathrm{d} t}$,

where $\alpha$ and $\beta$ are temperature-dependent parameters (Appendix $\mathrm{D}$ ), and $\frac{\mathrm{d} q_{\mathrm{i}, \text { nuc }}}{\mathrm{d} t}$ and $\frac{\mathrm{d} q_{\mathrm{i}, \text { pre }}}{\mathrm{d} t}$ are the local rates of ice crystal growth of recently nucleated and preexisting ice crystals, respectively. The latter is given by

$\frac{\mathrm{d} q_{\mathrm{i}, \text { pre }}}{\mathrm{d} t}=\frac{N_{\mathrm{i}, \text { pre }} \pi \beta c \rho_{\mathrm{i}} A_{\mathrm{i}}\left(S_{\mathrm{i}}-1\right)}{2 \lambda_{0, \mathrm{i}, \text { pre }}}$,

where it was assumed that the size of preexisting ice crystal follows a gamma distribution (Eq. 2). Introducing Eq. (C2) into Eq. (C1), we obtain

$\frac{\mathrm{d} S_{\mathrm{i}}}{\mathrm{d} t}=\alpha w_{\text {sub }} S_{\mathrm{i}}-\beta \frac{\mathrm{d} q_{\mathrm{i}, \text { nuc }}}{\mathrm{d} t}-\beta \frac{N_{\mathrm{i}, \operatorname{pre}} \pi \beta c \rho_{\mathrm{i}} A_{\mathrm{i}}\left(S_{\mathrm{i}}-1\right)}{2 \lambda_{0, \mathrm{i}, \text { pre }}}$,

Ice crystal nucleation in cirrus occurs over small $S_{\mathrm{i}}$ intervals (Barahona and Nenes, 2008; Kärcher and Lohmann, 2002). Therefore, to a good approximation, the size of preexisting ice crystals can be considered constant during ice nucleation. With this assumption, Eq. (C3) can be reorganized as

$$
\begin{aligned}
\frac{\mathrm{d} S_{\mathrm{i}}}{\mathrm{d} t} & =\alpha w_{\text {sub }} S_{\mathrm{i}}\left[1-\frac{N_{\mathrm{i}, \text { pre }} \pi \beta c \rho_{\mathrm{i}} A_{\mathrm{i}}\left(S_{\mathrm{hom}}-1\right)}{2 \lambda_{0, \mathrm{i}, \mathrm{pre}} \alpha w_{\text {sub }} S_{\mathrm{hom}}}\right] \\
& -\beta \frac{\mathrm{d} q_{\mathrm{i}, \text { nuc }}}{\mathrm{d} t},
\end{aligned}
$$

where it was assumed that $\frac{S_{\mathrm{i}}-1}{S_{\mathrm{i}}} \approx \frac{S_{\mathrm{hom}}-1}{S_{\mathrm{hom}}}$. If $N_{\mathrm{i}, \text { pre }}=0$ then Eq. (C4) reduces to the saturation balance of a parcel with no preexisting crystals present (Barahona and Nenes, 2008). The effect of preexisting crystals on ice nucleation can thus be accounted for by redefining the cloud scale vertical velocity in the form

$$
\begin{aligned}
& w_{\text {sub }, \text { pre }}= \\
& w_{\text {sub }} \max \left[1-\frac{N_{\mathrm{i}, \text { pre }} \pi \beta c \rho_{\mathrm{i}} A_{\mathrm{i}}\left(S_{\mathrm{hom}}-1\right)}{2 \lambda_{0, \mathrm{i}, \mathrm{pre}} \alpha w_{\text {sub }} S_{\mathrm{hom}}}, 0\right] .
\end{aligned}
$$

Equation (C5) shows that the effect of water vapor deposition onto preexisting crystals can be understood as a reduction in the rate of increase of supersaturation by expansion cooling. Since $w_{\text {sub }}$ is typically an input to ice cloud formation parameterizations, Eq. (C5) also provides a simple way of accounting for the effect of preexisting ice crystals on ice cloud formation, independently of the ice nucleation parameterization employed. 


\section{Appendix D}

Table D1. List of symbols and acronyms.

\begin{tabular}{|c|c|}
\hline $\begin{array}{l}\alpha_{L} \\
\alpha\end{array}$ & $\begin{array}{l}\text { Correction to } q^{*} \text { fom latent heat effects during condensation } \\
\frac{g \Delta H_{\mathrm{s}} M_{\mathrm{w}}}{c_{p} R T^{2}}-\frac{g M_{\mathrm{a}}}{R T}\end{array}$ \\
\hline$\beta$ & $\frac{M_{\mathrm{a}} p}{M_{\mathrm{w}} p_{\mathrm{s}, \mathrm{i}}}-\frac{\Delta H_{\mathrm{s}}^{2} M_{\mathrm{w}}}{c_{p} R T^{2}}$ \\
\hline$\gamma$ & Virtual mass coefficient \\
\hline$\gamma_{\mathrm{c}}$ & Cooling rate \\
\hline$\eta$ & Cloud tracer \\
\hline$\Delta H_{\mathrm{S}}$ & Enthalpy of sublimation of ice \\
\hline$\Delta q$ & Width of the total-water PDF \\
\hline$\Delta t$ & Model time step \\
\hline$\Delta t_{L}$ & Average time of a convective parcel within a model layer \\
\hline$\varphi_{\mathrm{X}}$ & Active site density of the species $x$ \\
\hline$\Phi_{i}$ & Aerosol particle number fraction in mode $i$ \\
\hline$\phi\left(\bar{w}, \sigma_{w}^{2}\right)$ & Subgrid distribution of vertical velocity \\
\hline$\kappa$ & Hygroscopicity parameter \\
\hline$\lambda$ & Entrainment rate \\
\hline$\lambda_{\mathrm{m}}$ & Value of $l_{\mathrm{m}}$ in the free troposphere \\
\hline$\lambda_{0, \mathrm{y}}$ & Slope parameter of $n_{\mathrm{y}}(D)$ \\
\hline$\mu_{\mathrm{y}}$ & Dispersion of $n_{\mathrm{y}}(D)$ \\
\hline$\rho_{\mathrm{i}}$ & Bulk density of ice \\
\hline$\sigma_{\mathrm{g}, \mathrm{x}}$ & Geometric size dispersion of the $\mathrm{x}$ species \\
\hline$\sigma_{w, \text { turb }}^{2}$ & Variance in $w_{\text {sub }}$ due to turbulence \\
\hline$\sigma_{w, \mathrm{gw}}^{2}$ & Variance in $w_{\text {sub }}$ due to gravity wave dynamics \\
\hline$\sigma_{w}$ & Standard deviation of $w_{\text {sub }}$ \\
\hline$\tau_{0}$ & Surface stress \\
\hline$A_{\mathrm{i}}$ & {$\left[\frac{\rho_{\mathrm{i}} \Delta H_{\mathrm{s}}^{2}}{k_{\mathrm{a}} R_{\mathrm{v}} T^{2}}+\frac{\rho_{\mathrm{i}} R_{\mathrm{v}} T}{p_{\mathrm{s}, \mathrm{w}} D_{\mathrm{w}}}\right]^{-1}$} \\
\hline CALIOP & Cloud-Aerosol Lidar with Orthogonal Polarization \\
\hline $\mathrm{CCN}$ & Cloud condensation nuclei \\
\hline CERES & Clouds and Earth's Radiant Energy System \\
\hline CMAP & CPC Merged Analysis of Precipitation \\
\hline$c_{p}$ & Specific heat capacity of air \\
\hline$D$ & Convective detrainment rate \\
\hline$D_{\mathrm{cs}}$ & Critical size for ice-snow autoconversion \\
\hline$D_{\mathrm{c}, \mathrm{y}}$ & Critical size for precipitation of the y cloud species \\
\hline$D_{\mathrm{g}, \mathrm{x}}$ & Geometric mean diameter of the $\mathrm{x}$ aerosol species \\
\hline$D_{\mathrm{y}}$ & Diameter of the y cloud species \\
\hline$D_{\mathrm{w}}$ & Water vapor diffusivity in air \\
\hline ERBE & Earth Radiation Budget Experiment \\
\hline$f_{\mathrm{c}}$ & Total cloud fraction \\
\hline$f_{\mathrm{c}}^{\prime}$ & Cloud fraction modified by the cloud microphysics \\
\hline$f_{\mathrm{gr}}$ & Fraction of ice existing as graupel \\
\hline$f_{\text {het }}$ & Fraction of ice crystals produced by heterogeneous ice nucleation \\
\hline$f_{\text {ice }}$ & Mass fraction of ice in the total condensate \\
\hline
\end{tabular}


Table D1. Continued.

\begin{tabular}{|c|c|}
\hline$f_{\mathrm{cn}}$ & Detrained anvil cloud fraction \\
\hline$g$ & Acceleration of gravity \\
\hline GPCP & Global Precipitation Climatology Project \\
\hline IN & Ice nuclei \\
\hline ISCCP & International Satellite Cloud Climatology Project \\
\hline IWC & Ice water content \\
\hline IWP & Ice water path \\
\hline$k_{\mathrm{a}}$ & Thermal conductivity of air \\
\hline$L$ & Weighted latent heat between liquid and ice \\
\hline$K_{T}$ & Mixing coefficient for heat \\
\hline$L_{\mathrm{c}}$ & Characteristic wavelength in cirrus \\
\hline$l_{\mathrm{m}}$ & Mixing length \\
\hline LWC & Liquid water content \\
\hline LWCF & Longwave cloud forcing \\
\hline LWP & Liquid water path \\
\hline$m_{1 \ldots n}$ & Moments of the aerosol number distribution \\
\hline$M_{\mathrm{W}}, M_{\mathrm{a}}$ & Molar masses of water and air, respectively \\
\hline MODIS & Moderate Resolution Imaging Spectroradiometer \\
\hline$N$ & Brunt-Väisälä frequency \\
\hline$N_{\mathrm{a}}, N_{\mathrm{X}}$ & Aerosol number concentration \\
\hline$N_{\mathrm{i}, \mathrm{cv}}$ & Ice crystal concentration within convective cumulus \\
\hline$N_{\mathrm{i}, \mathrm{suc}}^{\mathrm{s}}$ & Ice crystal concentration nucleated in a single parcel ascent \\
\hline$N_{\mathrm{i}, \text { nuc }}$ & Ice crystal concentration nucleated in cirrus \\
\hline$N_{1, \text { act }}$ & Activated cloud droplet number concentration \\
\hline$N_{1, \text { cum }}$ & Column-integrated droplet number concentration \\
\hline$n_{1}, N_{1}$ & Grid mean and in-cloud droplet number concentration, respectively \\
\hline$n_{\mathrm{i}}, N_{\mathrm{i}}$ & Grid mean and in-cloud ice crystal number concentration, respectively \\
\hline$n_{\mathrm{i}, \mathrm{cp}}$ & Ice crystal number concentration within convective parcels \\
\hline$N_{\mathrm{cnv}}$ & Detrained ice crystal concentration \\
\hline$N_{\text {dep }}$ & Ice crystal concentration produced by deposition and condensation nucleation \\
\hline$n_{\mathrm{gr}}, q_{\mathrm{gr}}$ & Graupel number concentration and mixing ratio, respectively \\
\hline$n_{\mathrm{i} / \mathrm{s}}, q_{\mathrm{i} / \mathrm{s}}$ & Ice plus snow number concentration and mixing ratio, respectively \\
\hline $\mathcal{N}_{\text {het }}$ & Ice nucleation spectrum \\
\hline$N_{\text {imm }}$ & Ice crystal concentration produced by immersion freezing \\
\hline$N_{0, \mathrm{y}}$ & Intercept parameter of $n_{\mathrm{y}}(D)$ \\
\hline$n_{\mathrm{s}, \mathrm{x}}$ & Immersion active site surface density for the $\mathrm{x}$ species \\
\hline$N_{\mathrm{X}}$ & Aerosol number concentration of the $\mathrm{x}$ species \\
\hline$n_{\mathrm{y}}(D)$ & Size distribution of the y species \\
\hline$p$ & Pressure \\
\hline$P_{q}(q)$ & Probability distribution of total cloud condensate \\
\hline$p_{\mathrm{s}, \mathrm{w}}, p_{\mathrm{s}, \mathrm{i}}$ & Liquid water and ice saturation vapor pressure, respectively \\
\hline$P_{\text {tot }}$ & Total precipitation \\
\hline$q^{*}$ & Weighted saturation mixing ratio between liquid and ice \\
\hline$q_{\mathrm{c}}$ & Total condensate mixing ratio \\
\hline$q_{\mathrm{c}, \mathrm{det}}$ & Detrained condensate mixing ratio \\
\hline
\end{tabular}


Table D1. Continued.

\begin{tabular}{|c|c|}
\hline$q_{\mathrm{cn}}$ & Mixing ratio of total condensate in a convective parcel \\
\hline$q_{\mathrm{gr}}$ & Graupel mass mixing ratio within a convective cumulus \\
\hline$q_{\mathrm{i}}$ & Grid cell mean ice water mixing ratio \\
\hline$q_{\mathrm{i}, \mathrm{cp}}$ & Ice water mixing ratio within convective parcels \\
\hline$q_{1}$ & Grid cell mean liquid water mixing ratio \\
\hline$q_{\mathrm{mx}}, q_{\mathrm{mn}}$ & Upper and lower limits of the total water distribution, respectively \\
\hline$q_{1}^{*}, q_{\mathrm{i}}^{*}$ & Saturation specific humidities for liquid and ice, respectively \\
\hline$q_{\mathrm{t}}$ & Total water mixing ratio, $\left(q_{\mathrm{v}}+q_{\mathrm{c}}\right)$ \\
\hline$q_{\mathrm{v}}$ & Water vapor mixing ratio \\
\hline$R$ & Universal gas constant \\
\hline$R_{\mathrm{eff}, \mathrm{liq}}$ & Cloud droplet effective radius \\
\hline$R_{\text {eff,ice }}$ & Ice crystal effective radius \\
\hline RH & Ambient relative humidity \\
\hline$R_{\mathrm{V}}$ & $R / M_{\mathrm{a}}$ \\
\hline$R_{\mathrm{vol}, \text { ice }}$ & Volumetric ice crystal radius, $\left(\frac{3 q_{\mathrm{i}}}{4 \pi N_{\mathrm{i}} \rho_{\mathrm{i}}}\right)^{1 / 3}$ \\
\hline$S_{\mathrm{i}, \mathrm{c}}$ & Clear sky saturation ratio \\
\hline $\mathrm{SCF}$ & Supercooled cloud fraction \\
\hline$S_{\text {crit }}$ & Critical saturation ratio \\
\hline$S_{\mathrm{i}}$ & Saturation ratio with respect to ice \\
\hline$S_{\mathrm{i}, \max }$ & Maximum water vapor supersaturation with respect to ice \\
\hline$S_{\mathrm{i}, \text { wsat }}$ & Value of $S_{\mathrm{i}}$ at water saturation \\
\hline$S_{1, \max }$ & Maximum water vapor supersaturation with respect to water \\
\hline $\bar{s}_{\mathrm{p}, \mathrm{X}}$ & Mean particle surface area of the $\mathrm{x}$ species \\
\hline SWCF & Shortwave cloud forcing \\
\hline$t$ & Time \\
\hline$T$ & Temperature \\
\hline$T_{\mathrm{V}}$ and $T_{\mathrm{v}}^{\prime}$ & Virtual temperature of the cloud and the environment, respectively \\
\hline TWP & Total water path \\
\hline$U$ & Horizontal wind \\
\hline $\bar{w}$ & Mean vertical velocity \\
\hline$w_{1 \mathrm{~s}}$ & Large-scale vertical velocity \\
\hline$w_{\text {sub }}$ & Subgrid-scale vertical velocity \\
\hline $\bar{w}_{\text {sub }}^{+}$ & Positive mean vertical velocity \\
\hline$w_{\text {term }}$ & Hydrometeor terminal velocity \\
\hline$w_{\mathrm{cp}}$ & Cumulus vertical velocity \\
\hline$W$ & Convective mass flux \\
\hline$z$ & Altitude \\
\hline
\end{tabular}




\section{Code availability}

The GEOS-5 source code is available under the NASA Open Source Agreement at http://opensource.gsfc.nasa.gov/projects/GEOS-5/.

Acknowledgements. Donifan Barahona was supported by the NASA Modeling, Analysis and Prediction program under WBS 802678.02.17.01.07. GPCC precipitation data was provided by the NOAA/OAR/ESRL PSD, Boulder, Colorado, USA, from their website at http://www.esrl.noaa.gov/psd/. MODIS data was downloaded from http://modis.gsfc.nasa.gov/data/. We thank Frank Li for providing level 3 CloudSat data. The authors thank Yong-Sang Choi for providing CALIOP-derived SCF data, and Minghuai Wang for his help with the analysis of field campaign data

Edited by: K. Gierens

\section{References}

Abdul-Razzak, H. and Ghan, S.: A parameterization of aerosol activation, 2. Multiple aerosol types, J. Geophys. Res., 105, 68376844, doi:10.1029/1999JD901161, 2000.

Arakawa, A.: The cumulus parameterization problem: Past, present, and future, J. Climate, 17, 2493-2525, 2004.

Bacmeister, J., Eckermann, S., Tsias, A., Carslaw, K., and Peter, T.: Mesoscale temperature fluctuations induced by a spectrum of gravity waves: A comparison of parameterizations and their impact on stratospheric microphysics, J. Atmos. Sci., 56, 19131924, 1999.

Bacmeister, J., Suarez, M., and Robertson, F. R.: Rain Reevaporation, Boundary Layer, Convection Interactions, and Pacific Rainfall Patterns in an AGCM, J. Atmos. Sci., 63, 3383-3403, doi:10.1175/JAS3791.1, 2006.

Baker, B. A.: On the Role of Phoresis in Cloud Ice Initiation, J. Atmos. Sci., 48, 1545-1548, doi:10.1175/15200469(1991)048<1545:OTROPI>2.0.CO;2, 1991.

Barahona, D.: On the ice nucleation spectrum, Atmos. Chem. Phys., 12, 3733-3752, doi:10.5194/acp-12-3733-2012, 2012.

Barahona, D. and Nenes, A.: Parameterization of cloud droplet formation in large scale models: including effects of entrainment, J. Geophys. Res., 112, D16026, doi:10.1029/2007JD008473, 2007.

Barahona, D. and Nenes, A.: Parameterization of cirrus formation in large scale models: Homogeneous nucleation, J. Geophys. Res., 113, D11211, doi:10.1029/2007JD009355, 2008.

Barahona, D. and Nenes, A.: Parameterizing the competition between homogeneous and heterogeneous freezing in cirrus cloud formation - monodisperse ice nuclei, Atmos. Chem. Phys., 9, 369-381, doi:10.5194/acp-9-369-2009, 2009a.

Barahona, D. and Nenes, A.: Parameterizing the competition between homogeneous and heterogeneous freezing in cirrus cloud formation - monodisperse ice nuclei, Atmos. Chem. Phys., 9, 369-381, doi:10.5194/acp-9-369-2009, 2009b.

Barahona, D. and Nenes, A.: Dynamical states of low temperature cirrus, Atmos. Chem. Phys., 11, 3757-3771, doi:10.5194/acp11-3757-2011, 2011.
Barahona, D., Rodriguez, J., and Nenes, A.: Sensitivity of the global distribution of cirrus Ice crystal concentration to heterogeneous freezing, J. Geophys. Res., 15, D23213, doi:10.1029/2010JD014273, 2010a.

Barahona, D., West, R. E. L., Stier, P., Romakkaniemi, S., Kokkola, H., and Nenes, A.: Comprehensively accounting for the effect of giant $\mathrm{CCN}$ in cloud activation parameterizations, Atmos. Chem. Phys., 10, 2467-2473, doi:10.5194/acp-10-2467-2010, $2010 \mathrm{~b}$.

Barkstrom, B.: The earth radiation budget experiment (ERBE), B. Am. Meteorol. Soc., 65, 1170-1185, 1984.

Blackadar, A. K.: The Vertical Distribution of Wind and Turbulent Exchange in a Neutral Atmosphere, J. Geophys. Res., 67, 30953102, 1962.

Bodas-Salcedo, A., Webb, M. J., Bony, S., Chepfer, H., Dufresne, J.-L., Klein, S. A., Zhang, Y., Marchand, R., Haynes, J. M., Pincus, R., and John, V. O.: COSP: Satellite simulation software for model assessment, B. Am. Meteorol. Soc., 92, 1023-1043, doi:10.1175/2011BAMS2856.1, 2011.

Burrows, S. M., Hoose, C., Pöschl, U., and Lawrence, M. G.: Ice nuclei in marine air: biogenic particles or dust?, Atmos. Chem. Phys., 13, 245-267, doi:10.5194/acp-13-245-2013, 2013.

Chiriaco, M., Chepfer, H., Minnis, P., Haeffelin, M., Platnick, S., Baumgardner, D., Dubuisson, P., McGill, M., Noël, V., Pelon, J., Spangenberg, D., Sun-Mack, S., and Wind, G.: Comparison of CALIPSO-like, LaRC, and MODIS retrievals of ice-cloud properties over SIRTA in France and Florida during CRYSTALFACE, J. Appl. Meteorol. Clim., 46, 249-272, 2007.

Choi, Y., Lindzen, R., Ho, C., and Kim, J.: Space observations of cold-cloud phase change, P. Natl. Acad. Sci., 107, 11211-11216, 2010.

Chou, M.-D. and Suarez, M.: An efficient thermal infrared radiation parameterization for use in general circulation models, Vol. 3 of NASA Tech. Memorandum 104606, NASA Goddard Space Flight Center, Greenbelt, MD, USA, 1994.

Chou, M.-D., Suarez, M., Ho, C.-H., Yan, M.-H., and Lee, K.-T.: A Solar Radiation Model for Use in Climate Studies, J. Atmos. Sci., 49, 762-772, 1992.

Colarco, P., da Silva, A., Chin, M., and Diehl, T.: Online simulations of global aerosol distributions in the NASA GEOS-4 model and comparisons to satellite and ground-based aerosol optical depth, J. Geophys. Res., 115, D14207, doi:10.1029/2009JD012820, 2010.

Conant, W. C., VanReken, T., Rissman, T., Varutbangkul, V., Jonsson, H., Nenes, A., Jimenez, J., Delia, A., Bahreini, R., Roberts, G., Flagan, R., and Seinfeld, J. H.: Aerosol-cloud drop concentration closure in warm clouds, J. Geophys. Res., 109, D13204, doi:10.1029/2003JD004324, 2004.

Cziczo, D. J., Froyd, K. D., Hoose, C., Jensen, E. J., Diao, M., Zondlo, M. A., Smith, J. B., Twohy, C. H., and Murphy, D. M.: Clarifying the Dominant Sources and Mechanisms of Cirrus Cloud Formation, Science, 340, 1320-1324, 2013.

Dean, S. M., Flowerdew, J., Lawrence, B. N., and Eckermann, S. D.: Parameterisation of orographic cloud dynamics in a GCM, Clim. Dynam., 28, 581-597, doi:10.1007/s00382-006-0202-0, 2007.

Del Genio, A., Yao, M., Kovari, W., and Lo, K.: A prognostic cloud water parameterization for global climate models, J. Climate, 9 , 270-304, 1996. 
Del Genio, A. D., Kovari, W., Yao, M.-S., and Jonas, J.: Cumulus Microphysics and Climate Sensitivity, J. Climate, 18, 23762387, doi:10.1175/JCLI3413.1, 2005.

DeMott, P. J., Prenni, A. J., Liu, X., Kreidenweis, S. M., Petters, M. D., Twohy, C. H., Richardson, M. S., Eidhammer, T., and Rogers, D. C.: Predicting global atmospheric ice nuclei distributions and their impacts on climate, P. Natl. Acad. Sci., 107, 11217-11222, doi:10.1073/pnas.0910818107, 2010.

Devasthale, A. and Thomas, M. A.: Sensitivity of Cloud Liquid Water Content Estimates to the Temperature-Dependent Thermodynamic Phase: A Global Study Using CloudSat Data, J. Climate, 25, 7297-7307, 2012.

Diehl, T., Heil, A., Chin, M., Pan, X., Streets, D., Schultz, M., and Kinne, S.: Anthropogenic, biomass burning, and volcanic emissions of black carbon, organic carbon, and $\mathrm{SO}_{2}$ from 1980 to 2010 for hindcast model experiments, Atmos. Chem. Phys. Discuss., 12, 24895-24954, doi:10.5194/acpd-12-24895-2012, 2012.

Eliasson, S., Buehler, S. A., Milz, M., Eriksson, P., and John, V. O.: Assessing observed and modelled spatial distributions of ice water path using satellite data, Atmos. Chem. Phys., 11, 375391, doi:10.5194/acp-11-375-2011, 2011.

Ferrier, S. B.: A Double-Moment Multiple-Phase Four-Class Bulk Ice Scheme. Part I: Description, J. Atmos. Sci., 51, 249-280, doi:10.1175/1520-0469(1994)051<0249:ADMMPF>2.0.CO;2, 1994.

Fornea, A. P., Brooks, S. D., Dooley, J. B., and Saha, A.: Heterogeneous freezing of ice on atmospheric aerosols containing ash, soot, and soil, J. Geophys. Res., 114, D13201, doi:10.1029/2009JD011958, 2009.

Fountoukis, C. and Nenes, A.: Continued development of a cloud droplet formation parameterization for global climate models, J. Geophys. Res., 110, D11212, doi:10.1029/2004JD005591, 2005.

Fountoukis, C., Nenes, A., Meskhidze, N., Bahreini, R., Conant, W. C., Jonsson, H., Murphy, S., Sorooshian, A., Varutbangkul, V., Brechtel, F., Flagan, R., and Seinfeld, J. H.: Aerosol-cloud drop concentration closure for clouds sampled during the International Consortium for Atmospheric Reseach on Transport and Transformation 2004 campaign, J. Geophys. Res., 112, D10S30, doi:10.1029/2006JD007272, 2007.

Frank, W. M. and Cohen, C.: Simulation of Tropical Convective Systems. Part I: A Cumulus Parameterization, J. Atmos. Sci., 44, 3787-3799, doi:10.1175/15200469(1987)044<3787:SOTCSP>2.0.CO;2, 1987.

Gayet, J., Ovarlez, J., Shcherbakov, V., Ström, J., Schumann, U., Minikin, A., Auriol, F., Petzold, A., and Monier, M.: Cirrus cloud microphysical and optical properties at southern and northern midlatitudes during the INCA experiment, J. Geophys. Res., 109, D20206, doi:10.1029/2004JD004803, 2004.

Gettelman, A. and Kinnison, D. E.: The global impact of supersaturation in a coupled chemistry-climate model, Atmos. Chem. Phys., 7, 1629-1643, doi:10.5194/acp-7-1629-2007, 2007.

Gettelman, A., Fetzer, E. J., Eldering, A., and Irion, F. W.: The global distribution of supersaturation in the upper troposphere from the Atmospheric Infrared Sounder, J. Climate, 19, 60896103, 2006.

Gettelman, A., Morrison, H., and Ghan, S. J.: A New TwoMoment Bulk Stratiform Cloud Microphysics Scheme in the Community Atmosphere Model, Version 3 (CAM3). Part II:
Single-Column and Global Results, J. Climate, 21, 3660-3679, doi:10.1175/2008JCLI2116.1, 2008.

Gettelman, A., Liu, X., Ghan, S. J., Morrison, H., Park, S., Conley, A. J., Klein, S. A., Boyle, J., Mitchell, D. L., and Li, J.-L. F.: Global simulations of ice nucleation and ice supersaturation with an improved cloud scheme in the Community Atmosphere Model, J. Geophys. Res., 115, D18216, doi:10.1029/2009JD013797, 2010.

Gettelman, A., Liu, X., Barahona, D., Lohmann, U., and Chen, C.: Climate impacts of ice nucleation, J. Geophys. Res., 117, D20201, doi:10.1029/2012JD017950, 2012.

Gierens, K., Schumann, U., Helten, M., Smit, H., and Marenco, A.: A distribution law for relative humidity in the upper troposphere and lower stratosphere derived from three years of MOZAIC measurements, Ann. Geophys., 17, 1218-1226, doi:10.1007/s00585-999-1218-7, 1999.

Golaz, J.-C., Salzmann, M., Donner, L. J., Horowitz, L. W., Ming, Y., and Zhao, M.: Sensitivity of the Aerosol Indirect Effect to Subgrid Variability in the Cloud Parameterization of the GFDL Atmosphere General Circulation Model AM3, J. Climate, 24, 3145-3160, doi:10.1175/2010JCLI3945.1, 2010.

Gregory, D.: Estimation of entrainment rate in simple models of convective clouds, Q. J. Roy. Meteorol. Soc., 127, 53-72, 2001.

Gultepe, I. and Isaac, G.: The relationship between cloud droplet and aerosol number concentrations for climate models, Int. J. Climatol., 16, 941-946, 1996.

Guo, H., Liu, Y., Daum, P., Senum, G., and Tao, W.: Characteristics of vertical velocity in marine stratocumulus: comparison of large eddy simulations with observations, Environ. Res. Lett., 3, 045020, doi:10.1088/1748-9326/3/4/045020, 2008.

Haag, W. and Kärcher, B.: The impact of aerosols and gravity waves on cirrus at midlatitudes, J. Geophys. Res., 109, D12202, doi:10.1029/2004JD004579, 2004.

Han, Q., Rossow, W. B., Chou, J., and Welch, R. M.: Global variation of column droplet concentration in low-level clouds, Geophys. Res. Lett., 25, 1419-1422, doi:10.1029/98GL01095, 1998.

Hendricks, J., Kärcher, B., and Lohmann, U.: Effects of ice nuclei on cirrus clouds in a global climate model, J. Geophys. Res., 116, D18206, doi:10.1029/2010JD015302, 2011.

Herzog, A. and Vial, F.: A study of the dynamics of the equatorial lower stratosphere by use of ultra-long-duration balloons, J. Geophys. Res., 106, 22745-22761, 2001.

Heymsfield, A. J., Bansemer, A., Field, P. R., Durden, S. L., Stith, J. L., Dye, J. E., Hall, W., and Grainger, C. A.: Observations and Parameterizations of Particle Size Distributions in Deep Tropical Cirrus and Stratiform Precipitating Clouds: Results from In Situ Observations in TRMM Field Campaigns., J. Atmos. Sci., 59, 3457-3491, doi:10.1175/15200469(2002)059<3457:OAPOPS>2.0.CO;2, 2002.

Heymsfield, A. J., van Zadelhoff, G.-J., Donovan, D. P., Fabry, F., Hogan, R. J., and Illingworth, A. J.: Refinements to Ice Particle Mass Dimensional and Terminal Velocity Relationships for Ice Clouds. Part II: Evaluation and Parameterizations of Ensemble Ice Particle Sedimentation Velocities, J. Atmos. Sci., 64, 10681088, doi:10.1175/JAS3900.1, 2007.

Hoose, C., Kristjánsson, J., and Burrows, S.: How important is biological ice nucleation in clouds on a global scale?, Environ. Res. Lett., 5, 024009, doi:10.1088/1748-9326/5/2/024009, 2010. 
Hu, Y., Rodier, S., Xu, K.-M., Sun, W., Huang, J., Lin, B., Zhai, P., and Josset, D.: Occurrence, liquid water content, and fraction of supercooled water clouds from combined CALIOP/IIR/MODIS measurements, J. Geophys. Res., 115, D00H34, doi:10.1029/2009JD012384, 2010.

Huffman, G., Adler, R., Arkin, P., Chang, A., Ferraro, R., Gruber, A., Janowiak, J., McNab, A., Rudolf, B., and Schneider, U.: The global precipitation climatology project (GPCP) combined precipitation dataset, B. Am. Meteorol. Soc., 78, 5-20, 1997.

IPCC: Climate change 2007: the physical basis. Contribution of working group I to the fourth assessment report of the Intergovernmental Panel on Climate Change, Cambridge University Press, Cambridge, United Kingdom and New York, NY, USA., 2007.

Jensen, E. and Pfister, L.: Transport and freeze-drying in the tropical tropopause layer, J. Geophys. Res., 109, D02207, doi:10.1029/2003JD004022, 2004.

Jensen, E. J., Pfister, L., Bui, T.-P., Lawson, P., and Baumgardner, D.: Ice nucleation and cloud microphysical properties in tropical tropopause layer cirrus, Atmos. Chem. Phys., 10, 1369-1384, doi:10.5194/acp-10-1369-2010, 2010.

Jensen, E. J., Pfister, L., and Bui, T. P.: Physical processes controlling ice concentrations in cold cirrus near the tropical tropopause, J. Geophys. Res., 117, D11205, doi:10.1029/2011JD017319, 2012.

Joos, H., Spichtinger, P., Gayet, J., and Minikin, A.: Orographic cirrus in the global climate model ECHAM5, J. Geophys. Res., 113, doi:10.1029/2007JD009605, 2008.

Joos, H., Spichtinger, P., and Lohmann, U.: Influence of a future climate on the microphysical and optical properties of orographic cirrus clouds in ECHAM5, J. Geophys. Res., 115, D19129, doi:10.1029/2010JD013824, 2010.

Kärcher, B. and Burkhardt, U.: A cirrus scheme for global circulation models, Q. J. Roy. Meteorol. Soc., 134, 1439-1461, doi:10.1002/Qj.301, 2008.

Kärcher, B. and Lohmann, U.: A parameterization of cirrus cloud formation: homogeneous freezing including effects or aerosol size, J. Geophys. Res., 107, 4698, doi:10.1029/2001JD001429, 2002.

Kärcher, B. and Ström, J.: The roles of dynamical variability and aerosols in cirrus cloud formation, Atmos. Chem. Phys., 3, 823838, doi:10.5194/acp-3-823-2003, 2003.

Kärcher, B., Hendricks, J., and Lohmann, U.: Physically based parameterization of cirrus cloud formation for use in global atmospheric models, J. Geophys. Res., 111, D01205, doi:10.1029/2005JD006219, 2006.

Kaufman, Y. J. and Koren, I.: Smoke and pollution aerosol effect on cloud cover, Science, 313, 655-658, 2006.

Kay, J., Hillman, B., Klein, S., Zhang, Y., Medeiros, B., Pincus, R., Gettelman, A., Eaton, B., Boyle, J., Marchand, R., and Ackerman, A.: Exposing global cloud biases in the Community Atmosphere Model (CAM) using satellite observations and their corresponding instrument simulators, J. Climate, 25, 5190-5207, 2012.

Khain, A., Ovtchinnikov, M., Pinsky, M., Pokrovsky, A., and Krugliak, H.: Notes on the state-of-the-art numerical modeling of cloud microphysics, Atmos. Res., 55, 159-224, doi:10.1016/S0169-8095(00)00064-8, 2000.
Khairoutdinov, M. and Kogan, Y.: A new cloud physics parameterization in a Large-Eddy simulation model of marine stratocumulus, Mon. Weather Rev., 128, 229-243, 2000.

King, M., Menzel, W., Kaufman, Y., Tanre, D., Gao, B.-C., Platnick, S., Ackerman, S., Remer, L., Pincus, R., and Hubanks, P.: Cloud and aerosol properties, precipitable water, and profiles of temperature and water vapor from MODIS, IEEE T. Geosci. Remote, 41, 442-458, doi:10.1109/TGRS.2002.808226, 2003.

Koop, T., Luo, B., Tslas, A., and Peter, T.: Water activity as the determinant for homogeneous ice nucleation in aqueous solutions, Nature, 406, 611-614, 2000.

Korolev, A. and Mazin, I.: Supersaturation of water vapor in clouds, J. Atmos. Sci., 60, 2957-2974, 2003.

Krämer, M., Schiller, C., Afchine, A., Bauer, R., Gensch, I., Mangold, A., Schlicht, S., Spelten, N., Sitnikov, N., Borrmann, S., de Reus, M., and Spichtinger, P.: Ice supersaturations and cirrus cloud crystal numbers, Atmos. Chem. Phys., 9, 3505-3522, doi:10.5194/acp-9-3505-2009, 2009.

Kumar, P., Nenes, A., and Sokolik, I. N.: Importance of adsorption for $\mathrm{CCN}$ activity and hygroscopic properties of mineral dust aerosol, Geophys. Res. Lett., 36, L24804, doi:10.1029/2009GL040827, 2009a.

Kumar, P., Sokolik, I. N., and Nenes, A.: Parameterization of cloud droplet formation for global and regional models: including adsorption activation from insoluble CCN, Atmos. Chem. Phys., 9, 2517-2532, doi:10.5194/acp-9-2517-2009, 2009 b.

Ladino, L., Stetzer, O., Lüönd, F., Welti, A., and Lohmann, U.: Contact freezing experiments of kaolinite particles with cloud droplets, J. Geophys. Res., 116, D22202, doi:10.1029/2011JD015727, 2011.

Lance, S., Nenes, A., and Rissman, T.: Chemical and dynamical effects on cloud droplet number: Implication for estimates of the aerosol indirect effect, J. Geophys. Res., 109, D22208, doi:10.1029/2004JD004596, 2004.

Lance, S., Shupe, M. D., Feingold, G., Brock, C. A., Cozic, J., Holloway, J. S., Moore, R. H., Nenes, A., Schwarz, J. P., Spackman, J. R., Froyd, K. D., Murphy, D. M., Brioude, J., Cooper, O. R., Stohl, A., and Burkhart, J. F.: Cloud condensation nuclei as a modulator of ice processes in Arctic mixed-phase clouds, Atmos. Chem. Phys., 11, 8003-8015, doi:10.5194/acp-11-80032011, 2011.

Li, J.-L. F., Waliser, D. E., Chen, W.-T., Guan, B., Kubar, T., Stephens, G., Ma, H.-Y., Deng, M., Donner, L., Seman, C., and Horowitz, L.: An observationally based evaluation of cloud ice water in CMIP3 and CMIP5 GCMs and contemporary reanalyses using contemporary satellite data, J. Geophys. Res., 117, D16105, doi:10.1029/2012JD017640, 2012.

Li, J.-L. F., Lee, S., Waliser, D. E., Lee, S., Guan, B., Stephens, G., and Teixeira, J.: Assessment of Cloud Liquid Water in CMIP3, CMIP5, and Contemporary GCMs and Reanalyses with Observations, J. Geophys. Res., under review, 2014.

Lindzen, R. S.: Turbulence and stress owing to gravity wave and tidal breakdown, J. Geophys. Res., 86, 9707-9714, doi:10.1029/JC086iC10p09707, 1981.

Liu, X., Shi, X., Zhang, K., Jensen, E. J., Gettelman, A., Barahona, D., Nenes, A., and Lawson, P.: Sensitivity studies of dust ice nuclei effect on cirrus clouds with the Community Atmosphere Model CAM5, Atmos. Chem. Phys., 12, 12061-12079, doi:10.5194/acp-12-12061-2012, 2012. 
Liu, Y., Daum, P., and Yum, S.: Analytical expression for the relative dispersion of the cloud droplet size distribution, Geophys. Res. Lett., 33, L02810, doi:10.1029/2005GL024052, 2006.

Liu, Y., Daum, P., Guo, H., and Peng, Y.: Dispersion bias, dispersion effect, and the aerosol-cloud conundrum, Environ. Res. Lett., 3, 045021, doi:10.1088/1748-9326/3/4/045021, 2008.

Locatelli, J. D. and Hobbs, P. V.: Fall Speeds and Masses of Solid Precipitation Particles, J. Geophys. Res., 79, 2185-2197, doi:10.1029/JC079i015p02185, 1974.

Loeb, N., Wielicki, B., Doelling, D., Smith, G., Keyes, D., Kato, S., Manalo-Smith, N., and Wong, T.: Toward optimal closure of the Earth's top-of-atmosphere radiation budget, J. Climate, 22, 748-766, 2009.

Lohmann, U.: Global anthropogenic aerosol effects on convective clouds in ECHAM5-HAM, Atmos. Chem. Phys., 8, 2115-2131, doi:10.5194/acp-8-2115-2008, 2008.

Lohmann, U. and Feichter, J.: Global indirect aerosol effects: a review, Atmos. Chem. Phys., 5, 715-737, doi:10.5194/acp-5-7152005, 2005.

Lohmann, U., Spichtinger, P., Jess, S., Peter, T., and Smit, H.: Cirrus cloud formation and ice supersaturated regions in a global climate model, Environ. Res. Lett., 3, 045022; doi:10.1088/17489326/3/4/045022, 2008.

Louis, J. F., Weill, A., and Vidal-Madjar, D.: Dissipation length in stable layers, Bound.-La. Meteorol., 25, 229-243, doi:10.1007/BF00119538, 1983.

Manabe, S., Smagorinsky, J., and Strickler, R. F.: Simulated climatology of a general circulation model with a hydrologic cycle 1, Mon. Weather Rev., 93, 769-798, 1965.

Marcolli, C., Gedamke, S., Peter, T., and Zobrist, B.: Efficiency of immersion mode ice nucleation on surrogates of mineral dust, Atmos. Chem. Phys., 7, 5081-5091, doi:10.5194/acp-7-50812007, 2007.

Marshall, J. S. and Palmer, W. M. K.: The distribution of raindrops with size, J. Meteorol., 5, 165-166, 1948.

McFarlane, N. A.: The Effect of Orographically Excited Gravity Wave Drag on the General Circulation of the Lower Stratosphere and Troposphere, J. Atmos. Sci., 44, 1775-1800, doi:10.1175/1520-0469(1987)044<1775:TEOOEG>2.0.CO;2, 1987.

McFarquhar, G. and Heymsfield, A.: Parameterization of tropical cirrus ice crystal size distributions and implications for radiative transfer: Results from CEPEX, J. Atmos. Sci., 54, 2187-2200, 1997.

Molod, A.: Constraints on the Total Water PDF in GCMs from AIRS and a High Resolution Model, J. Climate, 25, 8341-8352, 2012.

Molod, A., Takacs, L., Suarez, M., Bacmeister, J., Song, I., and Eichmann, A.: The GEOS-5 Atmospheric General Circulation Model: Mean Climate and Development from MERRA to Fortuna, Vol. 28 of Technical Report Series on Global Modeling and Data Assimilation, NASA Goddard Space Flight Center, Greenbelt, MD, USA, 2012.

Moorthi, S. and Suarez, M. J.: Relaxed Arakawa-Schubert - A parameterization of moist convection for general circulation models, Mon. Weather Rev., 120, 978-1002, 1992.

Morales, R. and Nenes, A.: Characteristic updrafts for computing distribution-averaged cloud droplet number, and stra- tocumulus cloud properties, J. Geophys. Res., 115, D18220, doi:10.1029/2009JD013233, 2010.

Morales Betancourt, R., Lee, D., Oreopoulos, L., Sud, Y. C., Barahona, D., and Nenes, A.: Sensitivity of cirrus and mixed-phase clouds to the ice nuclei spectra in McRAS-AC: single column model simulations, Atmos. Chem. Phys., 12, 10679-10692, doi:10.5194/acp-12-10679-2012, 2012.

Morrison, H. and Gettelman, A.: A New Two-Moment Bulk Stratiform Cloud Microphysics Scheme in the Community Atmosphere Model, Version 3 (CAM3). Part I: Description and Numerical Tests, J. Climate, 21, 3642-3659, doi:10.1175/2008JCLI2105.1, 2008.

Morrison, H., Curry, J. A., and Khvorostyanov, V. I.: A New Double-Moment Microphysics Parameterization for Application in Cloud and Climate Models. Part I: Description, J. Atmos. Sci., 62, 1665-1677, doi:10.1175/JAS3446.1, 2005.

Morrison, H., de Boer, G., Feingold, G., Harrington, J., Shupe, M. D., and Sulia, K.: Resilience of persistent Arctic mixed-phase clouds, Nat. Geosci., 5, 11-17, doi:10.1038/ngeo1332, 2012.

Murray, B. J., Broadley, S. L., Wilson, T. W., Atkinson, J. D., and Wills, R. H.: Heterogeneous freezing of water droplets containing kaolinite particles, Atmos. Chem. Phys., 11, 4191-4207, doi:10.5194/acp-11-4191-2011, 2011.

Murray, B. J., OSullivan, D., Atkinson, J., and Webb, M.: Ice nucleation by particles immersed in supercooled cloud droplets, Chem. Soc. Rev., 41, 6519-6554, 2012.

Nenes, A. and Seinfeld, J. H.: Parameterization of cloud droplet formation in global climate models, J. Geophys. Res., 108, 4415, doi:10.1029/2002JD002911, 2003.

Niemand, M., Möhler, O., Vogel, B., Vogel, H., Hoose, C., Connolly, P., Klein, H., Bingemer, H., DeMott, P., Skrotzki, J., and Leisner, T.: A particle-surface-area-based parameterization of immersion freezing on desert dust particles, J. Atmos. Sci., 69, 3077-3092, doi:10.1175/JAS-D-11-0249.1, 2012.

Peng, Y., Lohmann, U., and Leaitch, W.: Importance of vertical velocity variations in the cloud droplet nucleation process of marine stratocumulus, J. Geophys. Res., 110, D21213, doi:10.1029/2004JD004922, 2005.

Petters, M. D. and Kreidenweis, S. M.: A single parameter representation of hygroscopic growth and cloud condensation nucleus activity, Atmos. Chem. Phys., 7, 1961-1971, doi:10.5194/acp-71961-2007, 2007.

Phillips, V. T., Donner, L., and Garner, S.: Nucleation processes in deep convection simulated by a cloud-system-resolving model with double-moment bulk microphysics, J. Atmos. Sci., 64, 738761, doi:10.1175/JAS3869.1, 2007.

Phillips, V. T., DeMott, P., and Andronache, C.: An empirical parameterization of heterogeneous ice nucleation for multiple chemical species of aerosol, J. Atmos. Sci., 65, 2757-2783, doi:10.1175/2007JAS2546.1, 2008.

Phillips, V. T., Demott, P. J., Andronache, C., Pratt, K. A., Prather, K. A., Subramanian, R., and Twohy, C.: Improvements to an Empirical Parameterization of Heterogeneous Ice Nucleation and its Comparison with Observations, J. Atmos. Sci., 70, 378-409, doi:10.1175/JAS-D-12-080.1, 2013.

Pincus, R., Platnick, S., Ackerman, S., Hemler, R., and Patrick Hofmann, R.: Reconciling simulated and observed views of clouds: MODIS, ISCCP, and the limits of instrument simulators, J. Climate, 25, 4699-4720, 2012. 
Platnick, S., King, M., Ackerman, S., Menzel, W., Baum, B., Riédi, J., and Frey, R.: The MODIS cloud products: Algorithms and examples from Terra, IEEE T. Geosci. Remote., 41, 459-473, 2003.

Popovitcheva, O., Kireeva, E., Persiantseva, N., Khokhlova, T., Shonija, N., Tishkova, V., and Demirdjian, B.: Effect of soot on immersion freezing of water and possible atmospheric implications, Atmos. Res., 90, 326-337, 2008.

Pruppacher, H. and Klett, J.: Microphysics of clouds and precipitation, Kluwer Academic Publishers, Boston, MA, 2nd Edn., 1997.

Putman, W. and Suarez, M.: Cloud-system resolving simulations with the NASA Goddard Earth Observing System global atmospheric model (GEOS-5), Geophys. Res. Lett., 38, L16809, doi:10.1029/2011GL048438, 2011.

Quaas, J., Ming, Y., Menon, S., Takemura, T., Wang, M., Penner, J. E., Gettelman, A., Lohmann, U., Bellouin, N., Boucher, O., Sayer, A. M., Thomas, G. E., McComiskey, A., Feingold, G., Hoose, C., Kristjánsson, J. E., Liu, X., Balkanski, Y., Donner, L. J., Ginoux, P. A., Stier, P., Grandey, B., Feichter, J., Sednev, I., Bauer, S. E., Koch, D., Grainger, R. G., Kirkevåg, A., Iversen, T., Seland, Ø., Easter, R., Ghan, S. J., Rasch, P. J., Morrison, H., Lamarque, J.-F., Iacono, M. J., Kinne, S., and Schulz, M.: Aerosol indirect effects - general circulation model intercomparison and evaluation with satellite data, Atmos. Chem. Phys., 9, 8697-8717, doi:10.5194/acp-9-8697-2009, 2009.

Raatikainen, T., Nenes, A., Seinfeld, J. H., Morales, R., Moore, R. H., Lathem, T. L., Lance, S., Padro, L. T., Lin, J. J., Cerully, K. M., Bougiatioti, A., Cozic, J., Ruehl, C. R., Chuang, P. Y., Anderson, B. E., Flagan, R. C., Jonsson, H., Mihalopoulos, N., and Smith, J. N.: Worldwide data sets constrain the water vapor uptake coefficient in cloud formation, P. Natl. Acad. Sci., 110, 3760-3764, doi:10.1073/pnas.1219591110, 2013.

Ramanathan, V., Crutzen, P., Kiehl, J., and Rosenfeld, D.: Aerosols, climate, and the hydrological cycle, Science, 294, 2119-2124, 2001.

Reale, O., Lau, W. K., Kim, K.-M., and Brin, E.: Atlantic Tropical Cyclogenetic Processes during SOP-3 NAMMA in the GEOS-5 Global Data Assimilation and Forecast System, J. Atmos. Sci., 66, 3563-3578, doi:10.1175/2009JAS3123.1, 2009.

Ren, C. and Mackenzie, A.: Cirrus parameterization and the role of ice nuclei, Q. J. Roy. Meteorol. Soc., 131, 1585-1605, 2005.

Reynolds, R. W., Rayner, N. A., Smith, T. M., Stokes, D. C., and Wang, W.: An Improved In Situ and Satellite SST Analysis for Climate, J. Climate, 15, 1609-1625, doi:10.1175/15200442(2002)015<1609:AIISAS>2.0.CO;2, 2002.

Rienecker, M., Suarez, M., Todling, R., Bacmeister, J., Takacs, L., Liu, H.-C., Gu, W., Sienkiewicz, M., Koster, R., Gelaro, R., Stajner, I., and Nielsen, J.: The GEOS-5 Data Assimilation System - Documentation of Versions 5.0.1, 5.1.0, and 5.2.0., Vol. 27 of Technical Report Series on Global Modeling and Data Assimilation, NASA Goddard Space Flight Center, Greenbelt, MD, USA, 2008.

Rienecker, M. M., Suarez, M. J., Gelaro, R., Todling, R., Bacmeister, J., Liu, E., Bosilovich, M. G., Schubert, S. D., Takacs, L., Kim, G.-K., Bloom, S., Chen, J., Collins, D., Conaty, A., da Silva, A., Gu, W., Joiner, J., Koster, R. D., Lucchesi, R., Molod, A., Owens, T., Pawson, S., Pegion, P., Redder, C. R., Reichle, R., Robertson, F. R., Ruddick, A. G., Sienkiewicz, M., and Woollen, J.: MERRA: NASA's Modern-Era Retrospective Anal- ysis for Research and Applications, J. Climate, 24, 3624-3648, doi:10.1175/JCLI-D-11-00015.1, 2011.

Rosenfeld, D. and Woodley, W. L.: Deep convective clouds with sustained supercooled liquid water down to $-37.5^{\circ} \mathrm{C}$, Nature, 405, 440-442, doi:10.1038/35013030, 2000.

Rosenfeld, D., Lohmann, U., Raga, G. B., O’Dowd, C. D., Kulmala, M., Fuzzi, S., Reissell, A., and Andreae, M. O.: Flood or Drought: How Do Aerosols Affect Precipitation?, Science, 321, 1309-1313, doi:10.1126/science.1160606, 2008.

Rossow, W. and Schiffer, R.: Advances in understanding clouds from ISCCP, B. Am. Meteorol. Soc., 80, 2266-2288, 1999.

Salzmann, M., Ming, Y., Golaz, J.-C., Ginoux, P. A., Morrison, H., Gettelman, A., Krämer, M., and Donner, L. J.: Two-moment bulk stratiform cloud microphysics in the GFDL AM3 GCM: description, evaluation, and sensitivity tests, Atmos. Chem. Phys., 10, 8037-8064, doi:10.5194/acp-10-8037-2010, 2010.

Sato, K.: Vertical wind disturbances in the troposphere and lower stratosphere observed by the MU radar, J. Atmos. Sci., 47, $2803-$ 2817, 1990.

Seinfeld, J. H. and Pandis, S. N.: Atmospheric Chemistry and Physics, John Wiley and Sons, New York, NY, USA, 1998.

Slingo, J.: The development and verification of a cloud prediction scheme for the ECMWF model, Q. J. R. Meteorol. Soc., 113, 899-927, 1987.

Smith, R. N. B.: A scheme for predicting layer clouds and their water content in a general circulation model, Q. J. Roy. Meteorol. Soc., 116, 435-460, 1990.

Song, X. and Zhang, G. J.: Microphysics parameterization for convective clouds in a global climate model: Description and single-column model tests, J. Geophys. Res., 116, D02201, doi:10.1029/2010JD014833, 2011.

Spencer, R., Hood, R., and Goodman, H.: Precipitation retrieval over land and ocean with the SSM/I-Identification and characteristics of the scattering signal, J. Atm. Ocean. Tech., 6, 254-273, 1989.

Spichtinger, P. and Cziczo, D. J.: Impact of heterogeneous ice nuclei on homogeneous freezing events in cirrus clouds, J. Geophys. Res., 115, D14208, doi:10.1029/2009JD012168, 2010.

Stevens, B. and Feingold, G.: Untangling aerosol effects on clouds and precipitation in a buffered system, Nature, 461, 607-613, 2009.

Sud, Y. C. and Walker, G. K.: Microphysics of clouds with the relaxed Arakawa Schubert scheme (McRAS). Part I: Design and evaluation with GATE Phase III Data, J. Atmos. Sci., 56, 3196-3220, doi:10.1175/15200469(1999)056<3196:MOCWTR>2.0.CO;2, 1999.

Sud, Y. C., Lee, D., Oreopoulos, L., Barahona, D., Nenes, A., and Suarez, M. J.: Performance of McRAS-AC in the GEOS5 AGCM: aerosol-cloud-microphysics, precipitation, cloud radiative effects, and circulation, Geosci. Model Dev., 6, 57-79, doi:10.5194/gmd-6-57-2013, 2013.

Tiedtke, M.: Representation of clouds in large-scale models, Monthly Weather Review, 121, 3040, doi:10.1175/15200493(1993)121<3040:ROCILS>2.0.CO;2, 1993.

Tompkins, A.: A prognostic parameterization for the subgrid-scale variability of water vapor and clouds in large-scale models and its use to diagnose cloud cover, J. Atmos. Sci., 59, 1917-1942, 2002. 
Tonttila, J., O’Connor, E. J., Niemelä, S., Räisänen, P., and Järvinen, H.: Cloud base vertical velocity statistics: a comparison between an atmospheric mesoscale model and remote sensing observations, Atmos. Chem. Phys., 11, 9207-9218, doi:10.5194/acp-119207-2011, 2011.

Twomey, S.: The influence of pollution on the shortwave cloud albedo of clouds, J. Atmos. Sci., 34, 1149-1152, 1977.

Twomey, S.: Aerosols, clouds and radiation, Atmos. Environ., 25A, 2435-2442, 1991.

Wang, M. and Penner, J. E.: Cirrus clouds in a global climate model with a statistical cirrus cloud scheme, Atmos. Chem. Phys., 10, 5449-5474, doi:10.5194/acp-10-5449-2010, 2010.

Wiacek, A., Peter, T., and Lohmann, U.: The potential influence of Asian and African mineral dust on ice, mixed-phase and liquid water clouds, Atmos. Chem. Phys., 10, 8649-8667, doi:10.5194/acp-10-8649-2010, 2010.
Wise, M. E., Baustian, K. J., Koop, T., Freedman, M. A., Jensen, E. J., and Tolbert, M. A.: Depositional ice nucleation onto crystalline hydrated $\mathrm{NaCl}$ particles: a new mechanism for ice formation in the troposphere, Atmos. Chem. Phys., 12, 1121-1134, doi:10.5194/acp-12-1121-2012, 2012.

Xie, P. and Arkin, P.: Global precipitation: A 17-year monthly analysis based on gauge observations, satellite estimates, and numerical model outputs, B. Am. Meteorol. Soc., 78, 2539-2558, 1997.

Young, K. C.: The Role of Contact Nucleation in Ice Phase Initiation in Clouds, J. Atmos. Sci., 31, 768-776, doi:10.1175/15200469(1974)031<0768:TROCNI>2.0.CO;2, 1974. 